\title{
Loss of cyclin A2 in murine colonic epithelial cells disrupts colon homeostasis by triggering DNA damage and dysplasia and high cyclin A2 expression is
} a good-prognosis factor in patients with colorectal cancer

Yuchen Guo $^{1}$, Monica Gabola ${ }^{1 \#}$, Rossano Lattanzio ${ }^{2,3 \#}$, Conception Paul, Valérie Pinet $^{1}$, Ruizhi Tang ${ }^{1}$, Hulya Tulari ${ }^{1}$, Julie Bremond ${ }^{1}$, Chloé Maurizy ${ }^{1}$, Quentin Da Costa $^{4}$, Pascal Finetti ${ }^{4}$, Florence Boissière-Michot ${ }^{5}$, Céline Lemmers ${ }^{6}$, Séverine Garnier ${ }^{4}$, François Bertucci $^{4,7}$, Rania Azar ${ }^{8}$, Jean-Marie Blanchard ${ }^{1}$, Piotr Sicinski ${ }^{9}$, Emilie Mamessier $^{4 *}$ Bénédicte Lemmers $^{1 * \pi}$ and Michael Hahne ${ }^{1 * \pi}$

1. Institut de Génétique Moléculaire de Montpellier, University of Montpellier, CNRS, Montpellier, France

2. Department of Medical, Oral and Biotechnological Sciences, "G. d'Annunzio" University, Chieti, Italy

3. Center for Advanced Studies and Technology (CAST), "G. d'Annunzio" University, Chieti, Italy

4. Predictive Oncology Laboratory, Cancer Research Center of Marseille (CRCM), Inserm, U1068, CNRS UMR7258, Institut Paoli-Calmettes, Aix Marseille Université, Marseille,

France

5. Translationnal Research Unit, Montpellier Cancer Institute, Montpellier, France- Univ Montpellier, France

6. PVM, Biocampus, University of Montpellier, CNRS, Montpellier, France

7. Department of Medical Oncology, Institut Paoli-Calmettes, Marseille

8. Faculty of Pharmacy, Lebanese University, Lebanon

9. Dana Farber Institute, Boston, USA

\# co-authors

* co-last authors

II Corresponding authors: Michael Hahne (michael.hahne@igmm.cnrs.fr) and Bénédicte Lemmers (benedicte.lemmers@igmm.cnrs.fr), IGMM, UMR5535, 1919 route de Mende, 34293 Montpellier cedex 5.

The authors declare to have no conflicts of interest

Keywords: cyclin A2, murine colitis-associated cancer model, colorectal cancer (CRC), DNA damage, regenerative pathways, dysplasia, Consensus Molecular Subtypes (CMS), prognosis. 


\begin{abstract}
To clarify the function of cyclin A2 in colon homeostasis and colorectal cancer (CRC) we generated mice deficient for cyclin A2 in colonic epithelial cells (CEC). Colons of those mice displayed architectural changes in the mucosa, and signs of inflammation as well as an increased proliferation of CEC associated with the appearance of low- and high-grade dysplasia. The main initial events triggering those alterations in cyclin A2 deficient CEC appear to be abnormal mitoses and DNA damage. Cyclin A2 deletion in CEC promoted the development of dysplasia and adenocarcinomas in the murine colitis-associated cancer model. We next explored the status of cyclin A2 expression in clinical CRC samples at the mRNA and protein level and found higher expression in tumors of stage I and II patients compared to those of stage III and IV. A meta-analysis of 11 transcriptome datasets comprising 2,239 primary CRC tumors displayed different CCNA2 (the mRNA coding for cyclin A2) expression levels among the CRC tumor subtypes with highest in CMS1 and lowest in CMS4. Moreover, high expression of CCNA2 was found to be a good prognosis factor independently from other prognostic factors for the CMS1, CMS3 and CMS4 subtypes.
\end{abstract}


Cyclin A2 deficiency in colonic epithelial cells leads to dysplasia

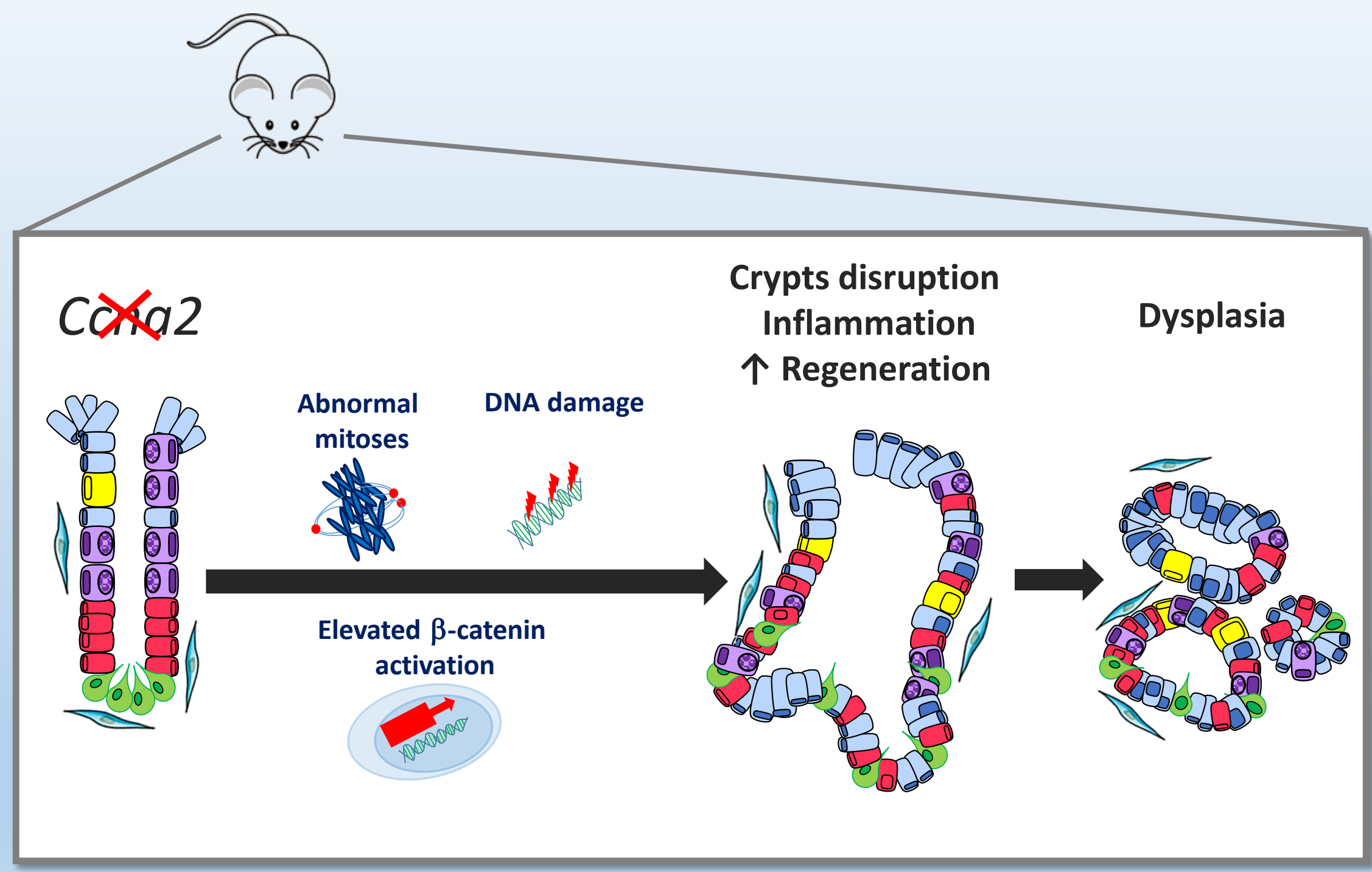

Cyclin A2 expression levels predict the outcome in colorectal cancer

\section{Better \\ Bad}

Prognosis Prognosis

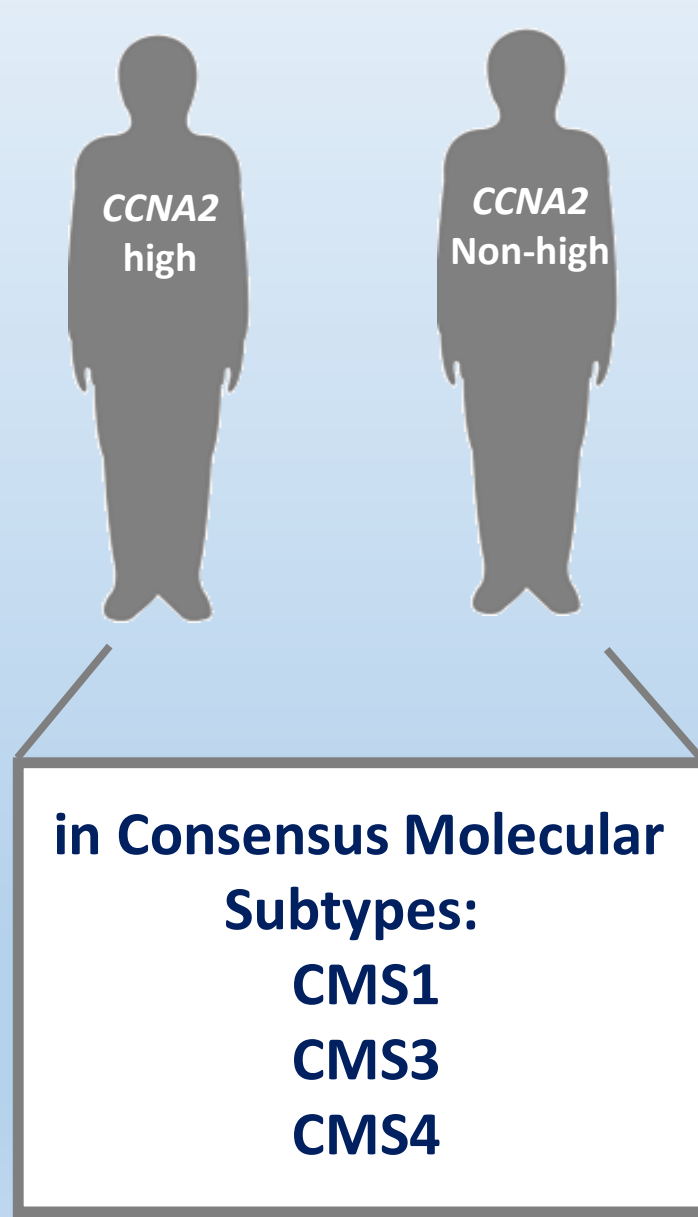


Colorectal cancer (CRC) is one of the leading causes of malignancy-related death worldwide with increasing incidence (International Agency for Research on Cancer, WHO; http://gco.iarc.fr/today/fact-sheets-cancers). Disease status of patients can be classified according to histologic tumor grade (differentiation) and anatomic extent of disease (i.e., (TNM, tumors/nodes/metastases, stages I-IV), which describes tumor growth into the wall of rectum or colon (stage II), involvement of regional lymph nodes (stage III) and metastatic spread to other organs (stage IV)(2). Once metastasis has developed, 5-year survival rates following surgery are below $10 \%$ (3). Also, adjuvant chemotherapy after surgical resection for stage III CRC and high-risk stage II tumor (i.e., tumors with poor differentiation, T4 classification, lymphovascular invasion, perineural invasion) increased the patients survival rates, but many patients will relapse or develop distant metastases $(4,5)$. Thus, there is an urgent need to better understand the molecular changes leading to the development of CRC to identify novel therapeutic strategies.

An important risk factor for CRC development is inflammation. Early-onset of chronic inflammatory bowel disease and widespread manifestation (i.e., pancolitis) have a higher probability of developing CRC (6). Besides, inherited mutations have been identified for 5\% of CRC patients, with diseases traditionally divided into polyposis syndromes, such as the Familial Adenomatous Polyposis (FAP), and non-polyposis syndromes like the Lynch Syndrome, also known as Hereditary Non-Polyposis Colorectal Cancer (HNPCC) (7). Sporadic CRC is a molecularly highly heterogeneous disease. Research teams from different institutions performed recently a meta-analysis on the different reported sub-classifications to define the existence of four distinct gene expression-based subtypes (Consensus Molecular Subtypes or CMS), i.e. immune (CMS1), canonical (CMS2), metabolic (CMS3) and mesenchymal (CMS4) subtype (8). Each CMS has a unique biology and gene expression pattern (8) providing now a frame for designing subtype-specific and personalized treatments. Indeed, CMS display different clinical features including prognosis and response to therapies, with CMS4 having the worst prognosis.

Cyclin A2 is an established regulator of cell proliferation and has been used for molecular diagnostics as a proliferation marker (9). However, several studies suggest that cell cycle regulators can exert additional functions, well beyond cell cycle control (10-12, 12-16). For example, cyclin-CDK inhibitors, p21, p27 and p57, as well as cyclin D1, have been involved in the control of apoptosis, transcription, cytoskeletal dynamics as well as cell migration $(12,13$, $13,16)$

We described a role for cyclin A2 in the regulation of cell migration and invasion (17- 
19). More specifically, we found that deletion of cyclin A2 in a murine mammary gland epithelial cell line (NMuMG) induces epithelial to mesenchymal transition (EMT) and increases invasiveness in vitro as well as in vivo in the avian embryo model $(18,19)$. This concurs with a recent report that identified cyclin A2 as a key regulatory component in EMT and metastasis of lung cancer cells by modulating the TGFbeta signaling pathway (20).

Few studies investigated the role of cyclin A2 in tumor development in vivo using genetically altered mice. One study described the generation of mutant mice with reduced cyclin A2 expression. These mice displayed spontaneous tumor development, in particular in the lung, and were also more susceptible to chemically-induced skin cancer (21). On the other hand, tissue-specific cyclin A2 inactivation in the liver was shown to impair hepatocellular carcinoma development and recapitulated the phenotype observed in absence of cyclin-dependent kinase 2 (CDK2) (22). These observations point to a tissue-specific role of cyclin A2.

We previously reported lower cyclin A2 expression in hepatic metastases compared to primary tumors derived from the same CRC patients (17). This prompted us to investigate the role of cyclin A2 in colon homeostasis and carcinogenesis using cell type-specific knockout mice. 


\section{Results}

\section{Generation of mice deficient for cyclin $A 2$ in the colonic epithelium}

We established two mouse models to study the function of cyclin A2 in colon homeostasis and colorectal cancer development by employing the previously established conditional cyclin A2 (Ccna2fl/fl) strain that is based on the Cre/LoxP system (23). Constitutive deletion of cyclin A2 in the intestinal epithelium was obtained by crossing cyclin A2 conditional knock-out (KO) mice with the villin-Cre mouse strain ( VilCre). Expression of Cre under the villin promoter was shown to be active in intestinal epithelial cells (24). In addition, we crossed Ccna2fl/fl mice with the inducible Cre mouse strain, villin-CreERT ${ }^{2}$ (VilCreERT2), in which Ccna2 is excised upon intraperitoneal injection of tamoxifen (24).

Efficient inactivation of cyclin A2 in purified colonic epithelial cells (CEC) of VilCreCcna2fl/fl mice was confirmed in a RNA sequencing experiment validating the deletion of exons 2 to 7 of the Ccna2 gene (Supplemental Fig 2A) as well as WB analysis (Fig 1A, left panel). Two tamoxifen injections at day 0 and 2 were sufficient to abrogate cyclin A2 expression in VilCreERT2Ccna2fl/fl mice (Fig 1A, right panel).

We also confirmed cyclin A2 loss in colonic crypts of VilCreCcna2fl/fl mice by immunohistochemistry (Fig 1B). For this, we analyzed the distal region, close to the anus, as well as the proximal region, close to the caecum (Supplemental Fig 1A), since biological and clinical differences for both segments are well established (25). In both regions we detected cyclin A2 expression in epithelial cells of the lower part of the crypts in control mice, whereas cyclin A2 expression was undetectable in colonic crypts of cyclin A2 KO mice (Fig 1B).

\section{Cyclin A2 depletion in the colon induces epithelial changes in the mucosa and inflammation}

During the analysis of cyclin A2 expression we noted epithelial changes in the colonic crypts as well as architectural changes in the mucosa of cyclin A2-deficient mice, but not in control animals (Fig 1B and Supplemental Fig 1C). We also detected immune cell infiltration in cyclin A2-deficient colons. The immune cell infiltrates exhibited morphological characteristics of macrophages and were immunostained using the macrophage marker F4/80. This revealed an increased number of F4/80-positive cells, about 2-fold in constitutive (Fig 1C and Supplemental Fig 1B, left panel) and 1.5-fold in induced (Supplemental Fig 1B, right panel) cyclin A2-deficient colons versus normal ones. Macrophages can be important producers of the pro-inflammatory cytokine IL6 (26) and in fact IL6 was detectable in the stroma of cyclin A2deficient colons, but not in those of control mice (Fig 1D). 
Finally, about $15 \%$ males and $10 \%$ females of VilCreCcna2fl/fl mice developed rectal prolapses within the first three months of age, which can be considered as an indicator of inflammation (27). Taken together, cyclin A2 deficiency in colonic epithelial cells induces epithelial and architectural changes of the colonic crypts and different signs of inflammation.

\section{RNA sequencing analysis reveals a prominent altered expression of genes involved in} cell cycle, mitotic process, chromosome segregation and DNA double-strand break repair

To gain insights into the molecular traits of Ccna2 mutant mice, RNA sequencing was performed using CEC isolated from the proximal colon of Ccna2fl/fl mice $(\mathrm{n}=4)$ and VilCreCcna2fl/fl mice $(\mathrm{n}=4)$ at four weeks of age. At this age VilCreCcna2fl/fl mice already display visible distortion of the crypt architecture that was validated by IHC analysis for the distal region of colons employed for this experiment.

The supervised analysis of the RNAseq data identified 469 upregulated and 640 downregulated genes in VilCreCcna2flffl mice samples versus Ccna2fl/fl mice samples (fold change $>2$, adjusted $\mathrm{p}$-value $|\mathrm{FDR}|>0.05$ ) (Table 1). Pathways analyses of the most altered genes revealed that the most significant biological functions associated with the genes upregulated in VilCreCcna2fl/fl mice were related to cell cycle (nuclear division and mitosis, regulation of mitotic cell cycle, $\mathrm{p}<2,79 \mathrm{e}^{-03}-1,15 \mathrm{e}^{-12}$ ), cellular assembly and organization (chromosome segregation, chromatin segregation, $\mathrm{p}<3,01 \mathrm{e}^{-03}-1,80 \mathrm{e}^{-09}$ ), as well as DNA replication, recombination and repair (double-strand break repair and homologous recombination, $\mathrm{p}<3,01 \mathrm{e}^{-03}-1,80 \mathrm{e}^{-09}$ ) (Table 1, Supplemental Table 4 and Supplemental Fig 2B). In line with this, the analysis highlighted increased levels of Mki67 (coding for Ki-67), Brcal, Brca2, Rad18, Rad51, Blm, Exo1 or Rpal (genes involved in the double-strand break repair mechanism) as well as $C d c 45, B u b 1, M a d 2$ and Rad21 (genes related to checkpoint controls of the cell cycle and to abnormal mitosis) (Supplemental Fig 2C).

\section{Cyclin A2 loss in colonic epithelial cells leads to increased proliferation of colonic epithelial cells and onset of dysplasia}

To validate the RNAseq results described above, we first tested the proliferation status of cyclin A2-deficient colonic epithelial cells by measuring BrdU-uptake. For this, mice received an intraperitoneal injection of the nucleoside analog BrdU and were sacrificed two hours later to isolate colons. The subsequent IHC analysis was performed by dissecting the different regions of the colon as described above (Supplemental Fig 1A) and by separating the bottom, middle and top parts of the crypts. As shown in Figure 2A, BrdU-positive cells were mainly 
located in the bottom of the crypts of control mice. In contrast, BrdU incorporation was most prominent in the middle part of the cyclin A2-deficient crypts with an average of more than 4 cells per crypt $(n=60, p<0.0001)$. Moreover, BrdU-positive cells were detectable in the upper crypt part of VilCreCcna2flffl but not in control mice. These specific profiles of BrdU incorporation of cyclin A2-deficient colonic epithelial cells were observed equally in distal, transverse as well as the proximal region. To confirm the increased proliferation rate of cyclin A2-deficient CEC, we analyzed Ki-67 expression, which is expressed during all active phases of the cell cycle (i.e., G1, S, G2, and M), but is absent in resting cells (28). Ki-67 expression in the distal region of colons was detectable at the bottom of the crypts in colons from control mice but localized to the middle and upper parts of the colonic crypts from Ccna2 knockout animals. A similar pattern was observed in the proximal region of colons (Fig 2B, Supplemental Fig $3 \mathrm{~A}$ and 3B) of constitutive as well as induced knockout mice (Supplemental Fig 3C) therefore confirming the observation made in the BrdU-uptake experiment. Thus, the elevated expression levels of Ki-67 detected by immunostaining in cyclin A2-deficient colons concurs with the upregulation of Mki67 transcripts detected in the RNAseq analysis.

Strikingly, colons deficient for cyclin A2, either constitutive or induced, revealed lowand high-grade dysplasia in around $80 \%$ of the mice analyzed that was mostly found in the proximal region (Fig 3A and B). Constitutive knockout mice showed an average occurrence of 4 low-grade dysplasia and nearly 2 high-grade dysplasia per colon, while induced knockout mice displayed a mean of about 3 low-grade and high-grade dysplasia per colon, whereas none were detectable in the control mice (Fig 3C and D). Notably, dysplasia has been already detectable eight days after tamoxifen injection in VilCreERT2Ccna2fl/fl mice.

\section{Cyclin A2 depletion in colonic epithelial cells leads to abnormal mitoses and DNA}

\section{damage}

We further explored cell cycle features and noticed an increased incidence of mitoses within the crypts when analyzing colons of constitutive and induced knockout mice (at day 8). Colons with constitutive and induced-Ccna2 deletion showed an average of 13 and 24 mitotic figures per $\mathrm{mm}^{2}$, respectively, whereas in control animals in average only 2 per $\mathrm{mm}^{2}$ were found $(\mathrm{n}=5, \mathrm{p}<0.01$ for the constitutive as well as induced knockout mouse strain, Fig 4A and B). Besides, CEC deficient for cyclin A2 harbored nuclear pleomorphism characterized by increased nuclear size compared to controls (Figure 4A and Supplemental Fig 4). Finally, abnormal mitosis, detected by combined staining for $\alpha$-tubulin to visualize mitotic spindles, $\gamma$ - 
tubulin to label centrosomes and DAPI to identify chromosomes, were prominent in induced cyclin A2-deficient but not control colons (Supplemental Fig 5 A and B).

Defective mitoses can lead to DNA damage (29), and we thus analyzed colons of tamoxifen-treated VilCreERT2Ccna2fl/fl mice by IHC using a marker for double-strand breaks (DSB), i.e. an anti- $\gamma \mathrm{H} 2 \mathrm{Ax}$ antibody, and found an average of more than $70 \gamma \mathrm{H} 2 \mathrm{AX}$ positive cells $/ \mathrm{mm}^{2}$ in cyclin A2-deficient CEC compared to 40 in control ones (Fig 4C, n=4, p<0.05). Mre11 is part of the NMR complex involved in the resolution of double-strand DNA (30). We therefore analyzed Mre11 foci formation by confocal microscopy analysis (31) and found that Mre11 foci formation was significantly increased in VilCreCcna2fl/fl nuclei (Fig 4D).

Altogether, the alterations found at the protein level correlate with the RNAseq results underpinning the presence of cell cycle perturbations, increased DNA damage and DNA double-strand break repair pathway activation in cyclin A2-deficient CEC.

\section{Activation of regenerative pathways in cyclin A2-deficient colons}

Tissue injury induces inflammation and in turn a regenerative response (32). Several pathways have been described that can promote tissue repair in the intestine including YAP/TAZ, NFאB and $\mathrm{WNT} / \beta$-catenin signaling $(32,33)$. We have previously shown that cyclin A2 inactivation in epithelial cells in vitro leads to increased $\beta$-catenin stability and activity $(18,19)$. For this reason we first tested $\beta$-catenin expression in the colons of constitutive knockout mice by IHC analysis revealing increased nuclear localization of $\beta$-catenin in CEC of cyclin A2 deficient colons by IHC (Fig 5A).

In addition, Western blot analysis of nuclear extracts derived from the constitutive knockout mice displayed elevated levels of both active $\beta$-catenin as well as the NFkB p65 subunit (Fig 5B). We also detected TAZ expression in crypts as well as surrounding stroma in colons of VilCreCcna2fl/fl mice (Fig 5 F).

We next examined the activation sequence of the different pathways modulated in cyclin A2-deficient CEC at the protein level. For this, we took advantage of the inducible Cre model (VilCreERT2Ccna2fl/fl mice) and examined the altered pathways four days upon Ccna2 depletion when colons still not display alterations such as changes of crypt architecture or immune cell infiltration (lower panel in Fig 5B and C). Expression levels of active $\beta$-catenin and NFkB were analyzed by Western blot (Fig 5C) and those of $\gamma \mathrm{H} 2 \mathrm{AX}$ and TAZ by IHC (Fig 5E-G). Besides, quantification of mitoses was performed on HE stained colons from induced knockout mice (Fig 5D). Elevated levels of active $\beta$-catenin, mitoses as well as $\gamma \mathrm{H} 2 \mathrm{AX}$ were 
already detectable at day 4 in cyclin A2-deficient CEC (Fig 5C-E), whereas NFkB and TAZ levels were unaltered at that time point between knockout and control animals (Fig 5C and 5G).

\section{Cyclin A2 deficiency in CEC promotes colon carcinogenesis in mice}

To test whether cyclin A2-deficiency modulates colon carcinogenesis, we subjected VilCreCcna2fl/fl and Ccna2fl/fl mice to chemically induced colon carcinogenesis, an established mouse model resembling the human pathology (39). This model depends on the intraperitoneal injection of the mutagen azoxymethane (AOM) and the subsequent induction of inflammation by adding dextran sodium sulphate (DSS) in the drinking water and is therefore named colitis-associated carcinogenesis (CAC). DSS is toxic to mucosal epithelial cells specifically in the colon, and the destruction of the mucosal barrier leads to chronic inflammation. In the classical protocol mice receive three DSS treatments for 5 days within 60 days. VilCreCcna2fl/fl mice displayed an about twofold more important weight loss at days 10 to 15 following the first DSS administration compared to control mice (Supplemental Fig 6B). We therefore decided to not expose the mice to additional DSS administrations (Supplemental Fig 6A). Mice were sacrificed sixty days after the AOM injection and colons isolated and embedded in paraffin. The grade of colitis was evaluated as described in Supplemental Table 2 (40) and was significantly enhanced in cyclin A2-deficient mice (average score of 4.5 for the mutant against 1.5 for the control animals, $n=6, p \leq 0.05$ ), which notably included submucosa as well as transmural disruption by immune cell infiltration that was not detectable in control mice (Fig 6A-B). The colon architecture was strongly affected in cyclin A2-deficient mice (Fig 6C) and incidence of low- and high-grade dysplasia was significantly higher in VilCreCcna2flffl mice and rather rare in control mice (Fig 6D). Moreover, the surfaces of both low- and highgrade dysplasia were significantly higher in cyclin A2-deficient versus control animals (Fig $6 \mathrm{E})$. In addition, adenocarcinomas were only detectable in cyclin A2 mutant mice, but not in control animals (Fig 6D-E). IHC analysis revealed increased expression levels of activated $\beta$ catenin, $\gamma \mathrm{H} 2 \mathrm{AX}$ as well as IL-6 in cyclin A2-deficient colons by comparison with controls (Fig 7).

Altogether, these observations show that cyclin A2 deficiency in CEC promotes chemically-induced colon carcinogenesis in mice.

\section{Cyclin A2 expression in CRC patient has a prognostic value}


Our finding that cyclin A2 deficiency in mice promotes spontaneous development of dysplasia in the colon as well as induced colon carcinogenesis prompted us to perform a metaanalysis of CCNA2 expression on available public datasets (Supplemental Table 5). The characteristics of the 2,239 patients with CRC profiled are summarized in Table 2. Briefly, the median patients' age was 68 years (range, 19 to 97), and the sex-ratio was balanced with $47 \%$ of females. The most frequent location was the right colon, followed by the left colon and sigmoid. The pathological stage included more stages III-IV than I-II. The pathological grade was mainly 2, and the mismatch repair (MMR) status was microsatellite stable (MSS) in most of cases. The CMS classification identified 20\% of samples as CMS1 (microsatellite instability immune), $32 \%$ as CMS2 (canonical), $17 \%$ as CMS3 (metabolic), and $31 \%$ as CMS4 (mesenchymal).

CCNA2 expression was heterogeneous across the 2,239 primary CRC tumors analyzed (Fig 9A). Compared to normal colon (NC) tissues, CCNA2 transcripts are up-regulated in most of the primary tumors. In contrast, expression levels in metastases of CRC (ANOVA, $\mathrm{p}=4.16 \mathrm{e}^{-}$ ${ }^{54}$ ) were significantly lower in comparison to those in primary tumors (Fig 8A). In addition, CCNA2 transcript levels were found to be lower in the stages III/IV versus stages I/II (Fig 8B). In parallel, we evaluated cyclin A2 protein expression by IHC on a TMA of CRC biopsies taken from 65 patients from stage I to IV (described in Supplemental Table 3) employing two different cyclin A2 antibodies (Fig 8C and Supplemental Fig 8A; see material and methods). Cyclin A2 expression was quantified as the number of epithelial positive cells per $\mathrm{mm}^{2}$ of tumor area. The IHC analysis confirmed the transcriptome data by revealing cyclin A2 protein levels to be lower in stages III and IV versus early stages (Fig 8C and Supplemental Fig 8A). In addition, we observed lower cyclin A2 levels in stage II MSS compared with MSI tumors (Fig 8C and Supplemental Fig 8A). We next evaluated CCNA2 levels according to the CMS consensus classification (8) and observed that CCNA2 expression was the highest in the CMS1 class, the lowest in the CMS4 class, and intermediary in CMS2 and CMS3 classes (Fig 8E).

CCNA2 expression was then measured as discrete value after comparison with the median expression of the 95 normal colon samples; upregulation, thereafter designated " $C C N A 2$ high"

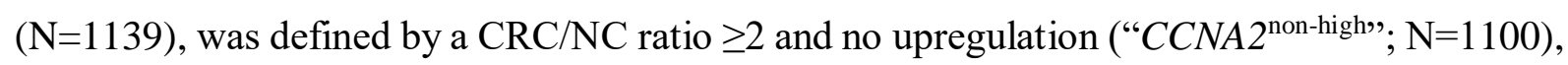
by a CRC/NC ratio $<2$. We searched for correlations between the $C C N A 2^{\text {high }}$ or $C C N A 2^{\text {non-high }}$ classification and the clinicopathological and molecular variables of the 2239 primary CRC samples (Table 2) and found no correlation between cyclin A2 mRNA levels and patients' age or sex. By contrast, when compared with the $C C N A 2^{\text {non-high }}$, the $C C N A 2^{\text {high }}$ class was associated (Fisher's exact test) with more frequent right and left tumor locations $\left(\mathrm{p}=2.04 \mathrm{e}^{-02}\right)$, pathological 
stages I and II ( $\mathrm{p}=3.19 \mathrm{e}^{-08}$; Table 2 and Fig $\left.8 \mathrm{~B}\right)$, pathological grade $3\left(\mathrm{p}=5.99 \mathrm{e}^{-03}\right)$ as well as MSI status $\left(\mathrm{p}=1.48 \mathrm{e}^{-05}\right)$ and CMS1 molecular subtype $\left(\mathrm{p}=1.00 \mathrm{e}^{-06}\right)$.

Relapse-Free-Survival (RFS) data were available for 1,882 out of 2,239 operated pCRC samples. The median follow-up was 42 months (range, 1-212); 496 patients (26\%) displayed an event, and the 5-year RFS was 70\% (95\%CI 68-73; Supplemental Fig 7A). Interestingly, the clinical outcome was different between the two CCNA2-based classes, with 281 events (31\%) in the $C C N A 2^{\text {non-high }}$ class $(\mathrm{N}=894)$ versus 215 events $(22 \%)$ in the $C C N A 2^{\text {high }}$ class $(\mathrm{N}=988$; $\mathrm{p}=2.32 \mathrm{e}^{06}{ }^{06}$, Fisher's exact test; Table 2). The 5-year relapse-free survival (RFS) was lower (65\%) for CCNA2 $2^{\text {non-high }}$ patients (95\%CI 61-69) versus $75 \%$ (95\%CI 72-79) for the CCNA2 $2^{\text {high }}$ class, respectively $\left(\mathrm{p}=8.86 \mathrm{e}^{-06}\right.$; Fig 8D). In univariate analysis for RFS (Table 3), the Hazard Ratio (HR) for the event was 0.67 (95\%CI 0.56-0.80) in the CCNA2 $2^{\text {high }}$ class when compared to the $C C N A 2^{\text {non-high }}$ class $\left(\mathrm{p}=1.01 \mathrm{e}^{-05}\right.$, Wald test). Other variables associated with relapse free survival (RFS) included the tumor location $\left(\mathrm{p}=1.35 \mathrm{e}^{-06}\right)$, the pathological stage $\left(\mathrm{p}=2.78 \mathrm{e}^{-15}\right)$, the MMR status $\left(\mathrm{p}=2.97 \mathrm{e}^{-04}\right.$ ) (with the $C C N A 2^{\text {non-high }}$ class being predominantly associated to the MSS status therefore concurring with the results obtained with the TMA) unlike patients' age and sex and pathological grade. In multivariate analysis (Table 3), the CCNA2-based classification remained associated with RFS ( $\mathrm{p}=2.99 \mathrm{e}^{-03}$, Wald test), as well as tumor location (right and sigmoid colon), pathological stage, and MMR status. Of note, it remained significant $\left(\mathrm{p}=4.13 \mathrm{e}^{-04}\right)$ in multivariate analysis incorporating the CMS molecular classification (Table 3). As shown in Fig 8F, the RFS of the eight classes defined by both the CCNA2 expression and the CMS was affected $\left(\mathrm{p}=1.82 \mathrm{e}^{-06}, \log\right.$-rank test): $C C N A 2$ expression correlated with the clinical outcome of three CMS, with a significantly reduced RFS in CCNA2 $2^{\text {non-high }}$ tumor patients by comparison to the CCNA2 $2^{\text {high }}$ class for the CMS1 $\left(59 \%\right.$ versus $\left.73, \mathrm{p}=1.64 \mathrm{e}^{-02}\right)$, CMS3 $(62 \%$ versus $79 \%, \mathrm{p}=0.05)$ and CMS4 consensus subtypes $\left(60 \%\right.$ versus $74 \%, \mathrm{p}=2.08 \mathrm{e}^{-}$ $\left.{ }^{02}\right)($ Fig 8E).

To further explore the biological alterations associated with CCNA2 expression, we compared the whole-genome expression profiles of $C C N A 2^{\text {non-high }}(\mathrm{N}=222)$ and $C C N A 2^{\text {high }}$ ( $\mathrm{N}=237)$ TCGA samples (learning set) (Supplemental Fig 7B and C). We identified 92 genes differentially expressed, including 20 genes overexpressed and 72 genes underexpressed in the $C C N A 2^{\text {high }}$ class (Supplemental Fig 7C; Table 4). A 92-gene GES based on metagene was used to classify samples. As expected, this GES was efficient to class the 459 samples of the learning set $\left(\mathrm{p}=1.08 \mathrm{e}^{-52}, \mathrm{t}\right.$-test). More importantly, its robustness was validated in a completely independent validation set including the 1780 remaining samples $\left(p=9.22 \mathrm{e}^{-180}\right.$, t-test; Supplemental Fig 7B). A detailed analysis of the 92 genes revealed that the 20 most significant 
altered genes were upregulated involved in cell proliferation and DNA repair (mitotic cell cycle regulation, genomic instability and replicative immortality pathways) (Table 4). 


\section{Discussion}

Cyclins are well-established drivers of the cell cycle by activating a specific family of kinases, the cyclin-dependent kinases (CDKs). Gene amplification as well as overexpression of cyclins have been frequently detected in cancer tissues, and cyclins have been proposed as biomarkers or therapeutic targets (41). For example, inhibition of cyclin A2 complexes has been shown to impair proliferation of some tumor cell lines (42).

In this report we describe that cyclin A2 deficiency in CECs induces epithelial changes in the mucosa, inflammation, increased cell proliferation and dysplasia in the colon rendering mice more susceptible to chemically-induced colon carcinogenesis. Elevated activation of $\beta$ catenin, abnormal mitosis as well as DNA DSBs are already detectable at day 4 after cyclin A2 inactivation and appear therefore to be the initial events. The IHC analysis performed suggests a spatial separation of both events in cyclin A2 deficient colons with nuclear staining of active $\beta$-catenin being more frequent in the lower part of colonic crypts, whereas $\gamma \mathrm{H} 2 \mathrm{AX}$ staining localized rather in the upper crypt region (Figs 4,5).

The WNT/ $\beta$-catenin pathway is well established to trigger regeneration in certain tissues by controlling the stem cell compartment and has also been shown to cooperate with the YAP/TAZ pathway during colonic tissue repair and regeneration $(33,43)$. One study showed that cyclin A2 is involved in stabilizing the Axin/GSK3 destruction complex thus promoting $\beta$ catenin degradation (44) that could explain $\beta$-catenin nuclear accumulation detected in cyclin A2-deficient colons. In line with this is our previous description that cyclin A2 depletion in murine mammary epithelial cells promotes $\beta$-catenin activity $(18,19)$.

A previous study established a role of cyclin A2 in DNA DSB repair by generating mutant mice bearing cyclin A2 knockout and hypomorphic alleles resulting in lower cyclin A2 expression (45). These mice fail to up-regulate the meiotic recombination 11 (Mre11) nuclease that causes impaired resolution of stalled replication forks, reduced repair of double-stranded DNA breaks, aberrant chromosome segregation and increased spontaneous and chemicallyinduced tumor development (Kanakkanthara et al., 2016). The same study described that cyclin A2 binds to Mre11 mRNA thus promoting its translation. We detected increased Mre11 foci formation in cyclin A2-deficient CEC suggesting that the increased DNA damage detected in the colons of cyclin A2-deficient mice results rather from a defective regulation of DNA replication and/or chromosome segregation. Indeed, phosphorylation of CDC6 by cyclin A/CDK2 has been shown to prevent re-replication during S phase and G2 (46). Moreover, 
cyclin A2/CDK activity has been demonstrated to be essential for centrosome duplication and proper sister chromatid segregation (47). Of note, mitoses detected in VilCreCcna2fl/fl mice, were mostly located in the middle part of colonic crypts whereas $\gamma \mathrm{H} 2 \mathrm{AX}$ positive cells were predominantly identified in the upper part. This is in accordance with the fact that generation of DSB following abnormal mitosis takes place once a cell exits the mitotic process entering the next cell cycle (48) thus during migration toward the top part of the crypts. Notably, high expression levels of $\gamma \mathrm{H} 2 \mathrm{AX}$ have been shown to predict a poor prognosis for CRC patients (49) and a more recent report describes a role for cyclin A2 in preventing chromosomal defects (CIN) in colon cancer cells (50).

It is well established that there is a crosstalk between DNA damage and inflammation and that either event can initiate the other one (51). Colons of cyclin A2-deficient mice display different signs of inflammation such as infiltration of macrophages and IL6 production, which correlated with an increased activation of NFKB in the colonic epithelial cells. In addition, rectal prolapse was detectable in VilCreCcna2fl/fl mice, a phenomenon which has been previously described in a mouse model, which develops colitis spontaneously (27). Increased expression and activation of NFKB has been observed in IBD and CRC patients, especially in mucosal macrophages and epithelial cells, accompanied by production of pro-inflammatory cytokines including IL6 (26). Finally, YAP/TAZ overexpression has been shown to promote tumor formation (52) and to correlate with poor prognosis in CRC (53). We therefore conclude that DNA damage combined with uncontrolled activation of several regenerative pathways promotes the development of dysplasia in cyclin A2-deficient mice.

Most studies evaluating the prognostic value of cyclin A2 in CRC concluded that cyclin A2 overexpression is an indicator for poor prognosis (54-56) whereas one report described a higher survival rate for patient with tumors expressing high levels of cyclin A2 (57). To clarify the prognostic value of cyclin A2 in CRC we performed a meta-analysis of 11 publicly available transcriptome datasets comprising 2239 primary tumor samples. This analysis revealed elevated CCNA2 transcript levels in primary tumors compared with normal tissues as well as metastases concurring with our previous analysis of biopsies using IHC and Western blot analysis (17). CCNA2 transcript expression was higher in tumors of stage I and II patients compared with those of stage III and IV. Importantly, this concurs with cyclin A2 protein expression analysis by IHC on our TMA. For the first time, we described that CCNA2 expression differs among CMS subtypes, with the highest in CMS1 and lowest in CMS4 consensus subtype. A stratification of the transcriptome samples in high and non-high expressers by taking the CCNA2 transcript expression ratio of CRC versus normal tissue $\geq 2$ as a cut-off displayed a 
higher RFS in the CCNA2 $2^{\text {high }}$ class. Importantly, such favorable prognostic value of high CCNA2 expression persisted in multivariate analysis incorporating the classical prognostic factors or the CMS subtypes, suggesting independent prognostic value. Whole-transcriptome supervised analysis of the two CCNA2 classes identified that the 20 most significant modulated genes upregulated in the $C C N A 2^{\text {high }}$ versus the $C C N A 2^{\text {non-high }}$ class were all involved in cell proliferation and DNA repair. Though expression data of multicellular tumor tissues cannot be directly correlated with the ones obtained in cell type specific knockout mice, it is remarkable that CCNA2 $2^{\text {high }} \mathrm{CRC}$ tumors and cyclin A2 deficiency in murine CEC trigger similar mechanisms such as DNA damage. We conclude that the expression pattern of cyclin A2 in CRC tissues mirrors distinct roles during colon carcinogenesis, such as driving cell proliferation in early stages, when highly expressed, but promoting aggressiveness in later stages, when expression levels are lower.

Taken together, our results establish that cyclin A2 deficiency in murine colonic epithelial cells induces DNA damage, inflammation and activation of different regenerative pathways triggering dysplasia. This renders mice more susceptible to chemically-induced colon carcinogenesis by elevated tumor initiation as well as aggressiveness. The observations made in mice are complemented by a meta-analysis of 2239 primary CRC tumors displaying that high CCNA2 expression is associated with better prognosis in CRC patients. Moreover, we describe here for the first time that CCNA2 expression differs between the previously described CMS subtypes. Importantly, dissecting the patient cohort into the consensus molecular subtypes identifies $C C N A 2^{\text {non-high }}$ expression as a bad prognosis factor within CMS1, CMS3 and CMS4, but not CMS2. In conclusion, CCNA2 expression was strongly correlated with several clinicopathological factors of CRC and may represent a favorable prognostic marker in patients with CRC. 


\section{Methods}

\section{Generation of cyclin $A 2$ conditional knockout mice in the intestinal epithelium}

To generate $c y c l i n$ A2 intestinal epithelium-specific knockout mice, $C c n a 2$ fl/fl mice (23) were crossed with transgenic mice carrying either a constitutively active Cre recombinase (vilCre) (24), which is expressed from the embryonic development (day 9) throughout adulthood in intestinal epithelial cells, or a tamoxifen-inducible Cre under the same promoter (vil-Cre$\left.E R^{T 2}\right)(24)$ ), which was induced in adult mice by two intraperitoneal injections of tamoxifen (Sigma, $150 \mathrm{mg} / \mathrm{kg}$ ). Mice were maintained on a C57BL6/129SV background for the cyclin A2 vil-Cre strain and C57BL/6 genetic background for the cyclin A2 vil-Cre-ER ${ }^{T 2}$ mice. Experimental groups were caged together according to gender. Genomic DNA from mice tails and colonic epithelial cells was used for genotyping using the primers listed in Supplemental Table 1.

\section{Immunohistochemical and immunofluorescence analyses on paraffin tissue section:}

Isolated colons specimens were rolled up lengthwise and embedded in paraffin after fixation in 10\% formalin (DiaPATH F0046, MM France) for 24 hours. Immunohistochemistry was performed on 4- $\mu \mathrm{m}$ sections. Tissue slides were deparaffinized and rehydrated by performing the following washes: xylene $(2 \times 5 \mathrm{~min}), 100 \%$ ethanol ( $5 \mathrm{~min}), 96 \%$ ethanol (3 $\mathrm{min}$ ), $70 \%$ ethanol (3 min) and $\mathrm{dH}_{2} \mathrm{O}(5 \mathrm{~min})$. Tissue slides were incubated with $10 \mathrm{mM}$ sodium citrate pH6.0 (T0050, DiaPATH) for $20 \mathrm{~min}$ at $100^{\circ} \mathrm{C}$ or Tris $10 \mathrm{mM}$-EDTA $1 \mathrm{mM}$ pH9.0, for antigen retrieval, depending on the antibody. Following two washes in PBS-Tween $0.2 \%$, tissue slides were incubated in PBS-3\% hydrogen (\#H1009, Sigma) for $5 \mathrm{~min}$ at room temperature for peroxidase inactivation. After blocking in $2.5 \%$ blocking serum-5\% BSA-5\% non-fat milk for $30 \mathrm{~min}$ at room temperature, tissue slides were incubated with primary antibody for 1 hour at $4^{\circ} \mathrm{C}$. Then corresponding secondary antibody reagents (ImmPRESS ${ }^{\mathrm{TM}}$ kit, Vector Laboratories), directed against rabbit, rat or mouse antibodies were used for detection. The following antibodies were used: rabbit anti-Cyclin A2 (Abcam, ab181591, $1: 1000$ dilution), rabbit anti-Ki67 (Abcam, ab16667, 1 :200 dilution), rat anti-F4/80 (Hycult biotech, HM1066 $1: 800$ dilution), rabbit anti-non-phospho (Active) $\beta$-catenin (Cell signaling, \#8814, $1: 1000$ dilution), rabbit anti- $\gamma \mathrm{H} 2 \mathrm{AX}$ (Abcam, ab11174, $1: 500$ ), rat anti-IL6 (Novus Biological, IL6/1270, 1:100), rabbit anti-TAZ (Novus Biological, NBP1-85067, 1:100).

For hematoxylin and eosin staining, tissue slides were incubated in Xylene (3x3 min), $100 \%$ ethanol ( $3 \times 3 \mathrm{~min}), 95 \%$ ethanol ( $3 \mathrm{~min}), 80 \%$ ethanol ( $3 \mathrm{~min}$ ) and $5 \mathrm{~min}$ in deionized water. Slides were then incubated in hematoxylin (Vector labs) for $3 \mathrm{~min}$, extensively rinsed in 
tap water and dipped 8 to 12 times in acid ethanol (0.03N HCl-70\% ethanol). After rinsing in tap water, tissue slides were transferred in deionized water for 2 minutes then stained in Eosin for 30 second (Vector Labs) followed by three incubations of 5 min in $95 \%$ ethanol then $100 \%$ ethanol. After three incubations in Xylene, coverslips were mounted using Permount media (Fisher Scientific). For the tissue microarray (TMA) analysis, the rabbit anti-Cyclin A2 antibody (Abcam, ab181591, 1:1000 dilution), validated on Ccna2-deficient mouse tissues as well as rabbit anti-Cyclin A2 from Novocastra (NCL-CYCLINA), were used.

To carry out immunofluorescence analysis, $4 \mu \mathrm{m}$ thick tissue slides were deparaffinized and rehydrated as described above and were incubated in $1 \mathrm{mM}$ EDTA antigen retrieval buffer (pH9.0) for the alpha and gamma-tubulin, or in $10 \mathrm{mM}$ citrate (pH6) for the anti-Mre11 staining. Blocking was performed for 30 minutes in 2,5\% blocking serum-5\% BSA-5\% non-fat milk at room temperature, and tissue slides were then incubated with primary antibodies (anti-Me11, Novus Biologicals NB-100-142, 1:500 dilution; anti-alpha-tubulin, Novus Biologicals NB-600506, 1:1000 dilution, anti-gamma tubulin, Sigma, T3320, 1:1000 dilution) for 1 hour at $4{ }^{\circ} \mathrm{C}$. Depending on primary antibodies, slides were incubated with goat anti-mouse, rat or rabbit secondary antibodies conjugated to either Alexa-488 or Alexa-555 (ThermoFisher Scientific) in addition with DAPI $(0.1 \mu \mathrm{g} / \mathrm{ml})$ for 1 hour at room temperature. Acquisition of the Mre11 staining was performed on the Leica confocal SP5-SMD and images were analyzed using Imaris software. Quantification of the Mre11 staining was performed using ImageJ. For the alpha/gamma-tubulin co-staining, images acquisition in the proximal colon was performed using Metamorph software on the Upright Zeiss Axioimager Z2 and images were analyzed using ImageJ software.

\section{BrdU incorporation assay}

For proliferation studies, mice were intraperitoneally injected with $100 \mu \mathrm{g} / \mathrm{g}$ of Bromodeoxyuridine (BrdU, B9285, Sigma) diluted in PBS. Colon specimens were dissected 2 hours after injection, flushed with cold PBS, and embedded in paraffin after fixation in 10\% formalin for 24hours. Incorporation of BrdU in proliferating intestinal epithelial cells was detected using an anti-BrdU antibody (Biolegend, 1:100 dilution) after deparaffinization of the tissues, antigen retrieval in citrate buffer, as described above, and DNA denaturation using $2 \mathrm{~N}$ $\mathrm{HCl}$ for 1 hour at $37^{\circ} \mathrm{C}$ followed by an incubation in $0.1 \mathrm{M}$ borax buffer $\mathrm{pH}$. Revelation was performed using the Avidin/Biotin Vectastain System kit (Vectorlab, USA) according to the protocol. 


\section{Isolation of colonic epithelial cells (CEC)}

Colons were removed from mice and flushed with cold PBS. Fat and adherent connective tissue were taken out, colons were cut longitudinally then placed in $10 \mathrm{ml}$ of cold wash buffer (PBS, 2\% FBS). Colons were treated with $10 \mathrm{ml}$ of CEC buffer (PBS, 1\% BSA, 1 mM EDTA, $1 \mathrm{mM}$ DTT, $5.6 \mathrm{mM}$ Glucose) at $37^{\circ} \mathrm{C}$ for 45 minutes under continuous shaking to release CECs. Purity of isolated cells was validated by FACS by using the cell surface markers EpCAM-APC (Biolegend, 118213, 1:50 dilution) and CD45-PE (Biolegend, 103105, 1:100 dilution), CD90.2-FITC (BD, 553013, 1:50 dilution) to identify epithelial and immune cells respectively.

\section{Isolation of CEC cytoplasmic and nuclear fractions}

Cells were treated with ice-cold hypotonic buffer $(10 \mathrm{mM}$ Hepes $\mathrm{pH} 7.9,10 \mathrm{mM} \mathrm{KCl}$, $0.1 \mathrm{mM}$ EDTA, $0.1 \mathrm{mM}$ EGTA, $0.5 \mathrm{mM}$ PMSF, $1 \mathrm{mM}$ DTT and $1 \times$ Complete inhibitor tabs, Roche, for $15 \mathrm{~min}$ ), then treated with $10 \%$ NP40 and vortexed. The nuclei were pelleted by centrifugation $(14,000 \mathrm{rpm}, 15 \mathrm{~s})$ while the supernatant was kept as the cytoplasmic fraction. Nuclei were lysed in $20 \mathrm{mM}$ Hepes pH 7.9, $0.4 \mathrm{mM} \mathrm{NaCl}, 1 \mathrm{mM}$ EDTA, $1 \mathrm{mM}$ EGTA, 0.5 mM PMSF, $1 \mathrm{mM}$ DTT, $1 \times$ complete inhibitor tabs (Sigma). The supernatant was collected as the nucleoplasmic fraction after centrifugation (14,000 rpm, $5 \mathrm{~min})$.

\section{Western blot analysis}

Protein samples were prepared in 4xLaemmli buffer, separated in sodium dodecyl sulfatepolyacrylamide gels and electro blotted onto nitrocellulose membranes (Millipore) using a wet/tank transfer system (Bio-Rad, Hercules, CA). The following antibodies were used in this study: anti-Cyclin A2 (Abcam, ab181591, 1:1000 dilution), anti-NF-kB p65 (Cell Signaling, \#8242, 1:1000 dilution) and anti-non-phospho (Active) $\beta$-catenin (Cell Signaling, \#8814, 1:1000 dilution). All the experiments were performed in triplicate and at least three times. Quantification of at least three immunoblots was carried out using the ImageJ software (National Institute of Health). Experimental values are expressed as a ratio of protein levels over control with the TFIIB (Biolegend, 1:2000 dilution) and Histone H3 (Abcam, Ab1791, 1:1000 dilution) signal for nucleoplasmic fraction or $\beta$-actin (Sigma, 1:5000 dilution) for total cell lysates.

\section{RNA sequencing samples preparation and bioinformatic analysis}

CEC were isolated as described above from the proximal colon part from 4 weeks-old 
Ccna2 flffl vil-Cre (KO) and Ccna2 fl/fl (control) mice. RNA was extracted using the Roche High Pure RNA isolation kit (Roche Molecular Systems, Inc.) according to the manufacturer protocol and purity as well as integrity controlled using the Agilent RNA 6000 nano kit (Agilent Technologies). RNA sequencing was performed on an Illumina NextSeq500 ${ }^{\mathrm{TM}}$ platform. The quantification of the gene transcripts was performed using the Kallisto program (58), which is based on pseudo-alignment principle, with default settings. GRCm38 Refseq was used to annotate the transcripts. We used the STAR program (59) to align the reads on the Mus musculus reference genome (GRCm38/mm10). For the differential expression analysis, we first filtered the transcripts with too low counts among the samples by using the filterByExpr function of edgeR, with default settings. To perform the data normalization and differential expression analysis (DEA) of Ccna2 deficient versus control samples, we ran standard steps of edgeR and DESeq2 in parallel on the filtered data. For both DEA methods, we applied a cutoff threshold of 0.05 on the adjusted p-values and a cutoff threshold of 2 on fold changes. The two resulting lists of significantly differentially expressed genes were intersected. We separated the up-regulated and the down-regulated genes of this unique list. To perform the functional enrichment analysis, these sub-lists were finally submitted to the dedicated function of the gProfile $\mathrm{R} R$ package, available on Bioconductor. The $\mathrm{R}$ code used is provided in the supplementary data.

\section{Colitis-associated carcinogenesis}

For induction of colitis-associated carcinogenesis in the VilCrecyclinA2fl/fl mice and their corresponding controls, mice were intraperitoneally injected with $6.25 \mathrm{mg} / \mathrm{kg}$ azoxymethane (AOM; Sigma). Mice were treated by one cycle of 5 days with $1.75 \%$ (w/v) dextran sodium sulphate (DSS; TdB Consultancy $\mathrm{AB}$ ) administered in the drinking water at day 5 of the protocol. Weight of the mice was checked every two days for two months, except for the week following the DSS treatment where the weight was measured every day. Mice were then sacrificed, and colon specimens prepared for histological analysis after fixation in $10 \%$ neutral buffered formalin. Tissues were embedded in paraffin, and 4- $\mu \mathrm{m}$ thick sections were stained with hematoxylin and eosin or incubated with the following primary antibodies (anti-active $\beta$ catenin, anti- $\gamma \mathrm{H} 2 \mathrm{AX}$, and anti-IL6) as above reported. Colitis was scored as outlined in Supplemental Table 2.

\section{Patient samples}


Details of the TMA generated at CRB-ICM (agreement number BB-033-00059) in Montpellier (France) are listed in Supplemental Table 3. Some tissue samples were generated as duplicates from the same patients but considered as individual templates, for the statistical analysis, due to tumor heterogeneity.

For the transcriptome meta-analysis, we collected clinicopathological and gene expression data of tissues from normal colon $(\mathrm{NC})$, primary colorectal adenocarcinoma samples (pCRC) and metastases from CRC samples (mCRC) from ten public data sets and one data set generated at the Institut Paoli Calmettes (Marseille, France) comprising at least one probe set representing CCNA2. Sets and raw data were collected from the National Center for Biotechnology Information (NCBI)/Genbank GEO, ArrayExpress and TCGA databases (Supplemental Table 5). Samples were profiled using whole-genome DNA microarrays (Affymetrix) or RNA sequencing (Illumina). The analyzed data set contained a total of 2,401 samples, including 95 normal (NC) samples, 2,239 primary tumor (pCRC) samples, and 67 metastases (mCRC) samples included in the present analysis (mCRC, located in the liver $(\mathrm{n}=47)$ and lung $(\mathrm{n}=20))$.

\section{Gene expression data analysis}

Data analysis required a step of pre-analytic processing. We first normalized each data set separately, by using Robust Multichip Average (RMA) (60) with the non-parametric quantile algorithm for the raw Affymetrix data. Normalization was done in $\mathrm{R}$ using Bioconductor and associated packages. We then mapped hybridization probes across the different microarrays represented as previously reported (61). When multiple probes mapped to the same GeneID, we retained the one with the highest variance in each data set. We $\log 2-$ transformed the available TCGA RNAseq data that were already normalized. Next, we extracted CCNA2 mRNA expression and corrected the batch effects through the 11 studies using z-score normalization. Briefly, for each expression value in each study separately, CCNA2 values were transformed by subtracting the mean of the gene in that data set divided by its standard deviation, mean and standard deviation being measured on primary samples. CCNA2 expression was measured as discrete value after comparison with median expression in the $95 \mathrm{NC}$ samples; upregulation, thereafter designated "CCNA2 ${ }^{\text {high" }}$ was defined by a $\mathrm{CRC} / \mathrm{NC}$ ratio $\geq 2$ and no upregulation ("CCNA2 ${ }^{\text {non-high") }}$ by a $\mathrm{CRC} / \mathrm{NC}$ ratio $<2$. The Consensus Molecular Subtype (CMS) classification (8) was based on the tool CMScaller made by Eide et al. (62). Finally, to explore the biological pathways associated with our CCNA2based classification, we applied a supervised analysis using learning and validation sets. The 
learning set included the 459 samples of the TCGA data set that included 222 CCNA2 ${ }^{\text {non-high }}$ and 237 CCNA2 $2^{\text {high }}$ samples. We used a moderated t-test with empirical Bayes statistic included in the limma R packages. False discovery rate (FDR) (63) was applied to correct the multiple testing hypothesis and significant genes were defined by the following thresholds: $\mathrm{p}<5 \%$, $\mathrm{q}<25 \%$ and fold change (FC) superior to $|2 \mathrm{x}|$. The resulting gene expression signature (GES) was based on a metagene score defined as the difference between mean expression of genes upregulated and mean expression of genes downregulated in the CCNA2 $2^{\text {high }}$ samples and using a cut-off equal to 0 . This score was then applied to both learning and validation sets to test the robustness of the GES (t-test). Ontology analysis of the gene list was based on GO biological processes of the Database for Annotation, Visualization and Integrated Discovery (DAVID; http://david.abcc.ncifcrf.gov/).

\section{Statistical analysis}

Correlations between the CCNA2 expression-based classes (non-high versus high) and the clinicopathological factors were calculated with the Fisher's exact test for the binary variables and the Student's t-test for the continuous variables. Our primary endpoint, relapsefree survival (RFS), was calculated from the date of diagnosis until the date of metastatic relapse or death from CRC. The follow-up was measured from the date of diagnosis to the date of last news for event-free patients. Survival was calculated using the Kaplan-Meier method and curves were compared with the log-rank test. Univariate and multivariate analyses were done using Cox regression analysis (Wald test). The variables tested in univariate analysis included the CCNA2-based classification (non-high versus high), patients' age and sex, tumor location, pathological stage and grade, MMR status, and the CMS classification. Multivariate analysis incorporated all variables with a p-value inferior to $5 \%$ in univariate analysis. All statistical tests were two-sided at the 5\% level of significance. Statistical analysis was done using the survival package (version 2.30) in the $\mathrm{R}$ software (version 2.15.2). This article is written in accordance with reporting recommendations for tumor marker prognostic studies criteria (REMARK) (64).

Statistical analysis of quantifications for the mouse study was performed in GraphPad using an unpaired t-test except for the Nuclear size distribution where the Kolmogorov-Smirnov test using R software was performed.

\section{Animal study approval:}

Mouse experiments were performed in strict accordance with the guidelines of the 
European Community (86/609/EEC), the French National Committee (87/848) for care and use of laboratory animals and were approved by the Regional Ethics committee under the 01556.02 reference number. 


\section{Acknowledgments:}

We are grateful to the excellent platforms in Montpellier, i.e. RIO imaging platform, the histology and animal experimentation platforms RHEM and RAM, as well as the IGMM mouse facility. Many thanks to Thierry Gostan for his help on the statistical analysis and Ula Hibner for carefully reading the manuscript. We are grateful to Maguy Del Rio for her help on cyclin A2 mRNA expression in patients. This work was supported by INCA (project 2013-111), by the SIRIC Montpellier Cancer Grant INCa_Inserm_DGOS_12553 and La Ligue contre Cancer -comité $34(\mathrm{BL})$.

\section{Author's contribution:}

YG, MG, CP, VP, RT, HT, JB, CM, QDS, PF, FB-M, CL, SG, RA, EM, BL: conducting experiments, acquiring data and analyzing data.

EM, BL, MH: designing research studies and analyzing data.

YG, FB, JMB, PS, EM, BL, MH: writing manuscript. 


\section{References}

1. http://gco.iarc.fr/today/fact-sheets-cancers

2. Zlobec I, Lugli A. Prognostic and predictive factors in colorectal cancer. J. Clin. Pathol. 2008;61(5):561-569.

3. Cuyle P-J, Prenen H. Current and future biomarkers in the treatment of colorectal cancer. Acta Clin. Belg. 2017;72(2):103-115.

4. Kannarkatt J, Joseph J, Kurniali PC, Al-Janadi A, Hrinczenko B. Adjuvant Chemotherapy for Stage II Colon Cancer: A Clinical Dilemma. J. Oncol. Pract. 2017;13(4):233-241.

5. McCleary NJ, Benson AB, Dienstmann R. Personalizing Adjuvant Therapy for Stage II/III Colorectal Cancer. Am. Soc. Clin. Oncol. Educ. Book Am. Soc. Clin. Oncol. Annu. Meet. 2017;37:232-245.

6. Beaugerie L et al. High risk of anal and rectal cancer in patients with anal and/or perianal Crohn's disease. Clin. Gastroenterol. Hepatol. Off. Clin. Pract. J. Am. Gastroenterol. Assoc. [published online ahead of print: November 30, 2017]; doi:10.1016/j.cgh.2017.11.041

7. $\mathrm{Ma} \mathrm{H}$ et al. Pathology and genetics of hereditary colorectal cancer. Pathology (Phila.) 2018;50(1):49-59.

8. Guinney J et al. The consensus molecular subtypes of colorectal cancer. Nat. Med. 2015;21(11):1350-1356.

9. Yasmeen A, Berdel WE, Serve H, Müller-Tidow C. E- and A-type cyclins as markers for cancer diagnosis and prognosis. Expert Rev. Mol. Diagn. 2003;3(5):617-633. 
10. Bendris N et al. Cyclin A2: a genuine cell cycle regulator?. Biomol. Concepts 2012;3(6):535-543.

11. Blanchard JM. To be or not to be a proliferation marker?. Oncogene 2014;33(8):954-955.

12. Jirawatnotai $\mathrm{S}$ et al. A function for cyclin D1 in DNA repair uncovered by protein interactome analyses in human cancers. Nature 2011;474(7350):230-234.

13. Li Z et al. Cyclin D1 induction of cellular migration requires p27(KIP1). Cancer Res. 2006;66(20):9986-9994.

14. Li Z et al. Cyclin D1 regulates cellular migration through the inhibition of thrombospondin 1 and ROCK signaling. Mol. Cell. Biol. 2006;26(11):4240-4256.

15. Li Z, Wang C, Prendergast GC, Pestell RG. Cyclin D1 functions in cell migration. Cell Cycle Georget. Tex 2006;5(21):2440-2442.

16. McAllister SS, Becker-Hapak M, Pintucci G, Pagano M, Dowdy SF. Novel p27(kip1) Cterminal scatter domain mediates Rac-dependent cell migration independent of cell cycle arrest functions. Mol. Cell. Biol. 2003;23(1):216-228.

17. Arsic $\mathrm{N}$ et al. A novel function for Cyclin A2: control of cell invasion via RhoA signalling. J. Cell Biol. 2011;in press.

18. Bendris $\mathrm{N}$ et al. Cyclin A2, a novel regulator of EMT [Internet]. Cell Mol Life Sci [published online ahead of print: May 31, 2014];http://www.ncbi.nlm.nih.gov/entrez/query.fcgi?cmd=Retrieve\&db=PubMed\&dopt=Cit ation\&list_uids=24879294. cited 
19. Cheung CT et al. Cyclin A2 modulates EMT via $\beta$-catenin and phospholipase $C$ pathways. Carcinogenesis [published online ahead of print: May 19, 2015]; doi:10.1093/carcin/bgv069

20. Wang D et al. Prefoldin 1 promotes EMT and lung cancer progression by suppressing cyclin A expression. Oncogene 2017;36(7):885-898.

21. Kanakkanthara A et al. Cyclin A2 is an RNA binding protein that controls Mre11 mRNA translation. Science 2016;353(6307):1549-1552.

22. Gopinathan L et al. Loss of Cdk2 and cyclin A2 impairs cell proliferation and tumorigenesis. Cancer Res. 2014;74(14):3870-3879.

23. Kalaszczynska I et al. Cyclin A is redundant in fibroblasts but essential in hematopoietic and embryonic stem cells. Cell 2009;138(2):352-365.

24. el Marjou F et al. Tissue-specific and inducible Cre-mediated recombination in the gut epithelium. Genes. N. Y. N 2000 2004;39(3):186-193.

25. Minoo P, Zlobec I, Peterson M, Terracciano L, Lugli A. Characterization of rectal, proximal and distal colon cancers based on clinicopathological, molecular and protein profiles. Int. J. Oncol. 2010;37(3):707-718.

26. Taniguchi K, Karin M. IL-6 and related cytokines as the critical lynchpins between inflammation and cancer. Semin. Immunol. 2014;26(1):54-74.

27. Laubitz D et al. Colonic gene expression profile in NHE3-deficient mice: evidence for spontaneous distal colitis. Am. J. Physiol. Gastrointest. Liver Physiol. 2008;295(1):G63-G77.

28. Sobecki M et al. Cell-Cycle Regulation Accounts for Variability in Ki-67 Expression Levels. Cancer Res. 2017;77(10):2722-2734. 
29. Hayashi MT, Karlseder J. DNA damage associated with mitosis and cytokinesis failure. Oncogene 2013;32(39):4593-4601.

30. van den Bosch M, Bree RT, Lowndes NF. The MRN complex: coordinating and mediating the response to broken chromosomes. EMBO Rep. 2003;4(9):844-849.

31. Rein K, Stracker TH. The MRE11 complex: an important source of stress relief. Exp. Cell Res. 2014;329(1):162-169.

32. Karin M, Clevers H. Reparative inflammation takes charge of tissue regeneration. Nature 2016;529(7586):307-315.

33. Yui S et al. YAP/TAZ-Dependent Reprogramming of Colonic Epithelium Links ECM Remodeling to Tissue Regeneration. Cell Stem Cell 2018;22(1):35-49.e7.

34. De Robertis M et al. The AOM/DSS murine model for the study of colon carcinogenesis: From pathways to diagnosis and therapy studies. J. Carcinog. 2011;10:9.

35. Erben $\mathrm{U}$ et al. A guide to histomorphological evaluation of intestinal inflammation in mouse models. Int. J. Clin. Exp. Pathol. 2014;7(8):4557-4576.

36. Hydbring P, Malumbres M, Sicinski P. Non-canonical functions of cell cycle cyclins and cyclin-dependent kinases. Nat. Rev. Mol. Cell Biol. 2016;17(5):280-292.

37. Chen W, Lee J, Cho SY, Fine HA. Proteasome-mediated destruction of the cyclin a/cyclin-dependent kinase 2 complex suppresses tumor cell growth in vitro and in vivo. Cancer Res. 2004;64(11):3949-3957.

38. Clevers H, Loh KM, Nusse R. Stem cell signaling. An integral program for tissue renewal and regeneration: Wnt signaling and stem cell control. Science 2014;346(6205):1248012. 
39. Kim SI et al. Cyclin-dependent kinase 2 regulates the interaction of Axin with betacatenin. Biochem. Biophys. Res. Commun. 2004;317(2):478-483.

40. Kanakkanthara A et al. Cyclin A2 is an RNA binding protein that controls Mre11 mRNA translation. Science 2016;353(6307):1549-1552.

41. Petersen BO, Lukas J, Sørensen CS, Bartek J, Helin K. Phosphorylation of mammalian CDC6 by cyclin A/CDK2 regulates its subcellular localization. EMBO J. 1999;18(2):396410.

42. Kabeche L, Compton DA. Cyclin A regulates kinetochore microtubules to promote faithful chromosome segregation. Nature 2013;502(7469):110-113.

43. Ganem NJ, Pellman D. Linking abnormal mitosis to the acquisition of DNA damage. $J$. Cell Biol. 2012;199(6):871-881.

44. Lee Y-C et al. High expression of phospho-H2AX predicts a poor prognosis in colorectal cancer. Anticancer Res. 2015;35(4):2447-2453.

45. Li J-A, Liu B-C, Song Y, Chen X. Cyclin A2 regulates symmetrical mitotic spindle formation and centrosome amplification in human colon cancer cells. Am. J. Transl. Res. 2018;10(8):2669-2676.

46. Georgakilas AG, Kotsinas A. Editorial: DNA Damage and Inflammation under Stress. Front. Genet. 2017;8:152.

47. Zanconato F, Cordenonsi M, Piccolo S. YAP/TAZ at the Roots of Cancer. Cancer Cell 2016;29(6):783-803. 
48. Yuen H-F et al. TAZ expression as a prognostic indicator in colorectal cancer. PloS One 2013;8(1):e54211.

49. Handa K, Yamakawa M, Takeda H, Kimura S, Takahashi T. Expression of cell cycle markers in colorectal carcinoma: superiority of cyclin A as an indicator of poor prognosis. Int. J. Cancer 1999;84(3):225-233.

50. Bahnassy AA et al. Cyclin A and cyclin D1 as significant prognostic markers in colorectal cancer patients. BMC Gastroenterol. 2004;4:22.

51. Nozoe T, Inutsuka S, Honda M, Ezaki T, Korenaga D. Clinicopathologic significance of cyclin A expression in colorectal carcinoma. J. Exp. Clin. Cancer Res. CR 2004;23(1):127133.

52. Li J-Q et al. Cyclin A correlates with carcinogenesis and metastasis, and p27(kip1) correlates with lymphatic invasion, in colorectal neoplasms. Hum. Pathol. 2002;33(10):10061015.

53. Bray NL, Pimentel H, Melsted P, Pachter L. Near-optimal probabilistic RNA-seq quantification. Nat. Biotechnol. 2016;34(5):525-527.

54. Dobin A et al. STAR: ultrafast universal RNA-seq aligner. Bioinforma. Oxf. Engl. 2013;29(1):15-21.

55. Irizarry RA et al. Exploration, normalization, and summaries of high density oligonucleotide array probe level data. Biostat. Oxf. Engl. 2003;4(2):249-264.

56. Bertucci F, Finetti P, Viens P, Birnbaum D. EndoPredict predicts for the response to neoadjuvant chemotherapy in ER-positive, HER2-negative breast cancer. Cancer Lett. 2014;355(1):70-75. 
57. Eide PW, Bruun J, Lothe RA, Sveen A. CMScaller: an R package for consensus molecular subtyping of colorectal cancer pre-clinical models. Sci. Rep. 2017;7(1):16618.

58. Hochberg Y, Benjamini Y. More powerful procedures for multiple significance testing. Stat. Med. 1990;9(7):811-818.

59. McShane LM et al. REporting recommendations for tumor MARKer prognostic studies (REMARK). Nat. Clin. Pract. Urol. 2005;2(8):416-422. 


\section{Figure Legends}

Figure 1: Cyclin A2 deletion leads to epithelial changes in the colon mucosa and inflammation. (A). Cyclin A2 depletion at the protein level in colonic epithelial cells (CEC) of constitutive (VilCreCcna2fl/fl, left panel) and tamoxifen-induced knockout mice (VilCreERT2Ccna2fl/fl, right panel) by comparison to control animals (Ccna2fl/fl) displayed by Western Blot analysis. (B, C, D). Immunostaining for cyclin A2 (B), F4/80 (C) and IL-6 (D) of the indicated parts of colon derived from control (Ccna2fl/fl), and constitutive (VilCreCcna2fl/fl) cyclinA2-deficient mice. Blow Up: 2.5X. Scale bars: $100 \mu \mathrm{m}$.

Figure 2: Cyclin A2 depletion in colonic epithelial cells induces cell proliferation. (A). Analysis of cell proliferation in colonic crypts of control (Ccna2fl/fl) and cyclinA2-deficient (VilCreCcna2fl/fl) mice by $\mathrm{BrdU}$ incorporation. Left panel: Representative images of immunostainings for BrdU from the distal and proximal parts of the colons taken from control (Ccna2fl/fl) and cyclinA2-deficient (VilCreCcna2fl/fl) mice 2 hours after intraperitoneal injection of the nucleoside analog. Right panel: Quantification of the numbers of BrdU positive cells per crypt segment. Crypts (depicted in red) were subdivided in 3 parts (dotted lines) for the analysis (bottom, middle and top, $n=120$ crypts for the distal and $n=110$ for the proximal part from 3 different mice; mean values \pm SEM are provided, $* * * * p<0.0001$; two-tailed unpaired t-test). (B). Representative images for Ki67 immunostaining in the proximal part of the colon from control (Ccna2fl/fl) animals, induced knockout mice 8 days after tamoxifen treatment (VilCreERT2Ccna2fl/fl) and constitutive knockout mice (VilCreCcna2fl/fl). Scale bars: $100 \mu \mathrm{m}$.

Figure 3: Dysplasia formation in cyclin A2-deficient mice. (A, B). Representative images of hematoxylin and eosin staining displaying low- and high-grade dysplasia (LGD and HGD, respectively) in the colons of constitutive (VilCreCcna2fl/fl) (A), and tamoxifen-induced (VilCreERT2Ccna2fl/fl) knockout mice (B). (C, D). Quantification of the number of low- and high-grade dysplasia and the area of dysplasia (in $\mathrm{mm}^{2}$ per $\mathrm{mm}^{2}$ of colon) in constitutive $(\mathrm{n}=7$; VilCreCcna2flffl) and induced knockout mice 8 days after tamoxifen treatment $(\mathrm{n}=8$; VilCreERT2Ccna2fl/fl) mice in comparison to control animals (n=7; Ccna2fl/fl). Scale bars: $100 \mu \mathrm{m}$. Blow-up in $\mathbf{A}$ and $\mathbf{C}$ is $2,5 \mathrm{x}$. 


\section{Figure 4: Elevated mitoses, DNA damage and activation of $\beta$-catenin following cyclin A2} deletion in the colonic epithelium. (A). Representative HE staining showing an increased number of mitoses (red arrowheads) in the proximal region of the colon from cyclin A2deficient mice compared to a colon of a control animal. Scale bar: $100 \mu \mathrm{m}$. (B). Quantification of mitotic events in constitutive (left panel; $n=5$ ) and induced knockout mice (day 8 following inactivation; right panel; $n=5)$ and control animals $(n=5)$; expressed as mean $\pm S E M, * * p<0.01$; two-tailed unpaired t-test. (C). $\gamma \mathrm{H} 2 \mathrm{AX}$ expression analyzed by immunohistochemistry on colon sections of control (Ccna2fl/fl; $\mathrm{n}=5$ ) and tamoxifen-induced knockout (VilCreERT2Ccna2fl/fl; $\mathrm{n}=4$ ) mice at day 8 following cyclin $\mathrm{A} 2$ inactivation. Representative $\gamma \mathrm{H} 2 \mathrm{AX}$ immunostaining and quantification of the number of $\gamma \mathrm{H} 2 \mathrm{AX}$ positive cells per $\mathrm{mm}^{2}$ of epithelium from the proximal part of colons are shown (expressed as mean $\pm \mathrm{SEM}$, $* \mathrm{p}<0.05$; two-tailed unpaired $\mathrm{t}$ test). Scale bar: $100 \mu \mathrm{m}$. (D). Confocal analysis of nuclei foci formation of Mre11 in crypts from the proximal part of colons from control (Ccna2fl/fl) and VilCreCcna2fl/fl mice. Representative images are shown; Scale bar: $10 \mu \mathrm{m}$; (staining of nuclei with DAPI in blue and Mre11 in red) as well as quantification of the Mre11 fluorescence intensity per nuclei surface (right panel; $\mathrm{n}=83$ different nuclear areas for control and $\mathrm{n}=65$ for cyclin A2-deficient mice; mean \pm SEM are provided, $* \mathrm{p}<0.05 ;$ two-tailed unpaired t-test).

Figure 5: Cyclin A2 deficiency triggers regenerative pathways. (A). Representative immunostaining for active $\beta$-catenin in control (Ccna2fl/fl) and constitutive knockout (VilCreCcna2flffl) mice. Arrowheads indicate nuclear localization of active $\beta$-catenin. Scale bar: $100 \mu \mathrm{m}$. (B). Western blot analysis of active $\beta$-catenin and NFאB in CEC extracts derived from constitutive cyclin A2-deficient mice and their control littermates. The right panel shows quantification of active $\beta$-catenin and NFKB after normalization with loading controls (TFIIB or Histone H3, n=9). (C). Western blot analysis of active $\beta$-catenin, and NFkB with their respective quantifications on nuclear extracts derived from CEC of control and tamoxifeninduced knockout mice (VilCreERT2Ccna2fl/fl) following deletion of cyclin A2 at day 4 (n=6). Lower panel: Representative HE staining of colons from control and induced knockout mice at day 4 following Ccna2 inactivation. (D-E). Colons of cyclin A2-deficient mice display DNA damage. Quantification of mitoses (D) and $\mathrm{gH} 2 \mathrm{AX}$ staining (E) in colons of control and VilCreERT2Ccna2fl/fl mice at day 4 following tamoxifen-induced Ccna2 depletion $(\mathrm{n}=8$ mice). (F, G). IHC analysis of TAZ expression (indicated by arrow) in constitutive mutant colons $(\mathbf{F})$ and in induced knockout mice at day 4 following Ccna2 deletion $(\mathbf{G})$, representative 
images are shown. Scale bar: $100 \mu \mathrm{m}$ in $\mathrm{B}, \mathrm{C}$ and $\mathrm{D}$; mean \pm SEM are provided, $* \mathrm{p}<0,05$, ** $\mathrm{p}<0.01$ and $* * * \mathrm{p}<0,001 ;$ two-tailed unpaired t-test.

Figure 6: Cyclin A2-deficient mice are more susceptible to colitis-associated colorectal (CAC) cancer. Ccna2fl/fl $(\mathrm{n}=6)$ and VilCreCcna2fl/fl $(\mathrm{n}=7)$ mice were exposed to a modified AOM/DSS protocol including only one DSS administration (Supplemental Fig S6A). (A, B). Quantification of the inflammatory score of colons from control and VilCreCcna2fl/fl mice (A) and representative HE staining showing transmural immune cell infiltration (indicated by the red oval) in the knockout mice (B) (the red arrows mark the muscularis mucosa). Scale bar: 100 $\mu \mathrm{m}$ (C). Representative images of HE stained colons of control and cyclin A2-deficient mice exposed to the CAC protocol. Scale bar: $2 \mathrm{~mm}$. (D, E). Number of dysplasia and adenocarcinoma occurrence per mouse and dysplasia and adenocarcinoma surface expressed in $\mathrm{mm}^{2}$ per $\mathrm{mm}^{2}$ of colon in control and VilCreCcna2flffl mice. LGD and HGD: Low- and HighGrade Dysplasia. ADK: Adenocarcinoma. Scale bar: $2 \mathrm{~mm}$. Mean $\pm \mathrm{SEM}$ are provided, * $\mathrm{p}<0,05, * * \mathrm{p}<0.01$ and $* * * \mathrm{p}<0,001 ;$ two-tailed unpaired t-test.

Figure 7: Lesions in colons from cyclin A2-deficient mice exposed to colitis-associated cancer display elevated levels of active $\beta$-catenin, DNA damage as well as IL6 expression. Representative immunostainings for active- $\beta$-catenin, $\gamma \mathrm{H} 2 \mathrm{AX}$ and IL6 in morphologically similar lesions in colons from control and cyclin A2-deficient mice at the end of the AOM/DSS protocol described in Supplemental Fig 6A. Blow Up: 2.5X. Scale bar: 100 $\mu$ m.

Figure 8: High cyclin A2 expression correlates with better prognosis in CRC patients. (A). Bot plots showing CCNA2 mRNA expression levels ( $\log ^{2}$ over normal colon) in primary CRC tumors (pCRC; $\mathrm{n}=2239$ ) and metastases (mCRC; $=67$ ). Expression was normalized to normal tissue samples as in (A). CCNA2 $2^{\text {high }}$ levels were defined as expression above 1 (horizontal red line) and CCNA2 $2^{\text {non-high }}$ levels were defined as expression below 1 . For each box plot, median and ranges are indicated. CCNA2 expression was compared between group using the ANOVA (multiple comparisons, $\mathrm{p}=4 \cdot 16 \mathrm{e}^{-54}$ ). (B). Cyclin A2 mRNA expression levels in stage I-II $(n=834)$ and III-IV $(n=785)$ in primary CRC tumors. Expression was normalized to normal tissue samples as in (A). CCNA2 expression was compared between group using the 2-tailed 
Student $\mathrm{t}$-test test (expressed as mean $\pm \mathrm{SD}, \mathrm{p}=9.32 \mathrm{e}^{-09}$ ). (C). Cyclin A2 protein expression determined by immunostaining using the anti-cyclinA2 antibody from Abcam validated on cyclin A2-deficient colon tissue and expressed as number of positive cells per $\mathrm{mm}^{2}$ of tumor analyzed from a TMA of CRC tumor samples derived from stage I ( $\mathrm{n}=23)$, II ( $\mathrm{n}=48$ with 24 MSS tumors and 24 MSI tumors =), III $(n=30)$ and IV $(n=26)$ patients. $(\mathrm{p}<0.01$ for the analysis between stage I and II-MSS, $\mathrm{p}<0.05$ for comparison between stage I and stage IV, $\mathrm{p}=0.01$ for stage II-MSI to IV). (D). Kaplan-Meier RFS Relapse-Free-Survival (RFS) of patients defined as carrier of CCNA2high $(\mathrm{n}=988)$ and non-high $(\mathrm{n}=894)$ tumors. Survivals were calculated using the Kaplan-Meier method and were compared with the log-rank test $\left(\mathrm{p}=8.86^{\mathrm{e}}-06\right)$. (E). Analysis of CCNA2 mRNA levels in the different consensus CRC subtypes, i.e. CMS1 ( $\mathrm{n}=389)$, CMS2 ( $\mathrm{n}=640)$, CMS3 (343) and CMS4 ( $\mathrm{n}=604)$ expressed as $\log ^{2}$ over normal colon as described in $(\mathbf{A})\left(\mathrm{p}=2.57 \mathrm{e}^{-79}\right.$ by the ANOVA test). (F). Kaplan-Meier RFS curves of all patients with pCRC according to both the CCNA2-based classification (CCNA2 $2^{\text {high }}$ and $C C N A 2^{\text {non-high }}$ classes with plain curve and dashed curve respectively) and the CMS subtypes ( $\mathrm{p}=1.64 \mathrm{e}^{-02}$ for the CMS1 subtype, 0.174 for CMS2, 0.053 for CMS3 and 2.08 $\mathrm{e}^{-02}$ for CMS4). 
Supplemental Figure 1: Cyclin A2-deficiency in colonic epithelial cells induces architectural changes in the mucosa and inflammation. (A). HE staining illustrating the subdivision of the colon in 3 parts for the histological analysis, i.e. the distal part close to the rectum, transverse and proximal part, close to the caecum. (B). Quantification of the F4/80 staining in control $(n=3)$, constitutive $(n=3)$ and inducible mutant mice $(n=4$; expressed as mean \pm SEM, *p<0.05; two-tailed unpaired t-test) expressed as number of F4/80 positive cells per $\mathrm{mm}^{2}$ of colon tissue. (C). Representative HE staining of irregular formed crypts in colons from a constitutive and inducible (day8 following tamoxifen injection) knockout mouse by comparison to colons from control animals. Scale bar: $100 \mu \mathrm{m}$.

\section{Supplemental Figure 2: RNA-seq analysis of altered expression of genes involved in cell} cycle regulation and DNA double-strand break repair in cyclin A2 deficient colonic epithelial cells (CEC). (A). Sashimi plot of Ccna2 reads for each mouse-derived CEC samples analyzed by RNA-seq. Plots show deletion of exons 2 to 7 in transcripts of CEC from VilCreCcna2fl/fl mice compared to controls. The coverage for each alignment track is plotted as a bar graph. Arcs representing splice junctions connect exons. Arcs display the number of reads split across the junction (junction depth). Genomic coordinates and the gene annotation track are shown below the junction tracks. (B). Gene Ontology over-representation analysis showing the genes up-regulated in Ccna $2 \mathrm{fl} / \mathrm{fl}$ mutant mice compared to controls. The top 20 of Gene Ontology terms (Biological Process) are shown here. The p-values have been corrected for multiple testing by the Benjamini-Hochberg method. In this dot plot, the color represents the adjusted p-values and the dot size represents the number of genes for each term. The gene ratio is shown on the $\mathrm{x}$-axis. (C). Alterations in the double-strand break KEGG pathway in cyclin A2 deficient CEC. Genes up-regulated in VilCreCcna2fl/fl mice samples are in red, whereas downregulated genes are in blue. The scale indicated on the figure represent the $\log 2$ Fold change. In grey are the genes absent from our data. For all analyses, only p-values $<0.05$ were considered as statistically significant. FC: Fold change; DSB: Double-strand break

\section{Supplemental Figure 3: Increased proliferation of colonic epithelial cells from cyclin A2-} deficient mice. (A, B, C). Quantification of Ki67 expression by IHC of the different parts of crypts from the distal and proximal part of the colon from control $(n=66$ crypts analyzed from 3 different mice) and constitutive cyclin A2-deficient mice $(\mathbf{A}, \mathbf{B})$ and proximal part of the colon from induced knockout mice at day 8 following inactivation $(\mathbf{C})$ compared to controls $(\mathrm{n}=120$ 
from 3 different mice). Mean values \pm SEM are provided, $* p<0,05, * * p<0.01$ and $* * * p<0,001$; two-tailed unpaired t-test.

Supplemental Figure 4: Increased nuclear size of colonic epithelial cells in cyclin A2deficient mice. Distribution curve representing the nuclear size of $C c n a 2 f l / f l$ colonic epithelial cells (white, $\mathrm{n}=398$ for the left panel and 578 for the right panel from 3 mice), VilCreCcna2fl/fl (black, left panel, $\mathrm{n}=400$ from 3 mice, $\mathrm{p}<1.10 \mathrm{e}^{-16}$ ) and VilCreERT2Ccna2fl/fl (black, right panel, $\mathrm{n}=566, \mathrm{p}<1.10 \mathrm{e}^{-16}$ ) colonic epithelial cells; $\mathrm{p}$-values were determined using KolmogorovSmirnov test.

Supplemental Figure 5: Examples of mitoses in colons of cyclin A2-deficient mice. (A). Immunofluorescence analysis of mitosis (indicated by red circles) using an anti- $\alpha$-tubulin antibody (green) to stain for the mitotic spindle in combination with $\gamma$-tubulin (centrosome in red) and DAPI for DNA in a colon of VilCreERT2Ccna2fl/fl mice at day 8 following inactivation (right panel) by comparison to controls (left panel). Scale bar: $100 \mu \mathrm{m}$. (B). The upper image shows normal mitosis, the lower panel several examples of abnormal mitoses observed in a Ccna2-deficient colon. Blow Up: $2.5 \mathrm{X}$

Supplemental Figure 6: Protocol and weight monitoring of the mice during the colitisassociated carcinogenesis. (A). Schematic representation of the modified AOM/DSS protocol applied to VilCreCcna2fl/fl and control mice (see Figs 6 and 7). (B). Monitoring of the relative weight (expressed as percentage relative to the weight at the beginning of the protocol) of VilCreCcna2fl/fl and control mice during the AOM/DSS protocol.

\section{Supplemental Figure 7: Cyclin A2 expression at the mRNA and protein level in CRC} patients. (A). Relapse-Free-Survival (RFS) curve of the overall patients analyzed for cyclin A2 mRNA expression levels (B). Metagene-based prediction score of outcome (using Student ttest and expressed as mean $\pm \mathrm{SD}$ ) of the $C C N A 2^{\text {high }}$ samples compared to those of $C C N A 2^{\text {non-high }}$ samples in the learning set (left) and in the independent validation set (right). (C). Volcano plot showing the 92 genes differentially expressed in the learning set (TCGA). Genes up-regulated in the $C C N A 2^{\text {high }}$ samples are colored in red and genes down-regulated in green. 


\section{Supplemental Figure 8: Cyclin A2 protein expression in CRC tumor samples from}

different stages. (A). Cyclin A2 expression analyzed on the same TMA shown in Figure 8, but using a different anti-cyclin A2 antibody from Novocastra. (Mean values \pm SEM, $p<0.05$ for the analysis between stage I and II-MSS, p<0.01 for comparison between stage I and stage III, $\mathrm{p}<0.001$ for stage I to IV, $<<0.01$ for stage II-MSI to stage IV, two-tailed unpaired t-test). (B). Representative immunostaining of stage I, II-MSS, II-MSI, III and IV tumor samples. Scale bar: $100 \mu \mathrm{m}$ 
EioRxiv preprint doi: https://doi.org/10.1101/690404; this version posted July 3, 2019. The copyright holder for this preprint (which was not

A

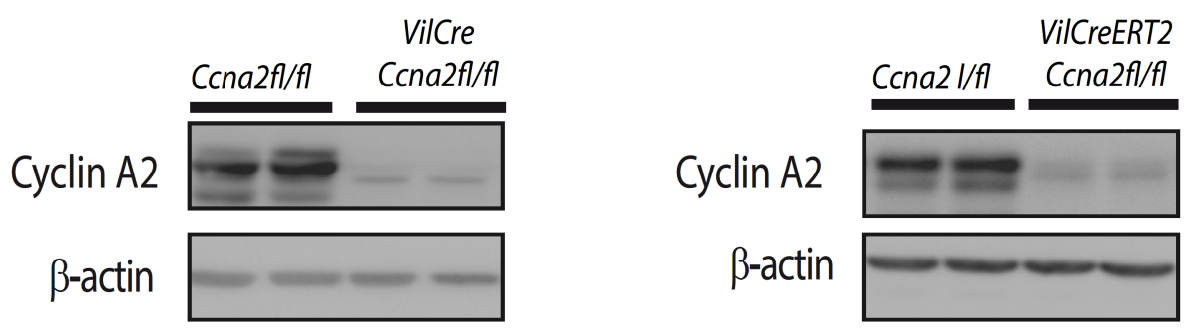

B
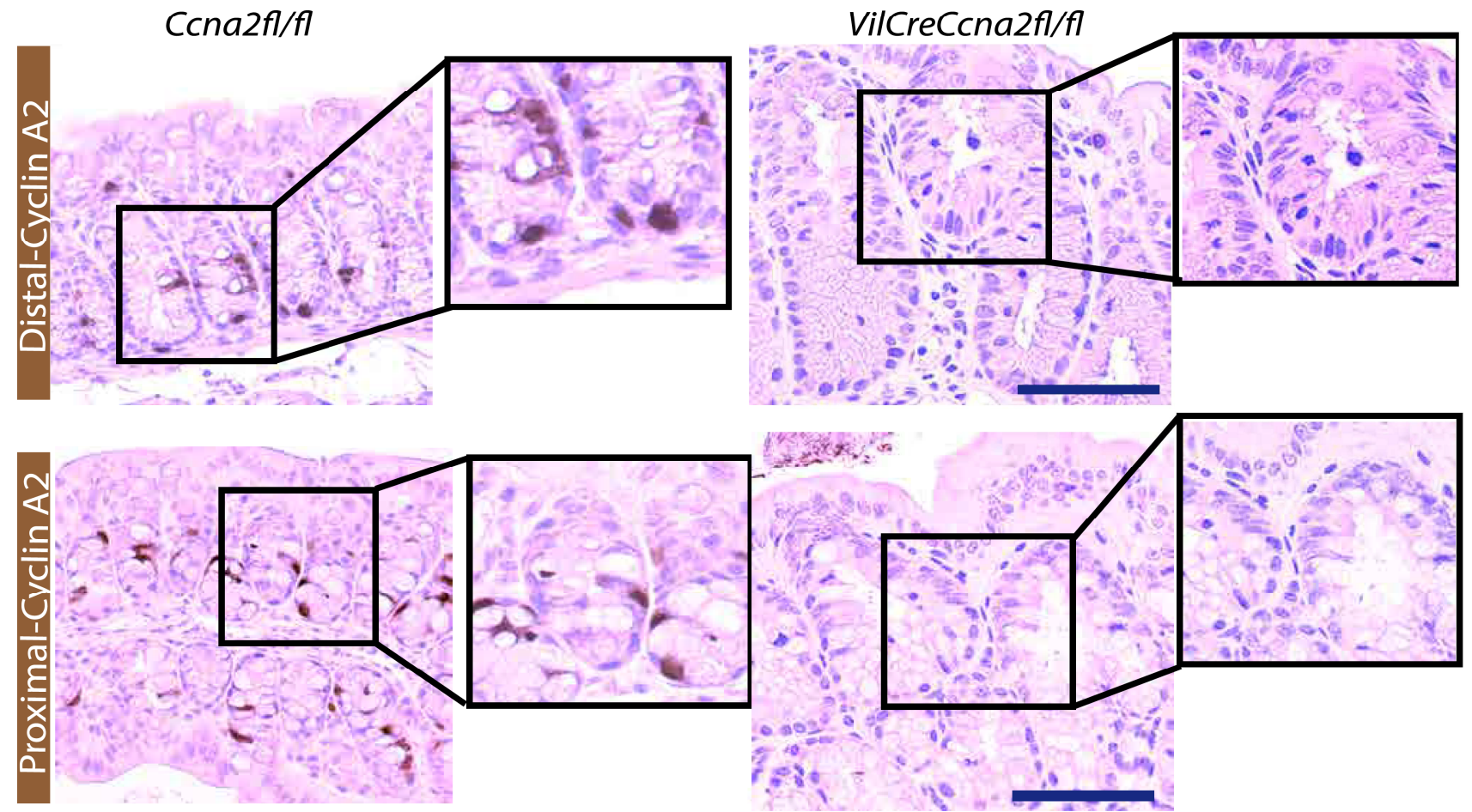

C
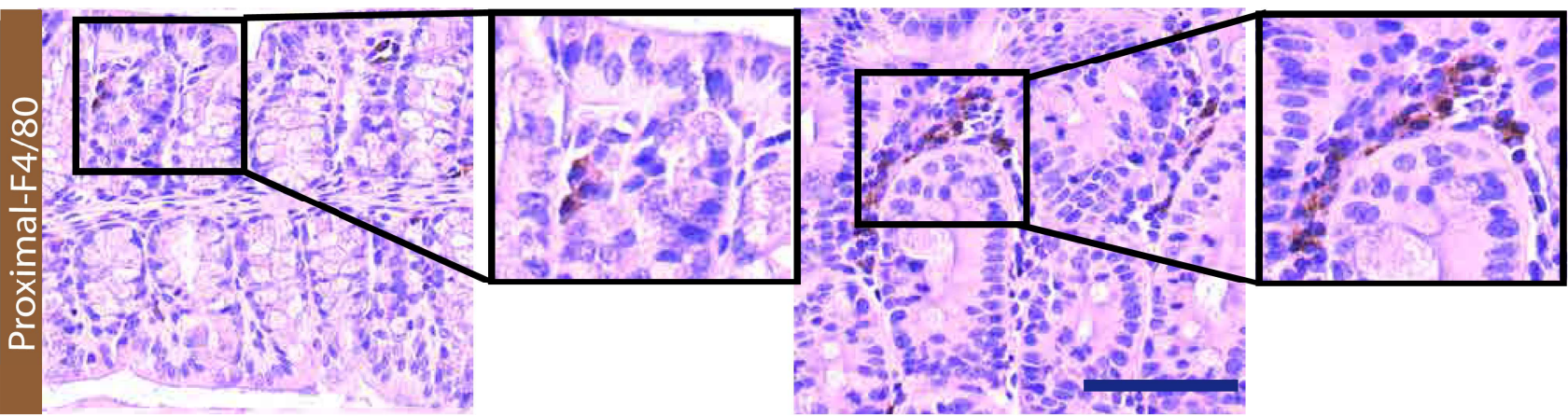

D
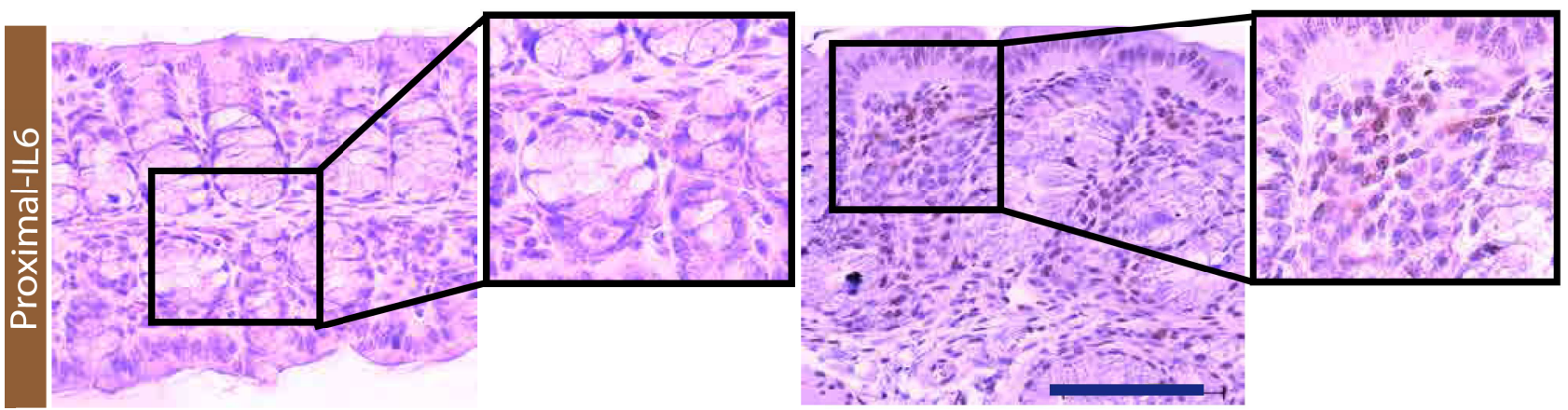

Figure 1: Cyclin A2 deletion leads to epithelial changes in the colon mucosa and inflammation. (A). Cyclin A2 depletion at the protein level in colonic epithelial cells (CEC) of constitutive (VilCreCcna2fl/fl, left panel) and tamoxifen-induced knockout mice (VilCreERT2Ccna2fl/fl, right panel) by comparison to control animals (Ccna2fl/fl) displayed by Western Blot analysis. (B, C, D). Immunostaining for cyclin A2 (B), F4/80 (C) and IL-6 (D) of the indicated parts of colon derived from control (Ccna2fl/fl), and constitutive (VilCreCcna2fl/fl) cyclinA2deficient mice. Blow Up: 2.5X. Scale bars: $100 \mu \mathrm{m}$ 


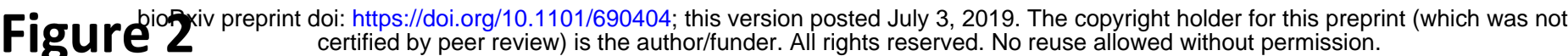

A Ccna2fl/fl

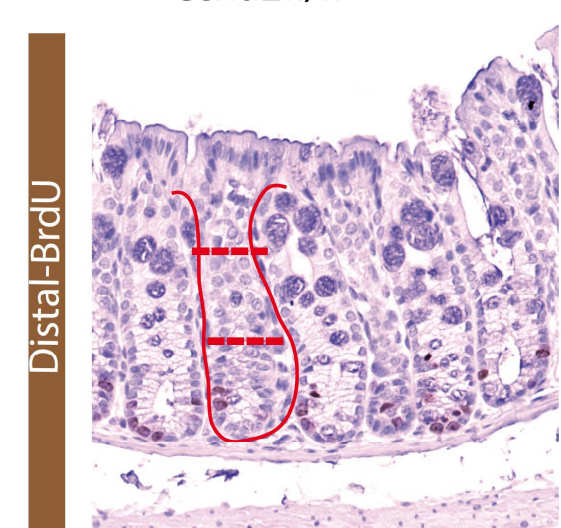

뭉

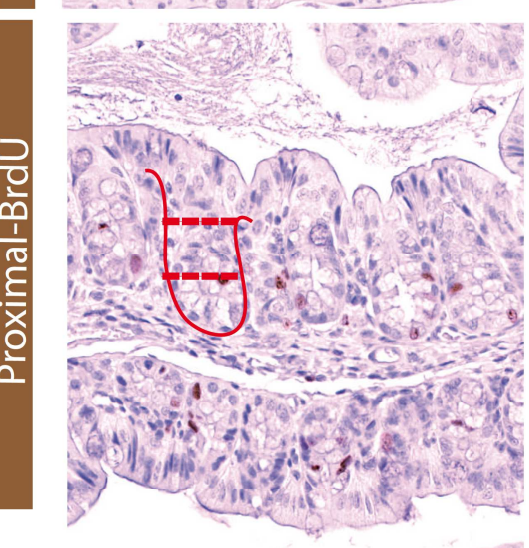

B

\section{VilCreCcna2fl/fl}
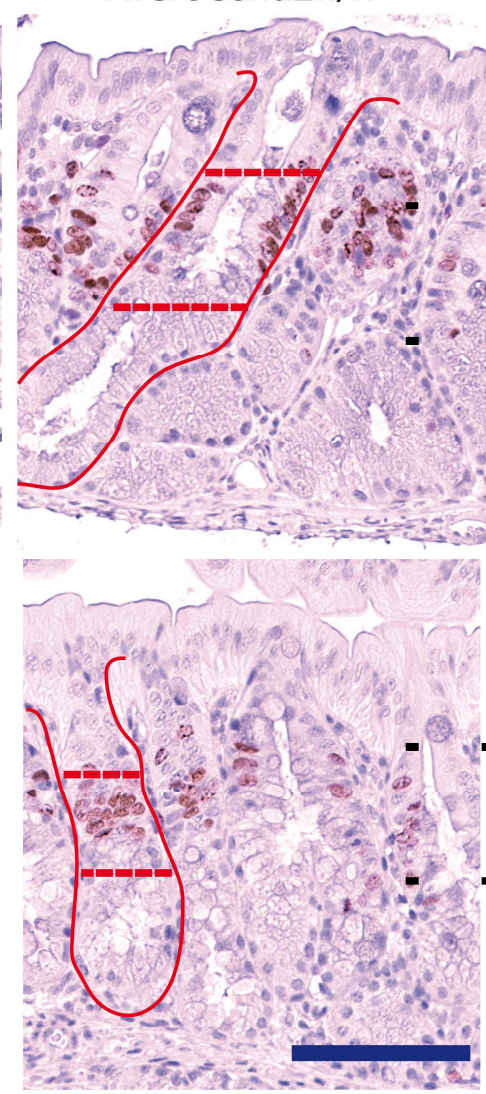

Ccna2fl/fl

VilCreCcna2fl/fl
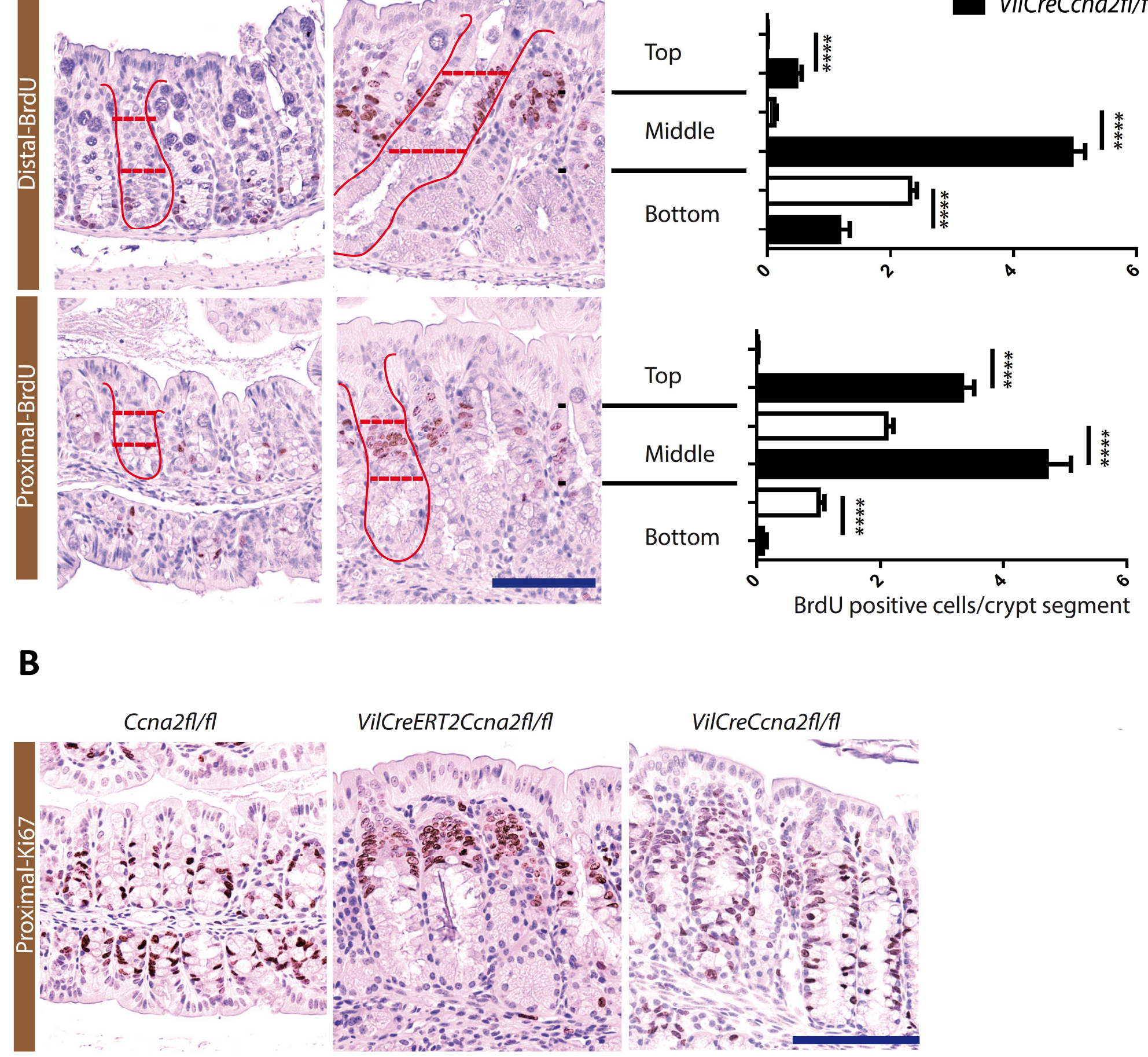

Ccna2fl/fl

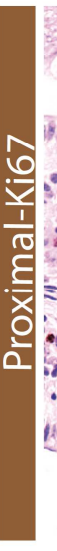

\section{VilCreERT2Ccna2fl/fl}

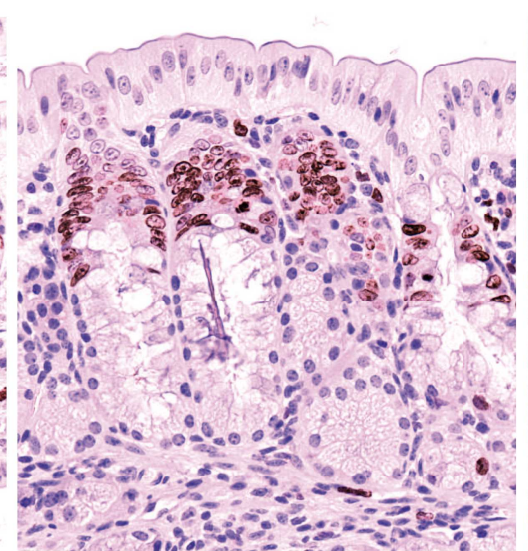

VilCreCcna2fl/fl

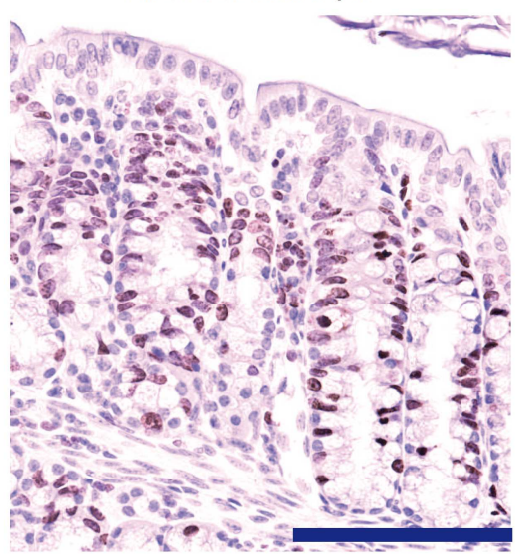

Figure 2: Cyclin A2 depletion in colonic epithelial cells induces cell proliferation. (A). Analysis of cell proliferation in colonic crypts of control (Ccna2fl/fl) and cyclin A2-deficient (VilCreCcna2fl/fl) mice by BrdU incorporation. Left panel: Representative images of immunostainings for BrdU from the distal and proximal parts of the colons taken from control (Ccna2fl/fl) and cyclin A2-deficient (VilCreCcna2fl/fl) mice 2 hours after intraperitoneal injection of the nucleoside analog. Right panel: Quantification of the numbers of BrdU positive cells per crypt segment. Crypts (depicted in red) were subdivided in 3 parts (dotted lines) for the analysis (bottom, middle and top, $n=120$ crypts for the distal and $\mathrm{n}=110$ for the proximal part from 3 different mice; mean values \pm SEM are provided, $* * * * \mathrm{p}<0.0001$; two-tailed unpaired t-test). (B). Representative images for Ki67 immunostaining in the proximal part of the colon from control (Ccna2fl/fl) animals, induced knockout mice 8 days after tamoxifen treatment (VilCreERT2Ccna2fl/fl) and constitutive knockout mice (VilCreCcna2fl/fl). Scale bars: $100 \mu \mathrm{m}$. 
Fiqurebięxiv preprint doi: https://doi.org/10.1101/690404; this version posted July 3, 2019. The copyright holder for this preprint (which was not A

B

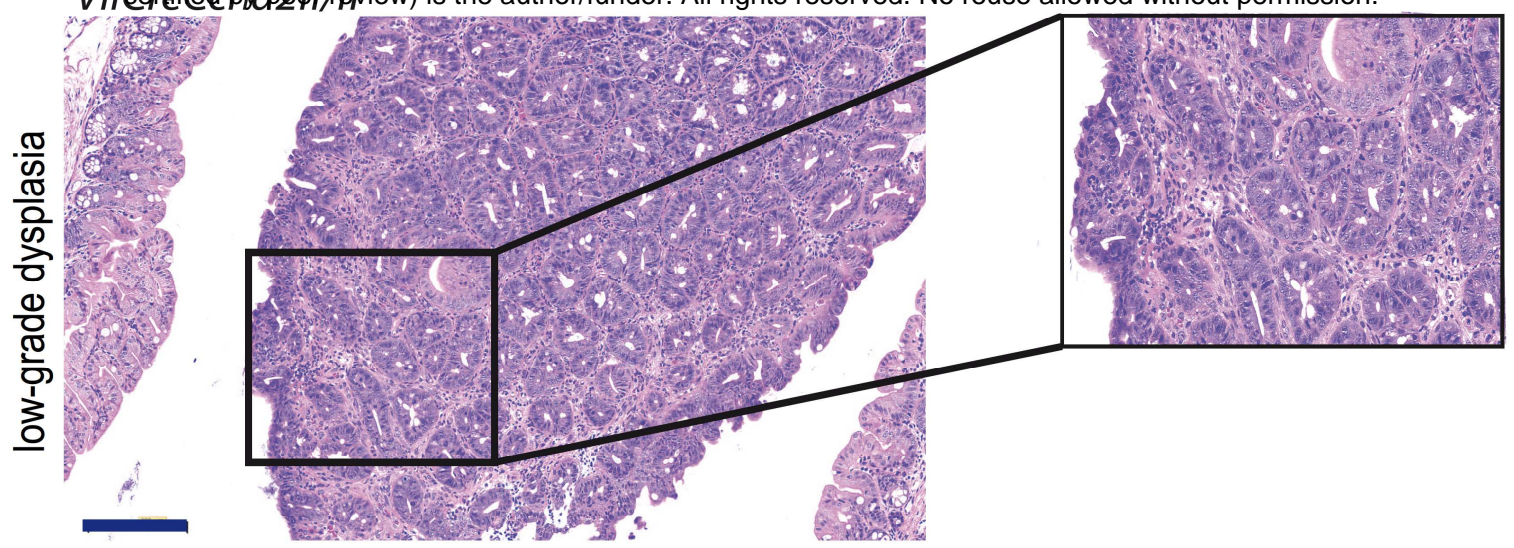

B VilCreERT2Ccna2fl/fl

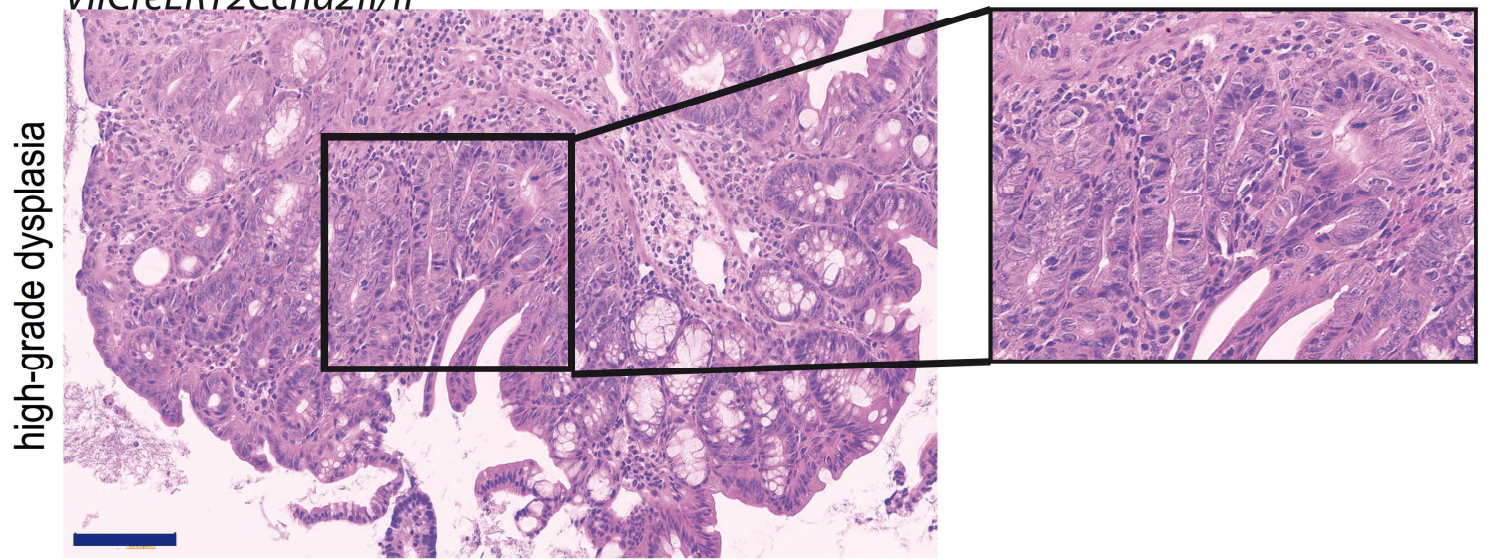

C
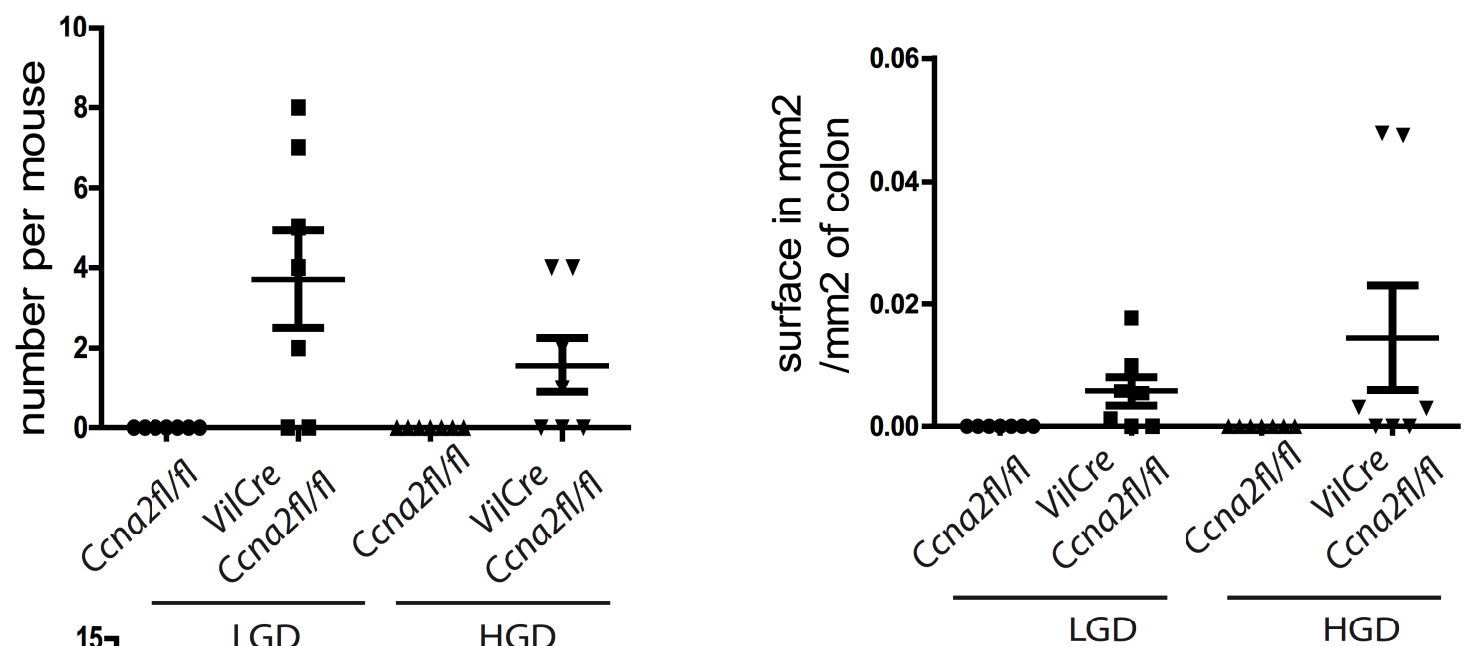

D
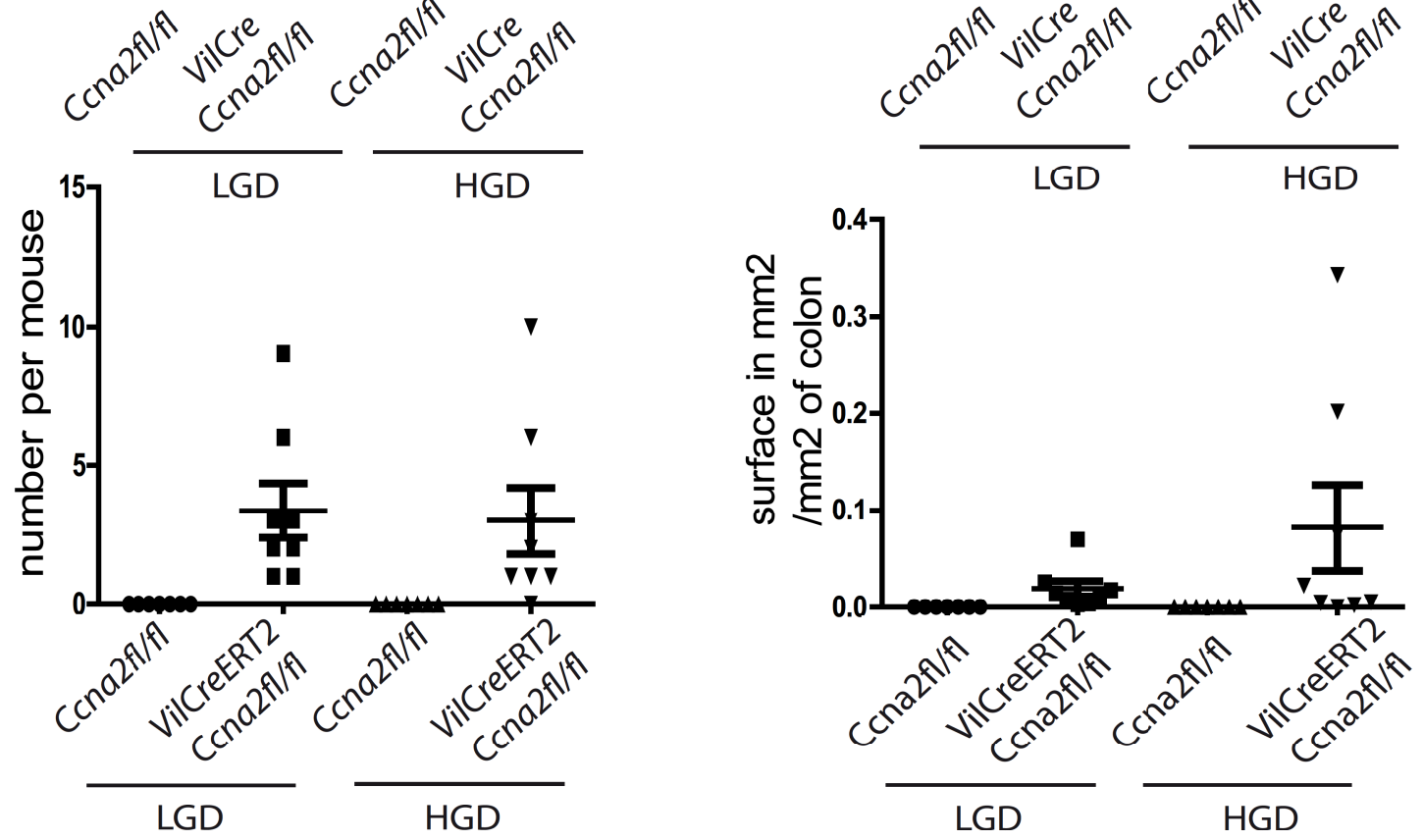

Figure 3: Dysplasia formation in cyclin A2-deficient mice. (A, B). Representative images of hematoxylin and eosin staining displaying low- and high-grade dysplasia (LGD and HGD, respectively) in the colons of constitutive (VilCreCcna2fl/fl) (A), and tamoxifen-induced (VilCreERT2Ccna2fl/fl) knockout mice (B). (C, D). Quantification of the number of low- and high-grade dysplasia and the area of dysplasia (in $\mathrm{mm}^{2}$ per $\mathrm{mm}^{2}$ of colon) in constitutive $(\mathrm{n}=7$; VilCreCcna2fl/fl) and induced knockout mice 8 days after tamoxifen treatment $(\mathrm{n}=8$; VilCreERT2Ccna2fl/fl) in comparison to control animals $(\mathrm{n}=7$; Ccna2fl/fl). Scale bars: $100 \mu \mathrm{m}$. Blow-up in $\mathbf{A}$ and $\mathbf{C}$ is $2,5 \mathrm{x}$. 
A

Ccna2fl/fl

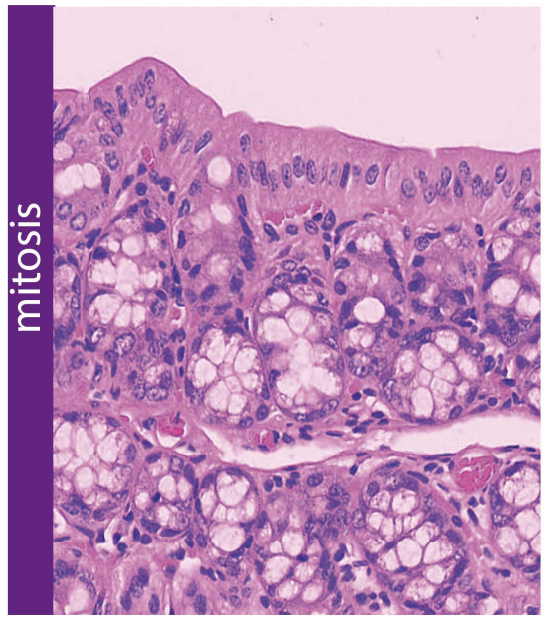

VilCreCcna2fl/fl

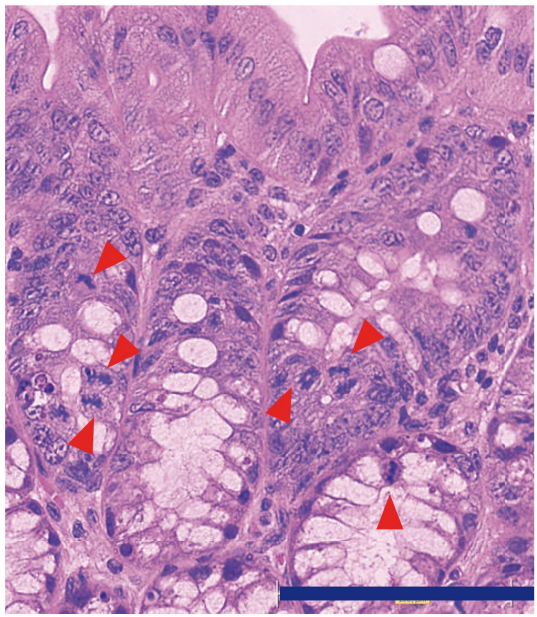

B
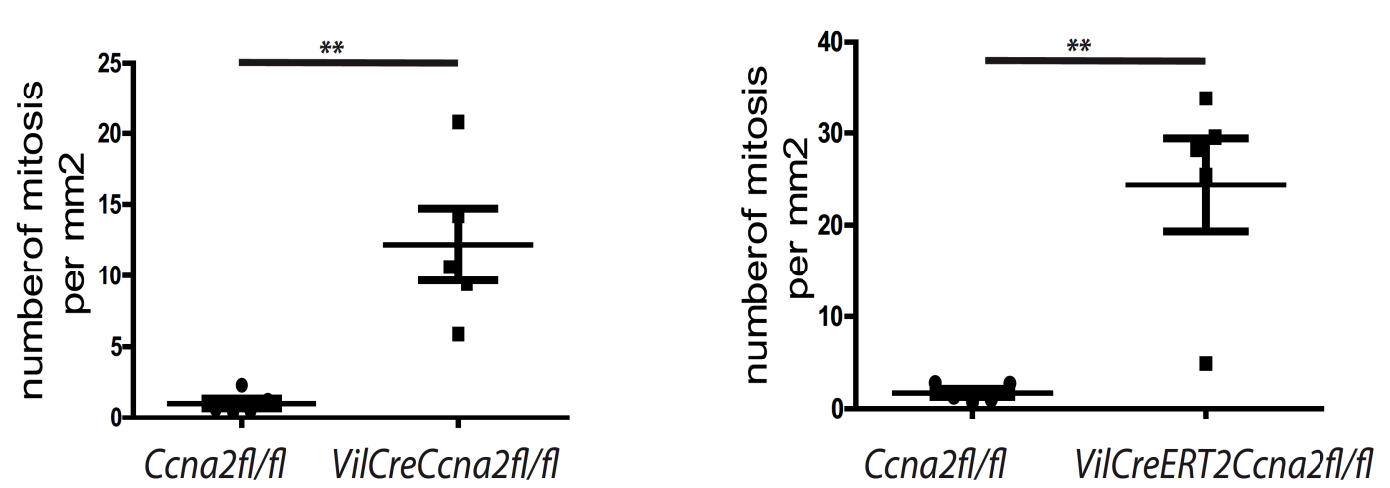

C

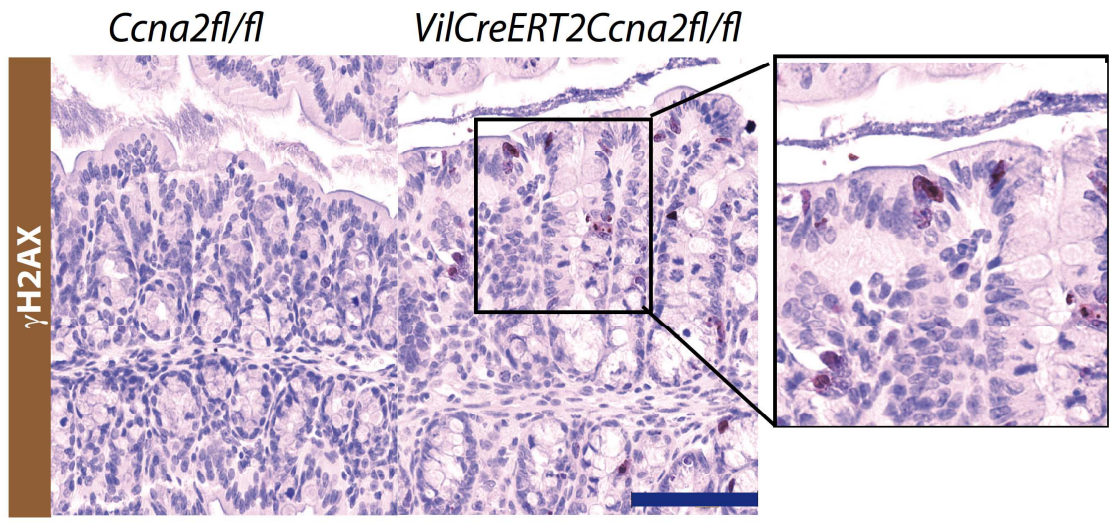

D
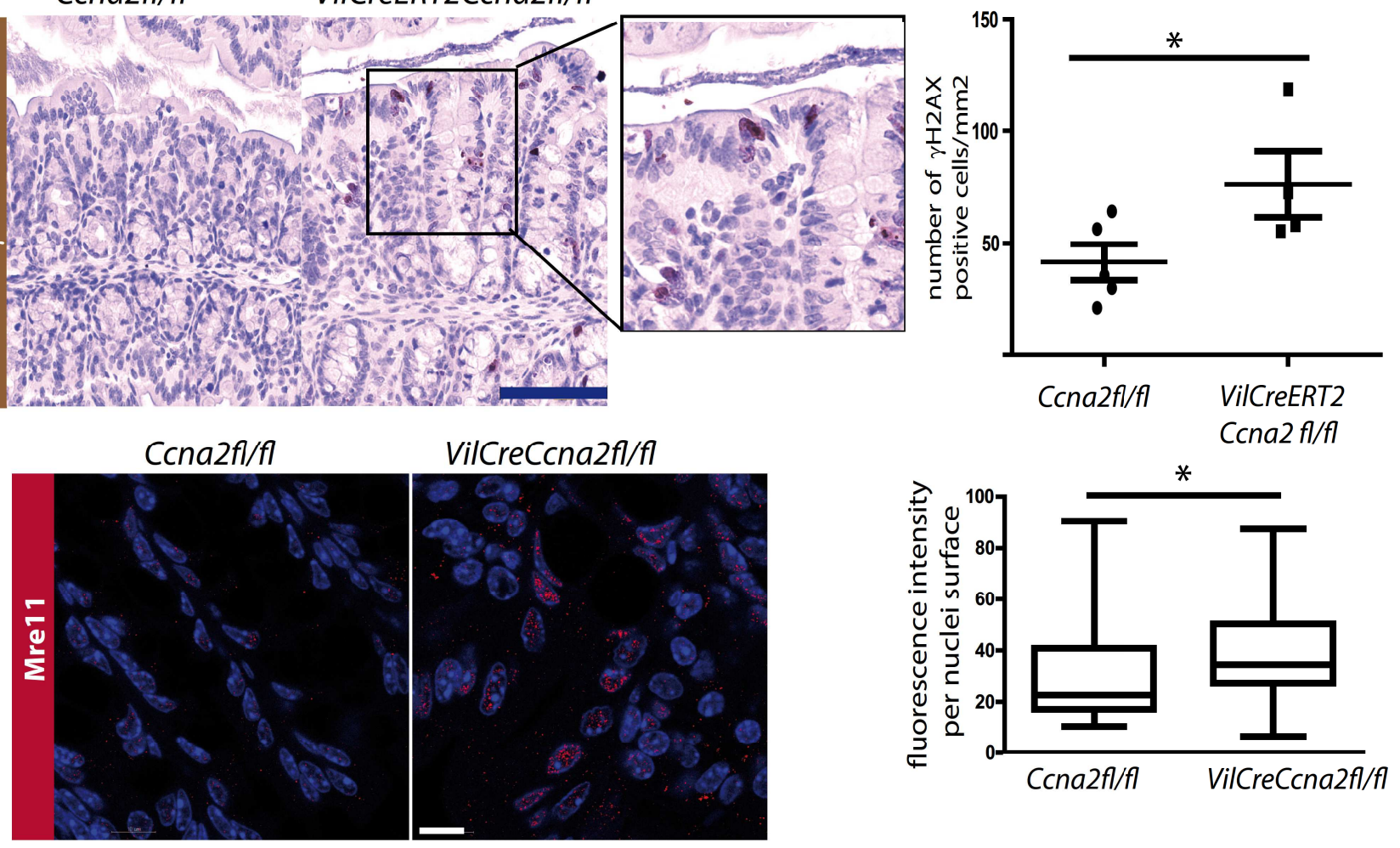

Figure 4: Elevated mitoses, DNA damage and activation of $\beta$-catenin following cyclin A2 deletion in the colonic epithelium. (A). Representative HE staining showing an increased number of mitoses (red arrowheads) in the proximal region of the colon from cyclin A2-deficient mice compared to a colon of a control animal. Scale bar: $100 \mu \mathrm{m}$. (B). Quantification of mitotic events in constitutive (left panel; $n=5$ ) and induced knockout mice (day 8 following inactivation; right panel; $n=5$ ) and control animals ( $n=5$ ); expressed as mean $\pm \mathrm{SEM},{ }^{* *} \mathrm{p}<0.01$; two-tailed unpaired t-test. (C). $\gamma \mathrm{H} 2 \mathrm{AX}$ expression analyzed by immunohistochemistry on colon sections of control (Ccna2fl/fl; $\mathrm{n}=5$ ) and tamoxifen-induced knockout (VilCreERT2Ccna2flffl; $\mathrm{n}=4$ ) mice at day 8 following cyclin A2 inactivation. Representative $\gamma \mathrm{H} 2 \mathrm{AX}$ immunostaining and quantification of the number of $\gamma \mathrm{H} 2 \mathrm{AX}$ positive cells per $\mathrm{mm}^{2}$ of epithelium from the proximal part of colons are shown (expressed as mean $\pm \mathrm{SEM},{ }^{*} \mathrm{p}<0.05$; two-tailed unpaired t-test). Scale bar: $100 \mu \mathrm{m}$. (D). Confocal analysis of nuclei foci formation of Mre11 in crypts from the proximal part of colons from control (Ccna2fl/fl) and VilCreCcna2fl/fl mice. Representative images are shown; Scale bar: $10 \mu \mathrm{m}$; (staining of nuclei with DAPI in blue and Mre11 in red) as well as quantification of the Mre11 fluorescence intensity per nuclei surface (right panel; $\mathrm{n}=83$ different nuclear areas for control and $\mathrm{n}=65$ for cyclin A2-deficient mice (three each); mean \pm SEM are provided, ${ }^{*} \mathrm{p}<0.05$; two-tailed unpaired t-test). 
Fig Ure.Exiv preprint doi: https://doi.org/10.1101/690404; this version posted July 3, 2019. The copyright holder for this preprint (which was not certified by peer review) is the author/funder. All rights reserved. No reuse allowed without permission.

A Ccna2fl/fl

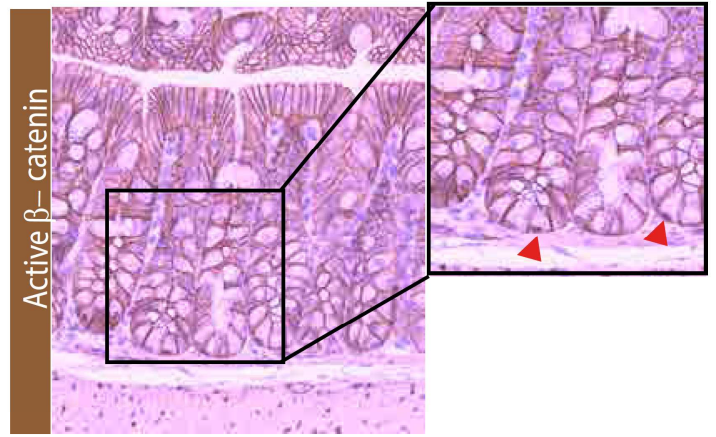

B

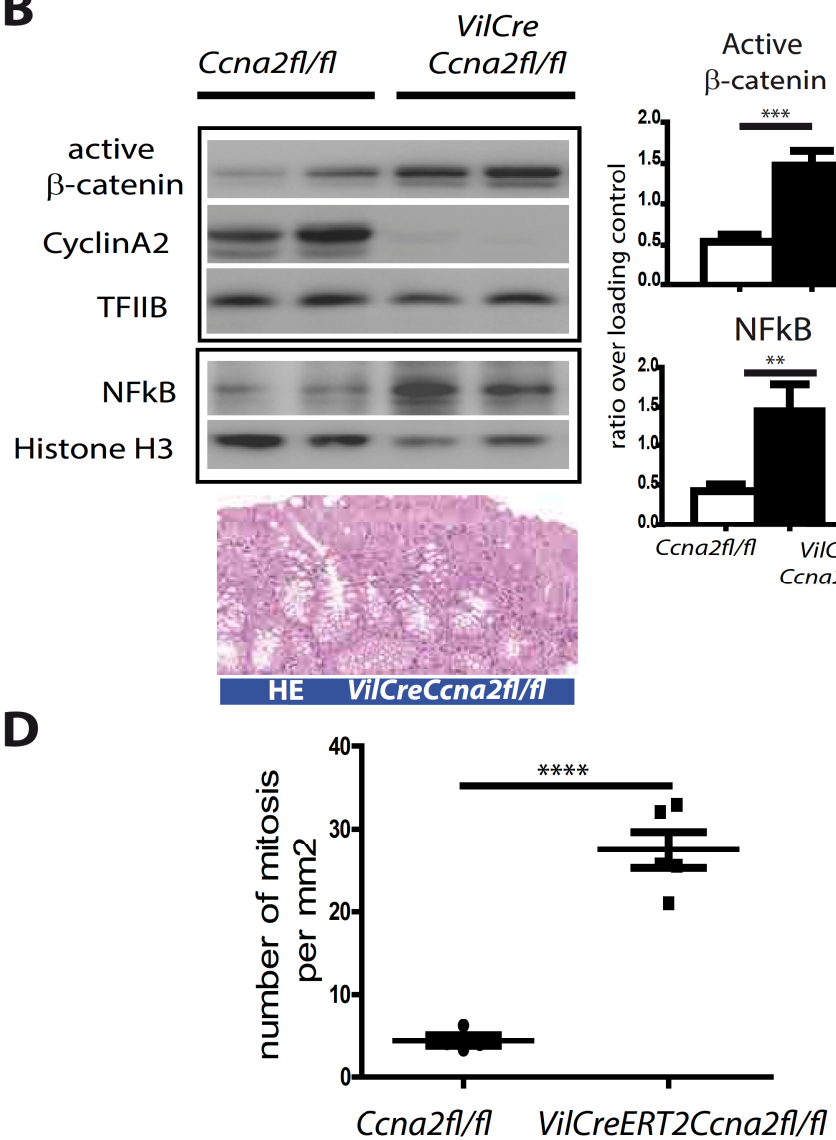

C Day 4
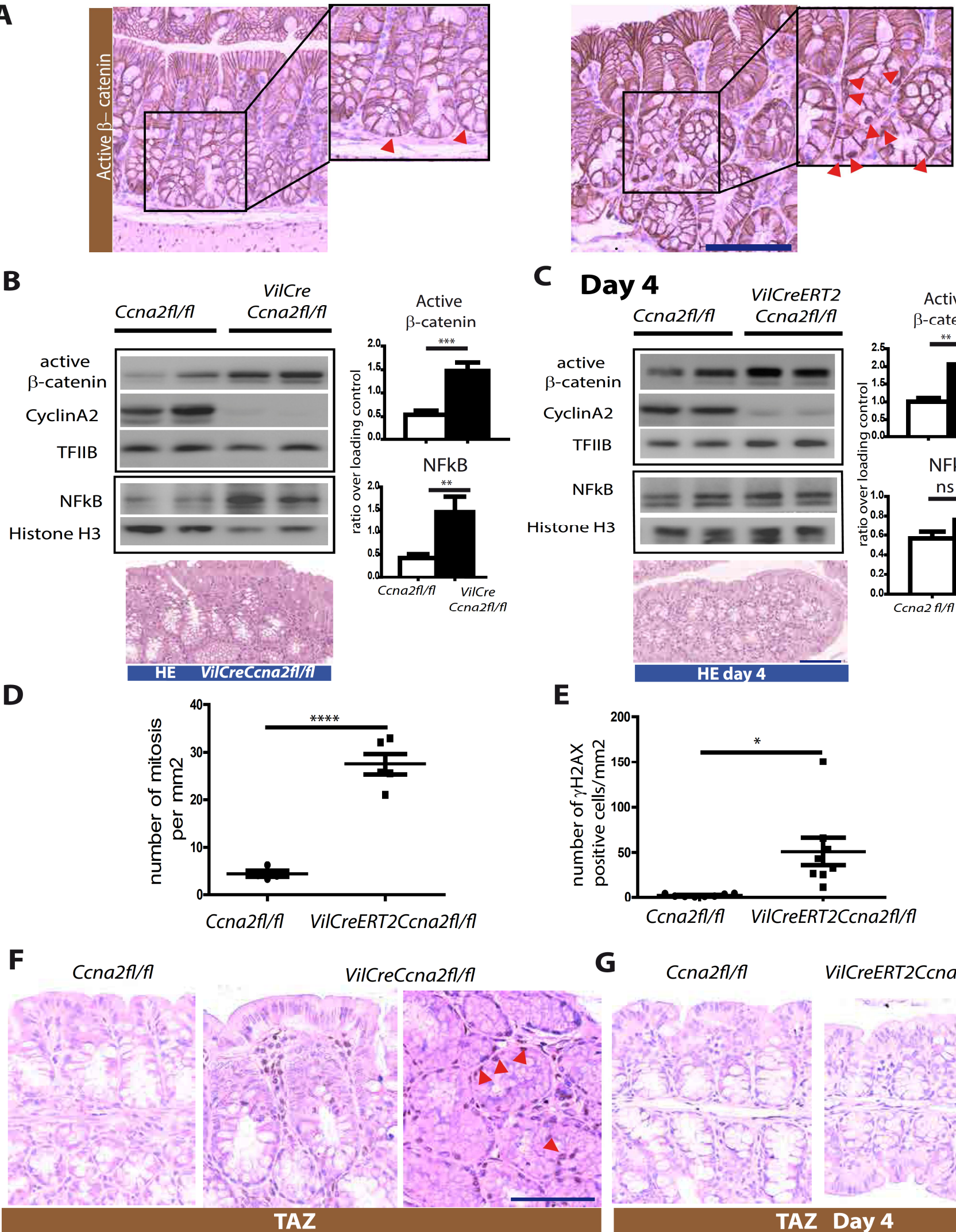

E
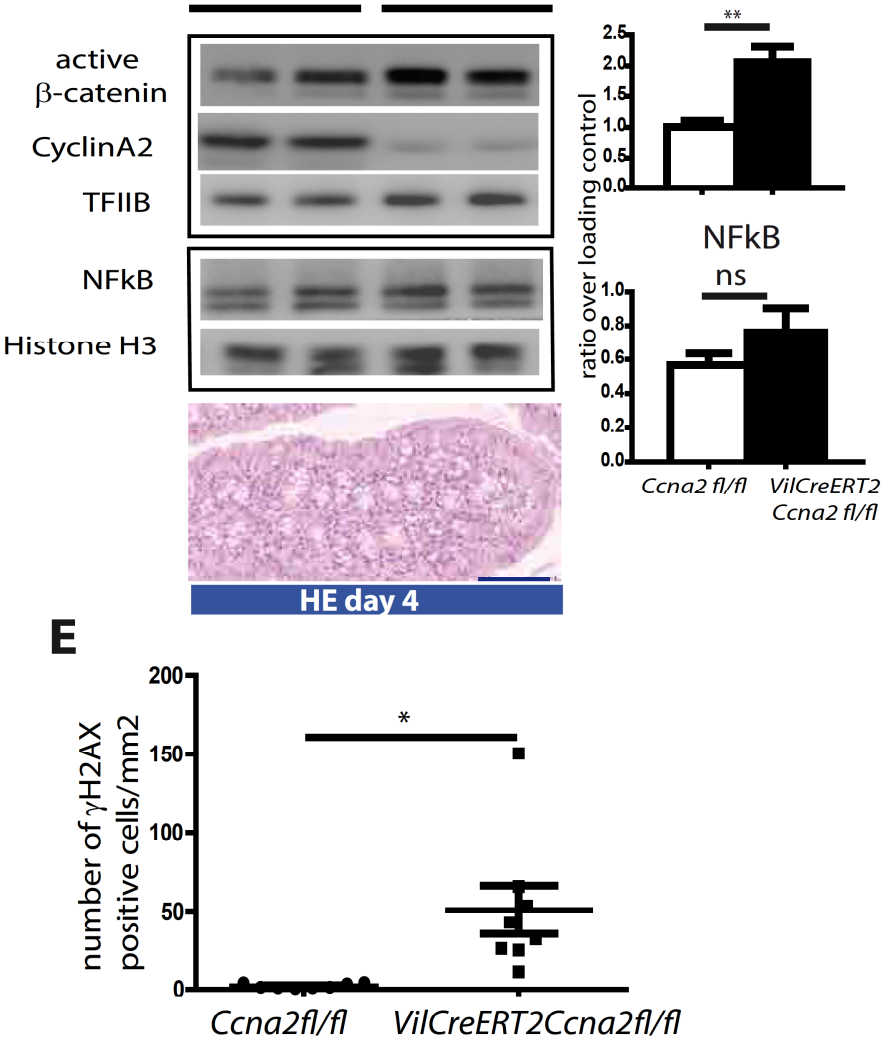

G

Ccna2fl/fl

VilCreERT2Ccna2 fl/fl
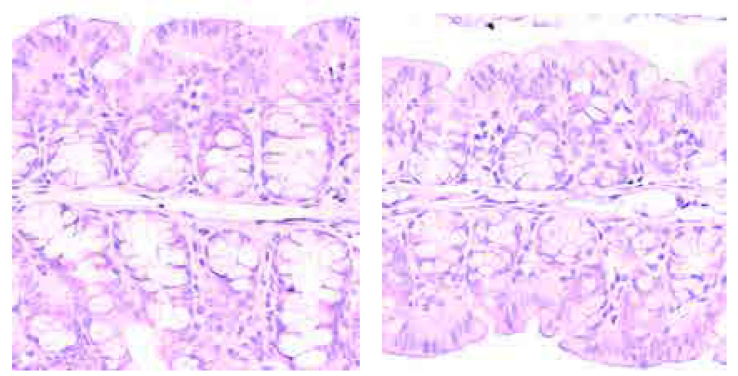

TAZ Day 4

Figure 5: Cyclin A2 deficiency triggers regenerative pathways. (A). Representative immunostaining for active $\beta$-catenin in control (Ccna2fl/fl) and constitutive knockout (VilCreCcna2fl/fl) mice. Arrowheads indicate nuclear localization of active $\beta$-catenin. Scale bar: $100 \mu \mathrm{m}$. (B). Western blot analysis of active $\beta$-catenin and NFkB in CEC extracts derived from constitutive cyclin A2-deficient mice and their control littermates. The right panel shows quantification of active $\beta$-catenin and NFKB after normalization with loading controls (TFIIB or Histone H3, n=9). (C). Western blot analysis of active $\beta$-catenin, and NFKB with their respective quantifications of nuclear extracts derived from CEC of control and tamoxifen-induced knockout mice (VilCreERT2Ccna2fl/fl) following deletion of cyclin A2 at day $4(\mathrm{n}=6)$. Lower panel: Representative HE staining of colons from control and induced knockout mice at day 4 following Ccna2 inactivation. (D-E). Colons of cyclin $\Lambda 2$-deficient mice display DN $\Lambda$ damage. Quantification of mitoses (D) and $\gamma \mathrm{H} 2 \mathrm{AX}$ staining (E) in colons of control and VilCreERT2Ccna2fl/fl mice at day 4 following tamoxifen-induced Ccna 2 depletion ( $\mathrm{n}=8$ mice). (F, G). IHC analysis of TAZ expression (indicated by arrow) in constitutive mutant colons (F) and in induced knockout mice at day 4 following Ccna2 deletion $(\mathbf{G})$, representative images are shown. Scale bar: 100 $\mu \mathrm{m}$ in $\mathbf{B}, \mathbf{C}$ and $\mathbf{D} ;$ mean \pm SEM are provided, ${ }^{*} \mathrm{p}<0,05, * * \mathrm{p}<0.01$ and $* * * \mathrm{p}<0,001$; two-tailed unpaired t-test. 


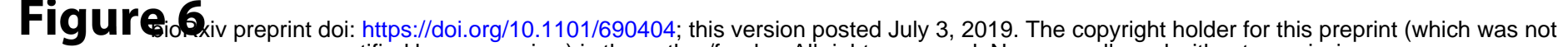
A certified by peer review) is the author/funder. All rights reserved No reuse allowed without permission.
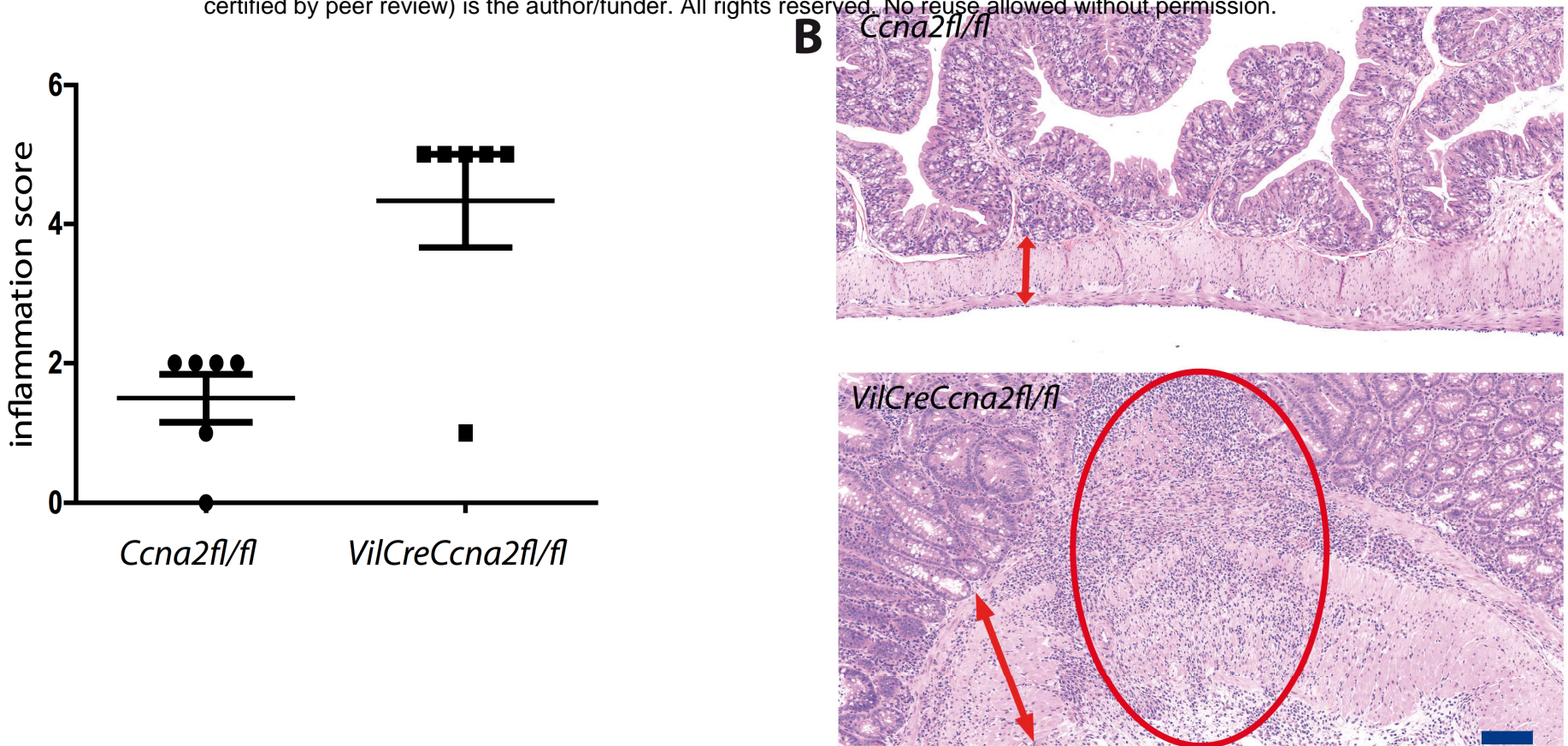

Ccna2fl/fl
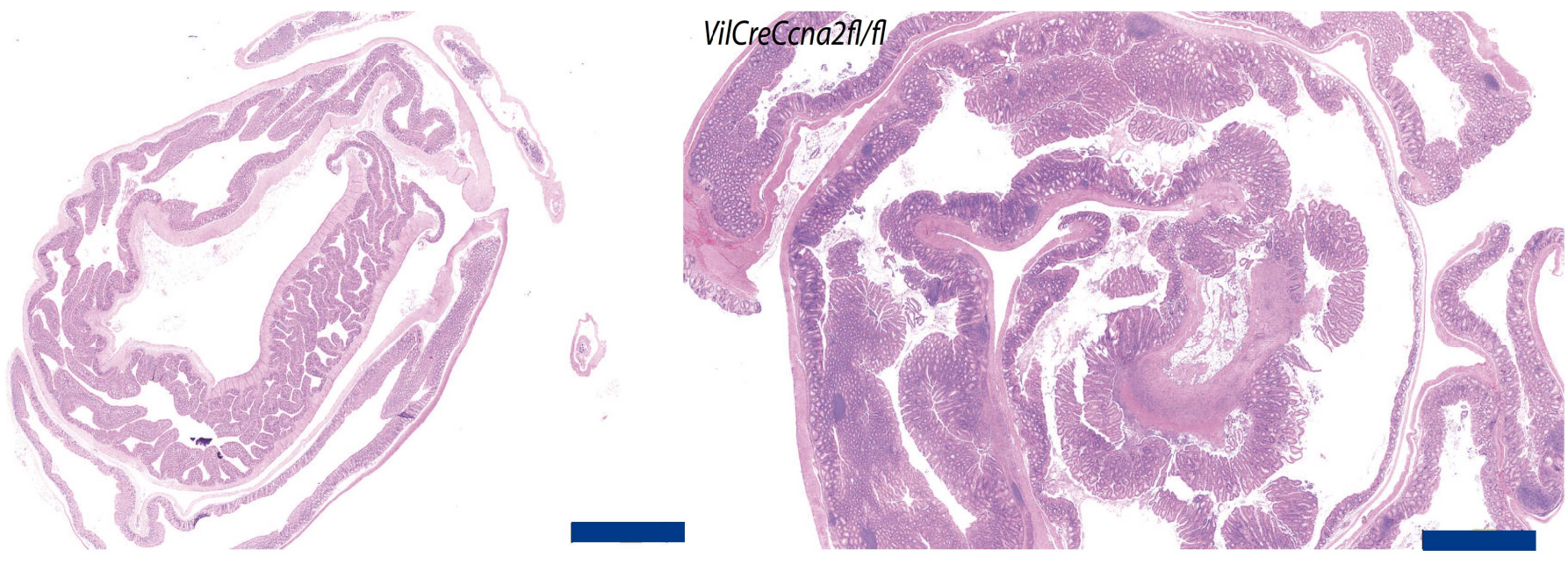

D
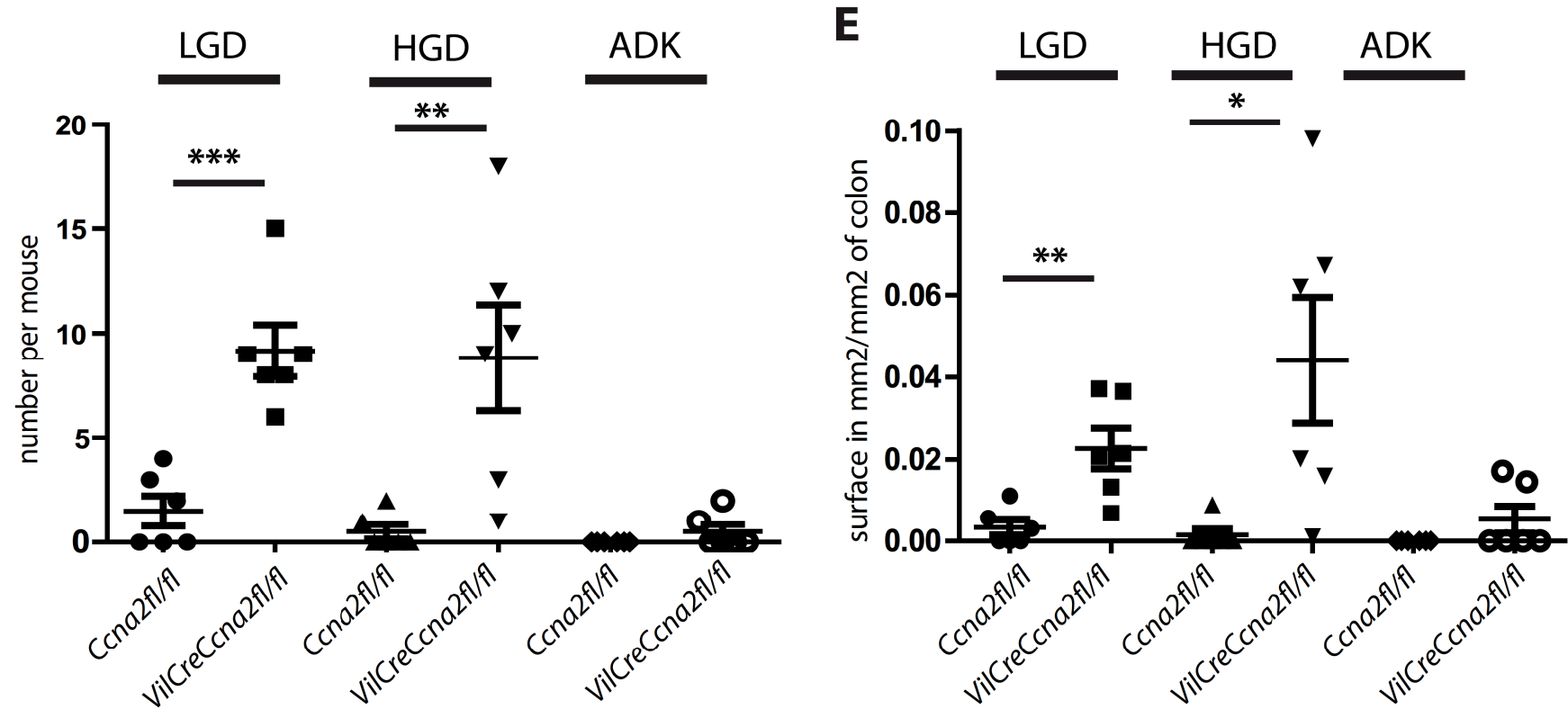

Figure 6: Cyclin A2 deficient mice are more susceptible to colitis-associated colorectal (CAC) cancer. Ccna $2 f l f l$ $(\mathrm{n}=6)$ and VilCreCcna2fl/fl $(\mathrm{n}=7)$ mice were exposed to a modified AOM/DSS protocol including only one DSS-administration (Supplemental Fig 6A). (A, B). Quantification of the inflammatory score of colons from control and $\mathrm{VilCreC}$ cna $2 f l / f l$ mice (A) and representative HE staining showing transmural immune cell infiltration (indicated by the red oval) in the knock-out mice (B) (the red arrows mark the muscularis mucosa). Scale bar: $100 \mu \mathrm{m}$. (C). Representative images of HE stained colons of control and cyclin A2-deficient mice exposed to the CAC protocol. Scale bar: $2 \mathrm{~mm}$. (D, E). Number of dysplasia and adenocarcinoma occurrence per mouse and dysplasia and adenocarcinoma surface expressed in $\mathrm{mm}^{2}$ per $\mathrm{mm}^{2}$ of colon in control and VilCreCcna $\mathrm{fl} / \mathrm{fl}$ mice. LGD and HGD: Low- and High-Grade Dysplasia. ADK: Adenocarcinoma. Scale bar: $2 \mathrm{~mm}$. Mean $\pm \mathrm{SEM}$ are provided, $* \mathrm{p}<0,05, * * \mathrm{p}<0.01$ and $* * * \mathrm{p}<0,001$; two-tailed unpaired t-test. 


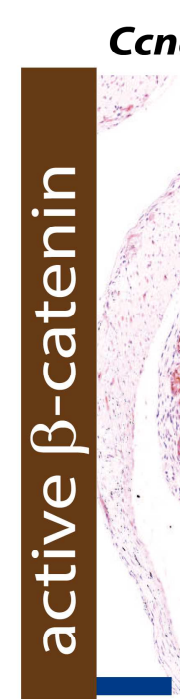

na2fl/f

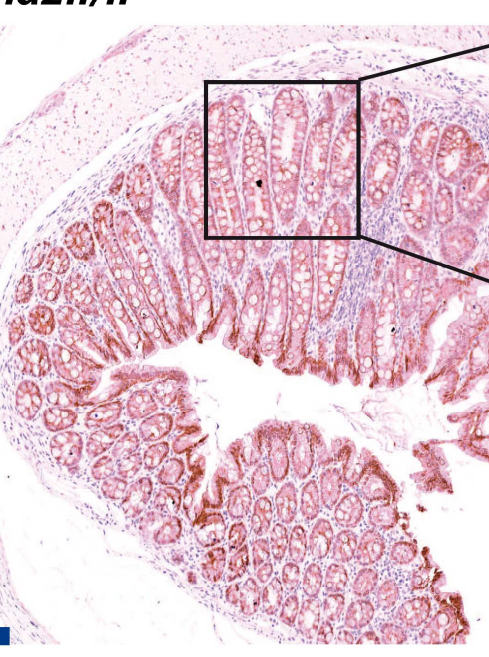

VilCreCcna2fl/f

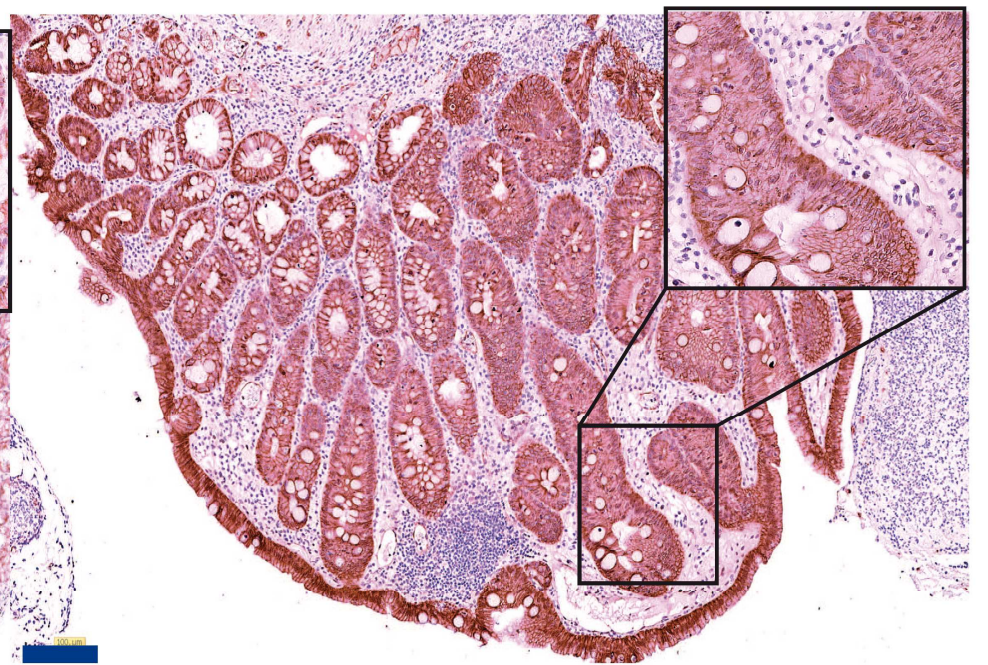

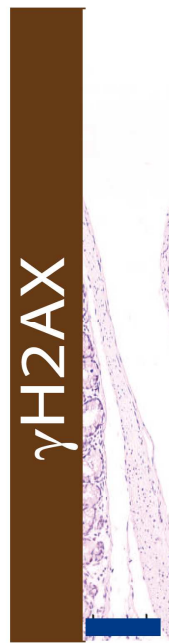
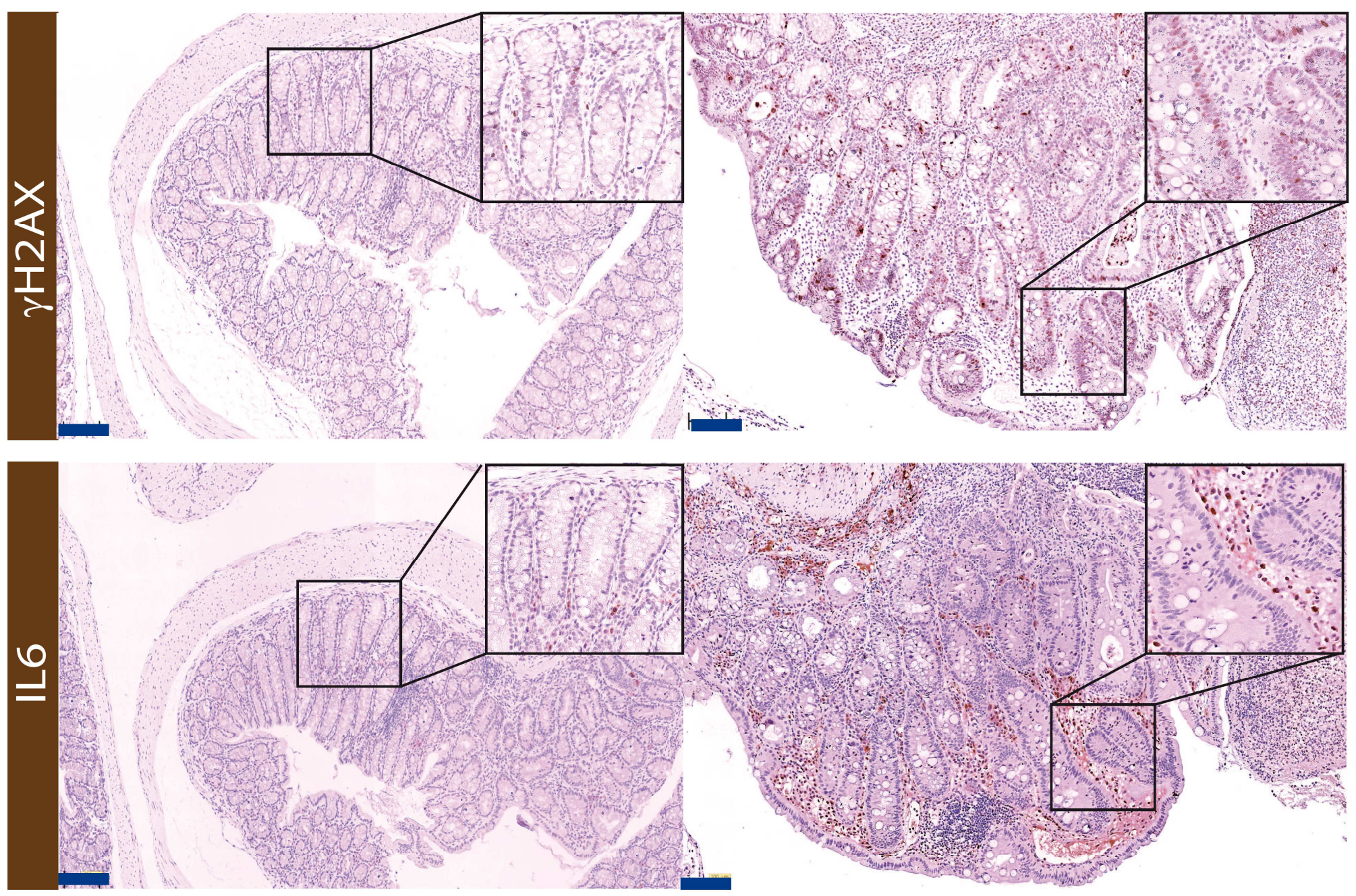

Figure 7: Lesions in colons from cyclin A2-deficient mice exposed to colitis-associated cancer display elevated levels of active $\beta$-catenin, DNA damage as well as IL6 expression. Representative immunostainings for active- $\beta$-catenin, $\gamma \mathrm{H} 2 \mathrm{AX}$ and IL6 in morphologically similar lesions in colons from control and cyclin A2-deficient mice at the end of the AOM/DSS protocol described in Supplemental Fig 6A. Blow Up: 2.5X. Scale bar: $100 \mu \mathrm{m}$. 
Figurire

A

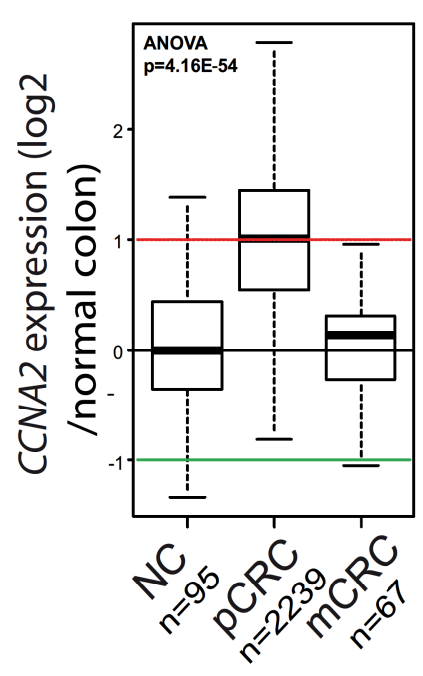

D

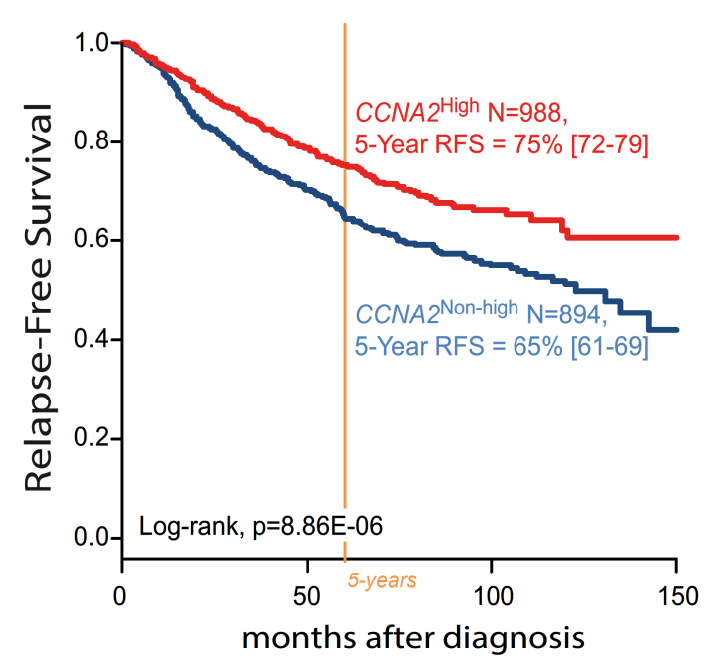

B

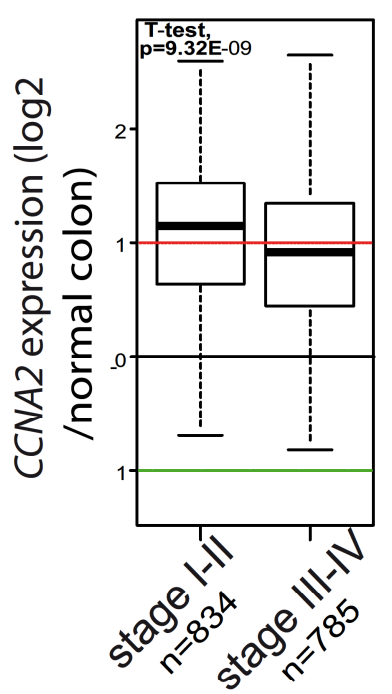

C

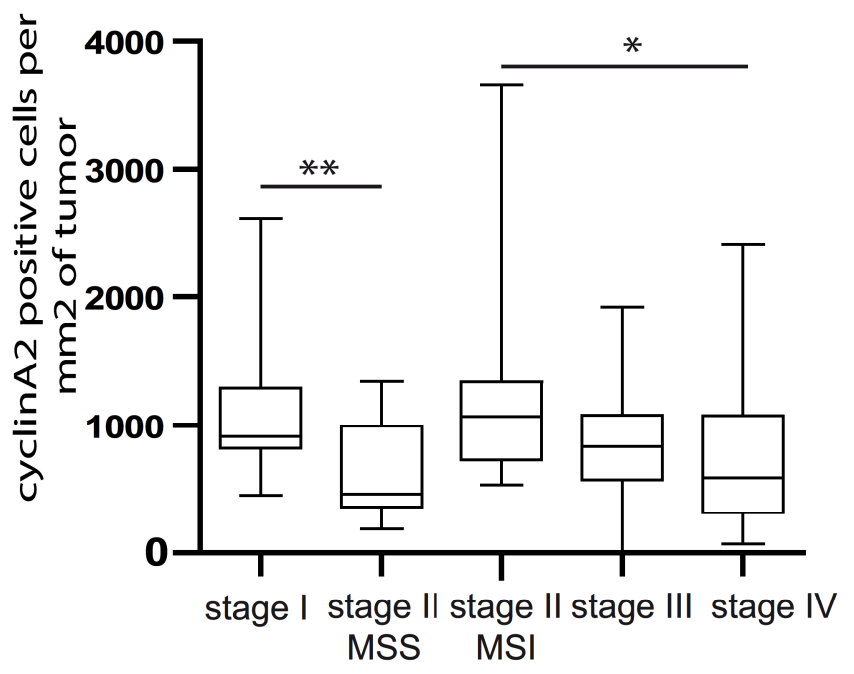

$\mathbf{E}$

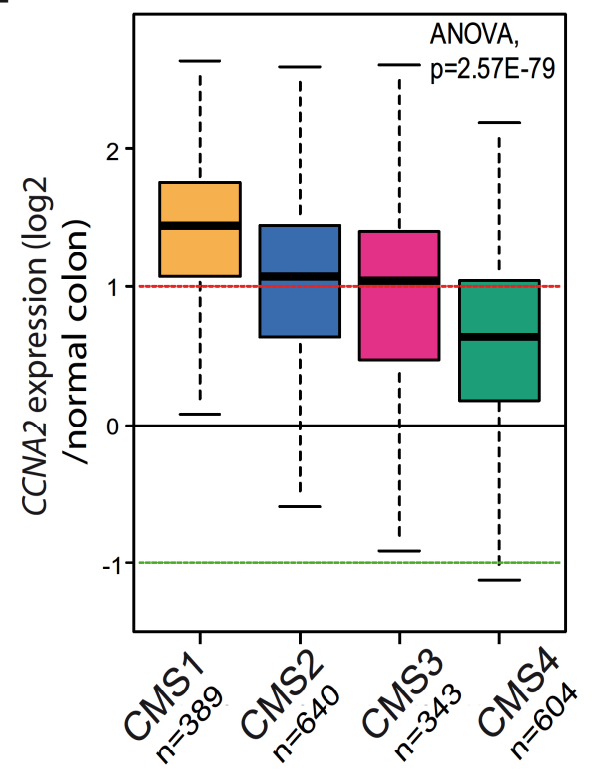

$\mathbf{F}$

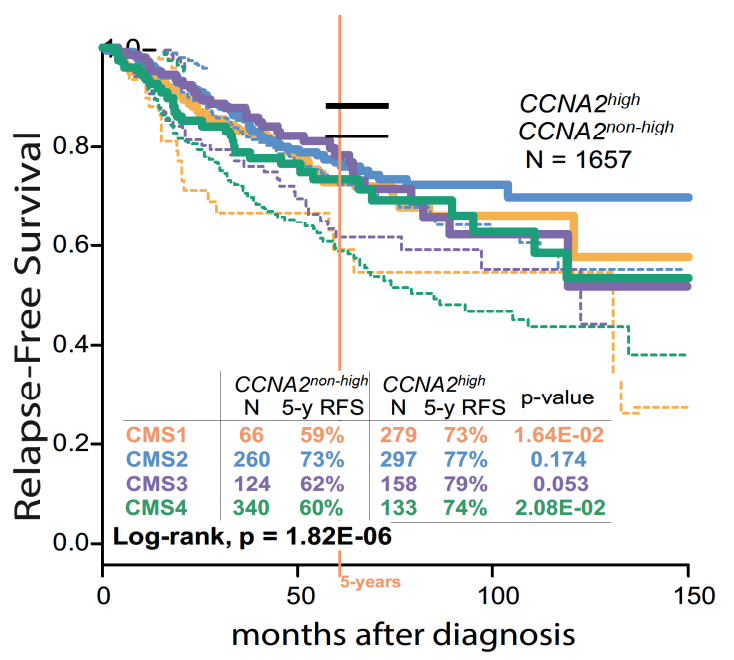

Figure 8: High cyclin A2 expression correlates with better prognosis in CRC patients. (A). Bot plots showing CCNA2 mRNA expression levels (log2 over normal colon) in primary CRC tumors (pCRC; $\mathrm{n}=2239)$ and metastases (mCRC; $\mathrm{n}=67$ ). Expression was normalized to normal tissue samples as in (A). CCNA2high levels were defined as expression above 1 (horizontal red line) and $C C N A 2$ non-high levels were defined as expression below 1 . For each box plot, median and ranges are indicated. CCNA2 expression was compared between group using the ANOVA (multiple comparisons, $\mathrm{p}=4.16 \mathrm{e}-54)$. (B). Cyclin A2 mRNA expression levels in stage I-II ( $\mathrm{n}=834$ ) and III-IV $(\mathrm{n}=785)$ in primary CRC tumors. Expression was normalized to normal tissue samples as in (A). CCNA2 expression was compared between group using the 2-tailed Student t-test test (expressed as mean $\pm \mathrm{SD}, \mathrm{p}=9.32 \mathrm{e}-09$ ). (C). Cyclin A2 protein expression determined by immunostaining using the anti-cyclinA2 antibody from Abcam validated on cyclin A2-deficient colon tissue and expressed as number of positive cells per mm2 of tumor analyzed from a TMA of CRC tumor samples derived from stage I ( $\mathrm{n}=23)$, II ( $\mathrm{n}=48$ with 24 MSS tumors and 24 MSI tumors $=)$, III $(n=30)$ and IV $(n=26)$ patients. (expressed as mean \pm SEM, $p<0.01$ for the analysis between stage I and II-MSS, $\mathrm{p}<0.05$ for comparison between stage I and stage IV, $\mathrm{p}=0.01$ for stage II-MSI to IV). (D). Kaplan-Meier RFS Relapse-Free-Survival (RFS) of patients defined as carrier of CCNA2high ( $\mathrm{n}=988$ ) and non-high ( $\mathrm{n}=894)$ tumors. Survivals were calculated using the Kaplan-Meier method and were compared with the log-rank test ( $\mathrm{p}=8.86 \mathrm{e}-06)$. (E). Analysis of CCNA2 mRNA levels in the different consensus CRC subtypes, i.e. CMS1 ( $\mathrm{n}=389$ ), CMS2 ( $\mathrm{n}=640)$, CMS3 (343) and CMS4 ( $\mathrm{n}=604)$ expressed as $\log 2$ over normal colon as described in (A) $(\mathrm{p}=2.57 \mathrm{e}-79$ by the ANOVA test). (F). Kaplan-Meier RFS curves of all patients with pCRC according to both the $C C N A 2$-based classification (CCNA2high and $C C N A 2$ non-high classes with plain curve and dashed curve respectively) and the CMS subtypes ( $\mathrm{p}=1.64 \mathrm{e}-02$ for the CMS1 subtype, 0.174 for CMS2, 0.053 for CMS3 and 2.08e-02 for CMS4). 
Table1 : List of the 1109 genes differentially expressed between VilCreCcna2fl/fl mice and Ccna2fl/fl mice samples (fold change $>2$, adjusted p-value $|F D R|<0.05$ ).

FC: Fold change, CPM: Counts-per-million, FDR: False Discovery Rate

\begin{tabular}{|c|c|c|c|c|c|}
\hline Gene & $\begin{array}{c}\text { edge R log } \\
\text { FC }\end{array}$ & $\begin{array}{l}\text { edgeR log } \\
\text { CPM }\end{array}$ & $\begin{array}{l}\text { edgeR } p \text { - } \\
\text { value }\end{array}$ & edgeR FDR & $\begin{array}{l}\text { edgeR Significant } \\
\text { differencial } \\
\text { expression }\end{array}$ \\
\hline$\overline{C k b}$ & 3,401 & 7,238 & $8,98 \mathrm{E}-10$ & $1,43 E-05$ & Up in $\mathrm{KO}$ \\
\hline Lama5 & 3,536 & 6,228 & $2,44 \mathrm{E}-08$ & $9,62 \mathrm{E}-05$ & Up in KO \\
\hline Pck1 & $-1,665$ & 6,962 & $3,32 E-08$ & $9,62 E-05$ & Down in KO \\
\hline Fbln1 & 3,592 & 3,066 & 7,37E-08 & $9,76 \mathrm{E}-05$ & Up in KO \\
\hline Nid1 & 4,862 & 2,592 & $2,92 \mathrm{E}-08$ & $9,62 \mathrm{E}-05$ & Up in KO \\
\hline 0610040F04Rik & 2,954 & 3,266 & $4,14 \mathrm{E}-08$ & $9,62 \mathrm{E}-05$ & Up in KO \\
\hline Gsdmc3 & $-3,495$ & 6,308 & 9,91E-08 & $1,12 \mathrm{E}-04$ & Down in KO \\
\hline LOC108167804 & 3,666 & 2,659 & $1,58 \mathrm{E}-07$ & $1,48 \mathrm{E}-04$ & Up in KO \\
\hline Cdc7 & 2,276 & 3,896 & $5,14 \mathrm{E}-08$ & $9,76 \mathrm{E}-05$ & Up in KO \\
\hline Bmp3 & $-2,567$ & 5,019 & $7,24 \mathrm{E}-08$ & $9,76 \mathrm{E}-05$ & Down in KO \\
\hline Slc25a45 & 2,526 & 2,539 & $6,22 \mathrm{E}-08$ & $9,76 \mathrm{E}-05$ & Up in KO \\
\hline Thpo & 2,319 & 2,996 & $2,53 \mathrm{E}-07$ & $1,83 \mathrm{E}-04$ & Up in KO \\
\hline Gm34583 & 3,145 & 1,775 & $1,92 \mathrm{E}-07$ & 1,61E-04 & Up in KO \\
\hline Hsd17b13 & $-2,805$ & 3,987 & $8,40 \mathrm{E}-08$ & $1,03 \mathrm{E}-04$ & Down in KO \\
\hline Grb10 & 4,234 & 1,705 & $4,24 \mathrm{E}-08$ & $9,62 \mathrm{E}-05$ & Up in KO \\
\hline Igf2bp1 & 3,063 & 3,504 & $2,41 \mathrm{E}-07$ & $1,82 \mathrm{E}-04$ & Up in KO \\
\hline Ccdc88a & 3,332 & 1,428 & $2,51 \mathrm{E}-08$ & $9,62 \mathrm{E}-05$ & Up in KO \\
\hline Erc2 & 3,380 & 1,245 & $3,15 E-07$ & $1,98 \mathrm{E}-04$ & Up in KO \\
\hline PrIr & $-3,696$ & 3,615 & $3,22 E-07$ & $1,98 \mathrm{E}-04$ & Down in KO \\
\hline Eomes & 4,194 & 2,904 & $1,45 \mathrm{E}-07$ & $1,48 \mathrm{E}-04$ & Up in KO \\
\hline Ptges & 3,070 & 2,040 & $5,54 \mathrm{E}-07$ & $2,44 \mathrm{E}-04$ & Up in KO \\
\hline Crip2 & 2,927 & 4,087 & $3,23 E-07$ & $1,98 \mathrm{E}-04$ & Up in $\mathrm{KO}$ \\
\hline Tgfbr2 & 1,439 & 5,664 & $1,52 \mathrm{E}-07$ & $1,48 \mathrm{E}-04$ & Up in KO \\
\hline Cacnale & $-5,906$ & 2,036 & $1,02 \mathrm{E}-06$ & $3,44 \mathrm{E}-04$ & Down in KO \\
\hline Add3 & $-1,446$ & 5,984 & $2,24 \mathrm{E}-07$ & $1,78 \mathrm{E}-04$ & Down in KO \\
\hline Gm34496 & 4,532 & 1,437 & $1,79 E-07$ & $1,58 \mathrm{E}-04$ & Up in KO \\
\hline Adamts15 & $-2,500$ & 3,342 & $6,00 \mathrm{E}-07$ & $2,57 \mathrm{E}-04$ & Down in KO \\
\hline Eda2r & 3,558 & 2,197 & $3,44 \mathrm{E}-06$ & $6,77 \mathrm{E}-04$ & Up in KO \\
\hline Skp2 & 1,891 & 3,185 & $6,87 \mathrm{E}-07$ & $2,79 E-04$ & Up in KO \\
\hline Slco2b1 & $-2,211$ & 3,926 & $3,86 \mathrm{E}-07$ & $2,13 \mathrm{E}-04$ & Down in KO \\
\hline Rarb & 3,239 & 1,309 & 7,19E-07 & $2,79 E-04$ & Up in KO \\
\hline Atp6v0e2 & 1,438 & 5,087 & $3,58 \mathrm{E}-07$ & $2,11 \mathrm{E}-04$ & Up in KO \\
\hline Rasgrf2 & $-2,413$ & 2,836 & 4,98E-07 & $2,33 \mathrm{E}-04$ & Down in KO \\
\hline Sult4a1 & 3,830 & 1,593 & $5,23 E-07$ & 2,37E-04 & Up in KO \\
\hline Con1 & $-1,663$ & 7,311 & $4,96 \mathrm{E}-07$ & $2,33 \mathrm{E}-04$ & Down in KO \\
\hline Rnf186 & $-1,638$ & 6,794 & $4,22 E-07$ & $2,16 \mathrm{E}-04$ & Down in KO \\
\hline Tmem184c & 1,974 & 2,893 & $1,36 \mathrm{E}-06$ & $3,88 \mathrm{E}-04$ & Up in KO \\
\hline Cpm & $-1,305$ & 4,115 & $7,16 \mathrm{E}-07$ & 2,79E-04 & Down in KO \\
\hline Pear1 & 1,301 & 3,892 & 1,07E-06 & $3,51 \mathrm{E}-04$ & Up in KO \\
\hline Gja1 & 3,281 & 3,297 & $1,93 \mathrm{E}-06$ & 4,94E-04 & Up in KO \\
\hline SIc27a2 & $-2,990$ & 1,336 & $2,80 \mathrm{E}-07$ & $1,93 \mathrm{E}-04$ & Down in KO \\
\hline Myo5a & 2,997 & 2,173 & $1,36 \mathrm{E}-06$ & $3,88 \mathrm{E}-04$ & Up in KO \\
\hline Tpbg & 2,599 & 3,888 & $1,13 \mathrm{E}-06$ & $3,51 \mathrm{E}-04$ & Up in KO \\
\hline Mmp7 & 4,861 & 3,968 & $6,89 \mathrm{E}-06$ & 1,07E-03 & Up in KO \\
\hline
\end{tabular}




\begin{tabular}{|c|c|c|c|c|c|}
\hline Neto2 & 2,173 & 1,660 & $7,75 \mathrm{E}-07$ & 2,93E-04 & Up in KO \\
\hline Lce3b & 6,735 & 1,797 & $9,16 \mathrm{E}-07$ & 3,31E-04 & Up in KO \\
\hline Chga & $-2,393$ & 5,481 & $1,22 \mathrm{E}-06$ & $3,65 E-04$ & Down in KO \\
\hline Sobp & $-4,192$ & 1,184 & $3,95 E-07$ & 2,13E-04 & Down in KO \\
\hline Apoc2 & 3,139 & 4,090 & 1,60E-06 & 4,32E-04 & Up in KO \\
\hline Gch1 & 1,372 & 5,684 & $6,46 \mathrm{E}-07$ & $2,70 \mathrm{E}-04$ & Up in KO \\
\hline Chgb & $-2,066$ & 5,881 & $1,10 \mathrm{E}-06$ & $3,51 \mathrm{E}-04$ & Down in KO \\
\hline Myl7 & 2,746 & 4,027 & 2,57E-06 & $5,82 E-04$ & Up in KO \\
\hline Dll1 & $-1,659$ & 2,701 & $2,13 E-06$ & 5,37E-04 & Down in $\mathrm{KO}$ \\
\hline Atg9b & 4,034 & 2,396 & 4,87E-06 & 8,73E-04 & Up in KO \\
\hline $\mathrm{Hfm} 1$ & 5,051 & 1,082 & 4,39E-07 & $2,18 \mathrm{E}-04$ & Up in KO \\
\hline Gnal & 2,476 & 5,000 & 1,60E-06 & 4,32E-04 & Up in KO \\
\hline Gsdmc2 & $-2,613$ & 8,110 & $2,63 \mathrm{E}-06$ & $5,87 \mathrm{E}-04$ & Down in KO \\
\hline Sprr1a & 1,420 & 6,106 & 1,15E-06 & 3,51E-04 & Up in KO \\
\hline Rec8 & 2,049 & 4,258 & $1,52 \mathrm{E}-06$ & 4,24E-04 & Up in KO \\
\hline Stil & 1,108 & 4,570 & 1,11E-06 & 3,51E-04 & Up in KO \\
\hline Hoxd4 & $-2,948$ & 2,379 & $2,54 \mathrm{E}-06$ & $5,82 \mathrm{E}-04$ & Down in KO \\
\hline E2f7 & 2,917 & 2,815 & $4,39 E-06$ & $8,20 \mathrm{E}-04$ & Up in KO \\
\hline Matk & $-2,085$ & 1,741 & $3,05 E-06$ & 6,39E-04 & Down in KO \\
\hline Aldh3b2 & 1,583 & 4,330 & $1,79 \mathrm{E}-06$ & $4,75 E-04$ & Up in KO \\
\hline Fer114 & 1,394 & 4,829 & $3,45 E-06$ & $6,77 \mathrm{E}-04$ & Up in KO \\
\hline Nr4a1 & $-1,517$ & 7,679 & $2,23 E-06$ & $5,46 \mathrm{E}-04$ & Down in KO \\
\hline Gm1600 & 2,490 & 0,757 & $9,90 \mathrm{E}-07$ & $3,42 E-04$ & Up in KO \\
\hline 9330182L06Rik & 2,596 & 1,195 & $9,71 E-06$ & $1,34 \mathrm{E}-03$ & Up in KO \\
\hline Sult1c2 & $-1,923$ & 4,975 & $3,06 \mathrm{E}-06$ & 6,39E-04 & Down in KO \\
\hline II3ra & 2,185 & 1,678 & 2,37E-06 & $5,63 \mathrm{E}-04$ & Up in KO \\
\hline Piezo1 & 1,644 & 5,170 & $2,27 \mathrm{E}-06$ & $5,46 \mathrm{E}-04$ & Up in KO \\
\hline E130008D07Rik & 1,913 & 1,579 & $3,84 \mathrm{E}-06$ & $7,35 E-04$ & Up in $\mathrm{KO}$ \\
\hline Agmo & $-2,472$ & 2,476 & $6,68 \mathrm{E}-06$ & $1,06 \mathrm{E}-03$ & Down in KO \\
\hline Cacna1a & $-2,097$ & 1,893 & $6,53 \mathrm{E}-06$ & $1,06 \mathrm{E}-03$ & Down in KO \\
\hline Gm32949 & 1,278 & 2,912 & $4,56 \mathrm{E}-06$ & $8,34 \mathrm{E}-04$ & Up in KO \\
\hline Polq & 1,653 & 2,547 & $4,25 E-06$ & $8,04 \mathrm{E}-04$ & Up in $\mathrm{KO}$ \\
\hline Fer114 & 2,884 & 2,510 & $2,27 \mathrm{E}-06$ & $5,46 \mathrm{E}-04$ & Up in KO \\
\hline Lrrc8b & 1,254 & 5,407 & $9,61 \mathrm{E}-07$ & $3,39 \mathrm{E}-04$ & Up in KO \\
\hline Atad2 & 1,404 & 4,750 & $3,31 E-06$ & $6,65 \mathrm{E}-04$ & Up in KO \\
\hline Ces1d & $-1,778$ & 4,999 & $3,06 \mathrm{E}-06$ & $6,39 \mathrm{E}-04$ & Down in KO \\
\hline Myo18b & 7,302 & 1,261 & $7,05 \mathrm{E}-08$ & $9,76 \mathrm{E}-05$ & Up in KO \\
\hline 5730507C01Rik & 1,886 & 3,329 & $5,60 \mathrm{E}-06$ & $9,68 \mathrm{E}-04$ & Up in KO \\
\hline 3930402G23Rik & 2,013 & 2,164 & $1,04 \mathrm{E}-05$ & $1,39 \mathrm{E}-03$ & Up in KO \\
\hline Gspt2 & 1,649 & 2,185 & $1,26 \mathrm{E}-05$ & $1,58 \mathrm{E}-03$ & Up in KO \\
\hline Sh3tc2 & 3,209 & 2,329 & $8,17 \mathrm{E}-06$ & $1,20 \mathrm{E}-03$ & Up in KO \\
\hline Zmat4 & $-4,692$ & 0,428 & 4,03E-07 & $2,13 E-04$ & Down in $\mathrm{KO}$ \\
\hline Ccl5 & $-3,404$ & 3,267 & $1,40 \mathrm{E}-05$ & $1,62 \mathrm{E}-03$ & Down in $\mathrm{KO}$ \\
\hline Tmem266 & 2,632 & 2,308 & $7,00 \mathrm{E}-06$ & $1,08 \mathrm{E}-03$ & Up in KO \\
\hline Gsdmc4 & $-2,325$ & 8,275 & $9,70 E-06$ & $1,34 \mathrm{E}-03$ & Down in $\mathrm{KO}$ \\
\hline Sass6 & 1,229 & 3,509 & 7,91E-06 & $1,17 \mathrm{E}-03$ & Up in KO \\
\hline Baiap3 & $-2,271$ & 1,585 & $3,14 \mathrm{E}-06$ & 6,39E-04 & Down in KO \\
\hline Mtap & 2,200 & 2,190 & $6,83 \mathrm{E}-06$ & 1,07E-03 & Up in KO \\
\hline Slc7a11 & 3,632 & 2,450 & $1,72 \mathrm{E}-05$ & $1,80 \mathrm{E}-03$ & Up in KO \\
\hline Tpm2 & 1,104 & 4,553 & $5,44 \mathrm{E}-06$ & $9,60 \mathrm{E}-04$ & Up in KO \\
\hline Tcf24 & 2,717 & 1,637 & $7,88 \mathrm{E}-06$ & 1,17E-03 & Up in KO \\
\hline Cul9 & $-2,160$ & 1,234 & 9,91E-06 & $1,36 \mathrm{E}-03$ & Down in $\mathrm{KO}$ \\
\hline
\end{tabular}




\begin{tabular}{|c|c|c|c|c|c|}
\hline Capg & 1,515 & 6,616 & 5,54E-06 & $9,68 \mathrm{E}-04$ & Up in KO \\
\hline Apoc1 & 4,382 & 0,172 & $8,03 E-07$ & 2,97E-04 & Up in KO \\
\hline Ntrk2 & $-1,624$ & 2,806 & $2,06 \mathrm{E}-05$ & 1,88E-03 & Down in KO \\
\hline Rab31 & 1,736 & 3,879 & 6,67E-06 & 1,06E-03 & Up in KO \\
\hline Defa24 & 10,107 & 1,246 & $7,86 \mathrm{E}-05$ & 4,04E-03 & Up in KO \\
\hline Rrm2 & 2,852 & 5,377 & 1,89E-05 & $1,85 \mathrm{E}-03$ & Up in KO \\
\hline Syt8 & 2,491 & 2,007 & $9,65 E-06$ & $1,34 \mathrm{E}-03$ & Up in KO \\
\hline Stom & 1,629 & 6,475 & $5,91 \mathrm{E}-06$ & $9,87 \mathrm{E}-04$ & Up in KO \\
\hline Ulbp1 & 2,587 & 1,065 & $3,11 \mathrm{E}-06$ & $6,39 \mathrm{E}-04$ & Up in $\mathrm{KO}$ \\
\hline Akr1b8 & 1,389 & 7,708 & $7,66 \mathrm{E}-06$ & $1,16 \mathrm{E}-03$ & Up in $\mathrm{KO}$ \\
\hline 1700017B05Rik & 1,222 & 4,551 & $5,69 \mathrm{E}-06$ & $9,72 \mathrm{E}-04$ & Up in KO \\
\hline 1700007E05Rik & 2,413 & 1,347 & $1,42 E-05$ & $1,62 \mathrm{E}-03$ & Up in KO \\
\hline Me1 & 2,220 & 6,645 & $1,29 \mathrm{E}-05$ & $1,58 \mathrm{E}-03$ & Up in KO \\
\hline Spag16 & 2,970 & 1,366 & $1,20 \mathrm{E}-05$ & $1,51 \mathrm{E}-03$ & Up in KO \\
\hline Ddit4l & 3,741 & 0,596 & 1,53E-05 & 1,71E-03 & Up in KO \\
\hline Gbp8 & $-4,429$ & 2,608 & $4,80 \mathrm{E}-05$ & 2,99E-03 & Down in $\mathrm{KO}$ \\
\hline Maf & 1,418 & 3,640 & $1,06 \mathrm{E}-05$ & $1,40 \mathrm{E}-03$ & Up in KO \\
\hline Pvt1 & 1,998 & 1,573 & $8,42 E-06$ & $1,23 \mathrm{E}-03$ & Up in KO \\
\hline Cit & 1,244 & 4,163 & $1,84 \mathrm{E}-05$ & $1,85 \mathrm{E}-03$ & Up in KO \\
\hline Sh3bp1 & 1,311 & 3,848 & 7,07E-06 & $1,08 \mathrm{E}-03$ & Up in KO \\
\hline Sprr2a3 & 1,419 & 9,911 & $1,47 E-05$ & $1,66 \mathrm{E}-03$ & Up in KO \\
\hline Edn2 & $-1,979$ & 4,829 & $1,05 E-05$ & 1,39E-03 & Down in $\mathrm{KO}$ \\
\hline Plb1 & 3,222 & 0,704 & $8,03 \mathrm{E}-05$ & 4,10E-03 & Up in KO \\
\hline Sis & 2,551 & 4,360 & $1,93 \mathrm{E}-05$ & $1,85 \mathrm{E}-03$ & Up in KO \\
\hline Zfp677 & $-1,966$ & 1,770 & $1,41 \mathrm{E}-05$ & $1,62 \mathrm{E}-03$ & Down in $\mathrm{KO}$ \\
\hline Ms4a10 & 2,343 & 1,620 & $1,88 \mathrm{E}-05$ & $1,85 \mathrm{E}-03$ & Up in KO \\
\hline Mybl1 & 1,666 & 2,331 & $1,91 \mathrm{E}-05$ & $1,85 \mathrm{E}-03$ & Up in KO \\
\hline Slc16a3 & 2,615 & 4,105 & $2,03 E-05$ & $1,88 \mathrm{E}-03$ & Up in KO \\
\hline Scgb2b15 & 3,725 & 1,443 & $2,35 \mathrm{E}-05$ & 1,97E-03 & Up in KO \\
\hline Scgb2b17 & 3,725 & 1,443 & $2,35 \mathrm{E}-05$ & $1,97 \mathrm{E}-03$ & Up in KO \\
\hline 9130227L01Rik & 1,518 & 1,851 & $1,38 \mathrm{E}-05$ & $1,62 \mathrm{E}-03$ & Up in KO \\
\hline Macrod1 & $-1,305$ & 3,458 & $1,20 \mathrm{E}-05$ & $1,51 \mathrm{E}-03$ & Down in $\mathrm{KO}$ \\
\hline Cotl1 & 1,270 & 6,433 & 1,17E-05 & $1,50 \mathrm{E}-03$ & Up in KO \\
\hline Pcsk6 & 3,771 & 1,252 & $3,31 \mathrm{E}-05$ & $2,43 E-03$ & Up in KO \\
\hline 1700016C15Rik & 2,754 & 0,162 & 1,37E-06 & $3,88 \mathrm{E}-04$ & Up in KO \\
\hline Ddias & 1,779 & 2,562 & $1,92 \mathrm{E}-05$ & $1,85 \mathrm{E}-03$ & Up in KO \\
\hline Gm31423 & 2,135 & 3,296 & $2,42 E-05$ & $2,00 \mathrm{E}-03$ & Up in KO \\
\hline Tph1 & $-2,188$ & 3,917 & $2,15 E-05$ & $1,92 \mathrm{E}-03$ & Down in $\mathrm{KO}$ \\
\hline Acta1 & $-2,504$ & 7,231 & $2,64 \mathrm{E}-05$ & $2,08 \mathrm{E}-03$ & Down in $\mathrm{KO}$ \\
\hline Cyp4b1 & $-2,024$ & 4,851 & $1,64 \mathrm{E}-05$ & $1,75 E-03$ & Down in $\mathrm{KO}$ \\
\hline Kcnh8 & $-3,517$ & 0,474 & $1,03 E-05$ & $1,39 \mathrm{E}-03$ & Down in $\mathrm{KO}$ \\
\hline Vav1 & $-1,463$ & 1,967 & $1,59 \mathrm{E}-05$ & 1,71E-03 & Down in $\mathrm{KO}$ \\
\hline Bmp8b & 1,635 & 2,405 & $2,18 \mathrm{E}-05$ & 1,93E-03 & Up in KO \\
\hline Igfbp4 & 3,283 & 2,937 & $4,73 E-05$ & $2,96 \mathrm{E}-03$ & Up in KO \\
\hline Ttc7b & 1,351 & 2,494 & $2,79 E-05$ & $2,19 E-03$ & Up in KO \\
\hline Steap4 & 2,025 & 2,626 & $1,91 \mathrm{E}-05$ & $1,85 \mathrm{E}-03$ & Up in KO \\
\hline Pcsk1n & $-2,889$ & 1,231 & $4,98 \mathrm{E}-05$ & $3,05 E-03$ & Down in $\mathrm{KO}$ \\
\hline Rad54b & 1,075 & 2,778 & $7,30 \mathrm{E}-05$ & $3,84 \mathrm{E}-03$ & Up in KO \\
\hline Trpm5 & $-2,748$ & 1,553 & $1,10 \mathrm{E}-05$ & $1,43 \mathrm{E}-03$ & Down in KO \\
\hline Mki67 & 1,555 & 7,569 & $1,75 \mathrm{E}-05$ & $1,82 \mathrm{E}-03$ & Up in KO \\
\hline Fat2 & 2,168 & 0,787 & $1,29 \mathrm{E}-05$ & $1,58 \mathrm{E}-03$ & Up in KO \\
\hline Suox & 2,065 & 5,819 & $2,53 E-05$ & $2,04 \mathrm{E}-03$ & Up in $\mathrm{KO}$ \\
\hline
\end{tabular}




\begin{tabular}{|c|c|c|c|c|c|}
\hline Tnni1 & 1,844 & 5,309 & $3,05 \mathrm{E}-05$ & $2,32 \mathrm{E}-03$ & Up in KO \\
\hline Rtn4rl1 & $-1,227$ & 2,216 & $3,75 \mathrm{E}-05$ & $2,63 \mathrm{E}-03$ & Down in $\mathrm{KO}$ \\
\hline LOC108168178 & 3,396 & 2,345 & $6,25 \mathrm{E}-05$ & 3,51E-03 & Up in KO \\
\hline Gipc3 & 2,408 & 1,351 & $4,66 \mathrm{E}-05$ & $2,94 \mathrm{E}-03$ & Up in KO \\
\hline Brca1 & 2,186 & 3,929 & 2,87E-06 & $6,24 \mathrm{E}-04$ & Up in KO \\
\hline Сур27a1 & $-1,371$ & 3,655 & $1,78 \mathrm{E}-05$ & $1,84 \mathrm{E}-03$ & Down in KO \\
\hline Il1rn & 1,508 & 6,015 & $2,24 \mathrm{E}-05$ & 1,95E-03 & Up in KO \\
\hline Slc28a2 & $-3,076$ & 1,659 & $6,44 \mathrm{E}-05$ & $3,56 \mathrm{E}-03$ & Down in KO \\
\hline Slc7a9 & 1,902 & 3,298 & $3,13 E-05$ & $2,34 \mathrm{E}-03$ & Up in KO \\
\hline Prss16 & 4,095 & 0,549 & 4,31E-05 & $2,76 \mathrm{E}-03$ & Up in KO \\
\hline Bmp1 & $-1,960$ & 3,137 & $2,58 \mathrm{E}-05$ & $2,07 \mathrm{E}-03$ & Down in $\mathrm{KO}$ \\
\hline Scgb2b10 & 3,267 & 1,995 & $6,13 E-05$ & $3,50 \mathrm{E}-03$ & Up in KO \\
\hline Grik5 & $-1,302$ & 3,119 & $2,50 \mathrm{E}-05$ & $2,04 \mathrm{E}-03$ & Down in $\mathrm{KO}$ \\
\hline Ren1 & $-2,959$ & 1,360 & 3,41E-05 & $2,48 \mathrm{E}-03$ & Down in KO \\
\hline Gm32555 & 1,437 & 1,907 & $3,56 \mathrm{E}-05$ & $2,56 \mathrm{E}-03$ & Up in KO \\
\hline Tcf기1 & 1,771 & 4,710 & $3,65 E-05$ & $2,58 \mathrm{E}-03$ & Up in KO \\
\hline Tnni2 & 3,374 & $-0,117$ & $5,78 \mathrm{E}-06$ & $9,76 E-04$ & Up in KO \\
\hline Gm40595 & 2,148 & 1,649 & $6,66 \mathrm{E}-05$ & $3,61 E-03$ & Up in KO \\
\hline Gprin1 & 1,690 & 1,007 & 1,91E-05 & $1,85 \mathrm{E}-03$ & Up in KO \\
\hline Frmd3 & 2,672 & 0,074 & 0,00014307 & $5,63 \mathrm{E}-03$ & Up in KO \\
\hline Atf7ip2 & 2,462 & 1,226 & 0,00010795 & 4,83E-03 & Up in KO \\
\hline Prss27 & 2,669 & 1,843 & 5,51E-05 & $3,28 \mathrm{E}-03$ & Up in KO \\
\hline Phlda3 & 2,986 & 2,258 & $8,12 \mathrm{E}-05$ & $4,12 \mathrm{E}-03$ & Up in KO \\
\hline Fam212b & 2,564 & 0,584 & $1,50 \mathrm{E}-05$ & 1,69E-03 & Up in KO \\
\hline Gm41896 & 3,314 & 2,087 & 0,0001096 & $4,88 \mathrm{E}-03$ & Up in KO \\
\hline Nsl1 & 1,730 & 2,923 & 0,00011348 & 4,97E-03 & Up in KO \\
\hline Zfp618 & $-1,464$ & 3,723 & 3,17E-05 & $2,36 \mathrm{E}-03$ & Down in KO \\
\hline Ap1s2 & 1,524 & 1,800 & 1,93E-05 & 1,85E-03 & Up in KO \\
\hline Asic1 & 1,432 & 1,474 & $4,16 \mathrm{E}-05$ & $2,74 \mathrm{E}-03$ & Up in KO \\
\hline Jag2 & 1,619 & 2,978 & $3,70 \mathrm{E}-05$ & $2,60 \mathrm{E}-03$ & Up in KO \\
\hline Tсp11/2 & $-1,063$ & 2,858 & $3,40 E-05$ & 2,47E-03 & Down in $\mathrm{KO}$ \\
\hline Ces1e & $-1,043$ & 3,782 & 2,84E-05 & 2,21E-03 & Down in KO \\
\hline Smc2 & 1,483 & 4,865 & $3,00 \mathrm{E}-05$ & $2,30 \mathrm{E}-03$ & Up in KO \\
\hline Adamts18 & $-7,563$ & 0,324 & $1,54 \mathrm{E}-05$ & 1,71E-03 & Down in $\mathrm{KO}$ \\
\hline Jph1 & 3,635 & $-0,046$ & 3,54E-05 & 2,55E-03 & Up in KO \\
\hline Idh1 & 1,059 & 7,856 & $3,35 \mathrm{E}-05$ & $2,45 E-03$ & Up in KO \\
\hline Prodh & $-1,418$ & 3,734 & $3,96 \mathrm{E}-05$ & $2,70 \mathrm{E}-03$ & Down in $\mathrm{KO}$ \\
\hline Agmat & 3,508 & 0,029 & $2,03 E-05$ & $1,88 \mathrm{E}-03$ & Up in KO \\
\hline Ccp110 & 1,355 & 3,166 & $3,66 \mathrm{E}-05$ & $2,58 \mathrm{E}-03$ & Up in KO \\
\hline Ticrr & 1,546 & 3,360 & $3,90 \mathrm{E}-05$ & $2,68 \mathrm{E}-03$ & Up in KO \\
\hline Fads3 & 1,503 & 5,044 & $3,87 E-05$ & $2,68 \mathrm{E}-03$ & Up in KO \\
\hline Cd3g & $-2,844$ & 1,892 & 6,94E-05 & $3,70 \mathrm{E}-03$ & Down in $\mathrm{KO}$ \\
\hline 2810417H13Rik & 2,600 & 5,507 & 0,00010218 & $4,72 \mathrm{E}-03$ & Up in KO \\
\hline Npnt & 3,520 & $-0,169$ & 2,06E-05 & $1,88 \mathrm{E}-03$ & Up in KO \\
\hline Slc25a48 & 2,335 & 0,426 & $3,88 \mathrm{E}-05$ & $2,68 \mathrm{E}-03$ & Up in KO \\
\hline LY6d & 2,171 & 3,992 & $6,53 \mathrm{E}-05$ & $3,59 E-03$ & Up in KO \\
\hline Krt27 & 4,641 & $-0,383$ & $4,89 \mathrm{E}-06$ & $8,73 E-04$ & Up in KO \\
\hline Cpe & 1,643 & 3,242 & $5,13 E-05$ & $3,08 \mathrm{E}-03$ & Up in KO \\
\hline Rasd1 & $-1,168$ & 5,337 & 2,99E-05 & $2,30 \mathrm{E}-03$ & Down in $\mathrm{KO}$ \\
\hline Zcchc3 & 3,046 & $-0,211$ & $6,08 \mathrm{E}-06$ & 1,01E-03 & Up in KO \\
\hline Diaph3 & 1,434 & 3,237 & 8,57E-05 & $4,25 E-03$ & Up in KO \\
\hline Bglap3 & 1,343 & 4,299 & 4,24E-05 & $2,74 \mathrm{E}-03$ & Up in KO \\
\hline
\end{tabular}




\begin{tabular}{|c|c|c|c|c|c|}
\hline Pla2g7 & 2,194 & 2,236 & $6,20 \mathrm{E}-05$ & $3,50 \mathrm{E}-03$ & Up in KO \\
\hline LOC101055907 & 1,655 & 0,825 & $5,98 \mathrm{E}-05$ & $3,50 \mathrm{E}-03$ & Up in KO \\
\hline Casp12 & $-3,578$ & 1,080 & 4,87E-05 & $3,00 \mathrm{E}-03$ & Down in KO \\
\hline Cadm1 & 2,090 & 1,064 & $3,65 \mathrm{E}-05$ & $2,58 \mathrm{E}-03$ & Up in KO \\
\hline Zwilch & 1,579 & 3,599 & 5,69E-05 & $3,37 E-03$ & Up in KO \\
\hline Ly6c1 & 3,318 & 1,884 & 0,00013489 & $5,48 \mathrm{E}-03$ & Up in KO \\
\hline Elavl2 & 7,881 & $-0,839$ & $1,05 \mathrm{E}-05$ & 1,39E-03 & Up in KO \\
\hline Scara5 & $-2,933$ & $-0,394$ & 1,93E-06 & 4,94E-04 & Down in KO \\
\hline$P d x 1$ & 3,696 & $-0,562$ & $6,15 E-06$ & $1,01 \mathrm{E}-03$ & Up in KO \\
\hline Brca2 & 1,716 & 2,663 & $9,04 \mathrm{E}-05$ & 4,34E-03 & Up in KO \\
\hline Fanca & 1,857 & 4,120 & $6,16 \mathrm{E}-05$ & $3,50 \mathrm{E}-03$ & Up in KO \\
\hline Ntn4 & $-1,651$ & 2,274 & $8,37 E-05$ & 4,18E-03 & Down in KO \\
\hline Rtn4r & $-1,290$ & 3,390 & 4,69E-05 & $2,95 \mathrm{E}-03$ & Down in KO \\
\hline Nr2e3 & $-2,997$ & $-0,038$ & 1,56E-05 & $1,71 \mathrm{E}-03$ & Down in KO \\
\hline Fndc5 & $-2,902$ & 2,180 & 0,00012079 & $5,09 E-03$ & Down in KO \\
\hline Tdrp & 2,477 & 1,771 & 0,00011869 & $5,08 \mathrm{E}-03$ & Up in KO \\
\hline Casc5 & 1,195 & 3,552 & $3,80 \mathrm{E}-05$ & $2,65 E-03$ & Up in KO \\
\hline Btbd19 & 1,387 & 3,467 & $5,06 \mathrm{E}-05$ & $3,08 \mathrm{E}-03$ & Up in KO \\
\hline Cmah & 1,701 & 6,998 & $6,70 \mathrm{E}-05$ & $3,61 E-03$ & Up in KO \\
\hline C77370 & 1,268 & 2,860 & 0,00010455 & 4,76E-03 & Up in KO \\
\hline Hoxd3 & $-2,936$ & 0,502 & 5,51E-05 & $3,28 \mathrm{E}-03$ & Down in KO \\
\hline Proc & 1,622 & 1,985 & 0,00010789 & 4,83E-03 & Up in KO \\
\hline Apbb1ip & $-1,638$ & 1,371 & 5,99E-05 & $3,50 \mathrm{E}-03$ & Down in KO \\
\hline Lgr5 & $-2,425$ & 1,218 & $8,62 \mathrm{E}-05$ & $4,26 \mathrm{E}-03$ & Down in KO \\
\hline $\mathrm{Cd} 3 \mathrm{e}$ & $-2,907$ & 1,303 & $9,75 \mathrm{E}-05$ & 4,56E-03 & Down in KO \\
\hline Cdkn2a & 5,251 & $-0,312$ & $1,34 \mathrm{E}-05$ & $1,60 \mathrm{E}-03$ & Up in KO \\
\hline Nebl & 2,117 & 1,396 & 0,00019362 & $6,55 \mathrm{E}-03$ & Up in $\mathrm{KO}$ \\
\hline Trim29 & 1,799 & 2,910 & $6,72 \mathrm{E}-05$ & $3,61 E-03$ & Up in KO \\
\hline Gm38563 & 1,741 & 1,357 & $5,02 \mathrm{E}-05$ & $3,07 E-03$ & Up in KO \\
\hline Card11 & $-2,200$ & 1,481 & $7,51 \mathrm{E}-05$ & $3,91 \mathrm{E}-03$ & Down in KO \\
\hline Limch1 & $-3,790$ & $-0,399$ & 4,18E-05 & $2,74 \mathrm{E}-03$ & Down in KO \\
\hline Hpgds & $-1,326$ & 1,626 & 0,00015104 & $5,78 \mathrm{E}-03$ & Down in $\mathrm{KO}$ \\
\hline Krt23 & $-1,958$ & 2,665 & $8,71 \mathrm{E}-05$ & $4,27 E-03$ & Down in KO \\
\hline Tlcd2 & 1,312 & 4,310 & 4,81E-05 & 2,99E-03 & Up in KO \\
\hline Psat1 & 2,060 & 3,425 & 0,00011085 & $4,90 \mathrm{E}-03$ & Up in KO \\
\hline Wnk2 & $-1,234$ & 3,656 & 4,09E-05 & $2,74 \mathrm{E}-03$ & Down in KO \\
\hline Tiam1 & 1,692 & 3,820 & 1,37E-05 & 1,61E-03 & Up in KO \\
\hline H2-T3 & $-1,836$ & 2,683 & $7,06 \mathrm{E}-05$ & $3,75 E-03$ & Down in KO \\
\hline Ppp4r4 & 2,211 & 0,878 & $3,95 \mathrm{E}-05$ & $2,70 \mathrm{E}-03$ & Up in KO \\
\hline Pde1c & $-2,698$ & 0,104 & 0,0003991 & $9,64 \mathrm{E}-03$ & Down in KO \\
\hline Gm33198 & 3,080 & 3,415 & 0,00022703 & 7,07E-03 & Up in KO \\
\hline Gm30069 & 3,343 & 1,198 & 0,00017353 & $6,27 \mathrm{E}-03$ & Up in KO \\
\hline $\mathrm{Cd} 74$ & $-5,375$ & 7,263 & 0,00015249 & $5,82 \mathrm{E}-03$ & Down in KO \\
\hline Dclk3 & $-2,542$ & 1,715 & 0,00013131 & $5,40 \mathrm{E}-03$ & Down in KO \\
\hline Gm28207 & 6,370 & $-0,121$ & 3,61E-06 & $7,00 \mathrm{E}-04$ & Up in KO \\
\hline Amigo2 & $-3,506$ & $-0,060$ & $2,20 \mathrm{E}-05$ & 1,93E-03 & Down in $\mathrm{KO}$ \\
\hline Cpne5 & 1,945 & 0,393 & $3,27 \mathrm{E}-05$ & $2,42 \mathrm{E}-03$ & Up in KO \\
\hline Vav2 & $-1,856$ & 4,232 & $9,34 \mathrm{E}-05$ & $4,42 E-03$ & Down in KO \\
\hline Pcdhga7 & $-3,265$ & $-0,291$ & $9,73 E-05$ & $4,56 \mathrm{E}-03$ & Down in KO \\
\hline Fmnl3 & 1,476 & 2,154 & $8,12 \mathrm{E}-05$ & 4,12E-03 & Up in KO \\
\hline Plcb2 & $-1,922$ & 0,622 & $6,57 \mathrm{E}-05$ & $3,60 \mathrm{E}-03$ & Down in KO \\
\hline Gm39143 & 2,960 & 2,502 & 0,00023242 & $7,16 \mathrm{E}-03$ & Up in KO \\
\hline
\end{tabular}




\begin{tabular}{|c|c|c|c|c|c|}
\hline Prkcdbp & 1,382 & 1,679 & 0,00013813 & 5,54E-03 & Up in KO \\
\hline Ccne1 & 2,112 & 3,704 & 0,0001451 & $5,65 E-03$ & Up in KO \\
\hline 6030426L16Rik & 1,314 & 2,195 & 1,59E-05 & 1,71E-03 & Up in KO \\
\hline Rdh9 & 1,641 & 5,140 & $9,35 \mathrm{E}-05$ & 4,42E-03 & Up in KO \\
\hline Slc6a20a & $-2,264$ & 0,094 & $2,52 \mathrm{E}-05$ & $2,04 \mathrm{E}-03$ & Down in KO \\
\hline Npc1l1 & 1,954 & 2,434 & 0,00012135 & $5,09 E-03$ & Up in KO \\
\hline Ranbp17 & 1,832 & 2,053 & 0,00019673 & $6,55 \mathrm{E}-03$ & Up in KO \\
\hline Nav1 & $-2,366$ & 1,212 & 7,35E-05 & $3,85 E-03$ & Down in KO \\
\hline Ly6d & 6,468 & 4,217 & $2,28 \mathrm{E}-05$ & 1,95E-03 & Up in KO \\
\hline Scgb2b20 & 5,120 & $-0,432$ & 4,57E-06 & $8,34 \mathrm{E}-04$ & Up in KO \\
\hline Gimap4 & $-3,060$ & 2,783 & 0,00025267 & $7,43 E-03$ & Down in KO \\
\hline Mybl2 & 1,786 & 3,949 & 0,0001377 & 5,54E-03 & Up in KO \\
\hline Map9 & 1,099 & 3,523 & $8,65 \mathrm{E}-05$ & $4,26 \mathrm{E}-03$ & Up in KO \\
\hline Dyrk3 & 2,091 & 1,243 & 0,00019827 & $6,56 \mathrm{E}-03$ & Up in KO \\
\hline Hdac11 & $-1,021$ & 4,915 & 7,47E-05 & $3,90 \mathrm{E}-03$ & Down in KO \\
\hline Dnah2 & 1,077 & 1,551 & 0,00011531 & $5,00 \mathrm{E}-03$ & Up in KO \\
\hline Cyp2d9 & 1,921 & 6,037 & 0,00014406 & $5,64 \mathrm{E}-03$ & Up in KO \\
\hline Mylip & $-1,019$ & 3,791 & 7,83E-05 & 4,04E-03 & Down in KO \\
\hline Gdf15 & 1,672 & 6,425 & $9,68 \mathrm{E}-05$ & 4,55E-03 & Up in KO \\
\hline Gm33617 & $-2,436$ & 0,193 & 4,47E-05 & 2,83E-03 & Down in $\mathrm{KO}$ \\
\hline sept-06 & $-1,225$ & 1,870 & $6,69 E-05$ & $3,61 \mathrm{E}-03$ & Down in KO \\
\hline Sh2d6 & $-1,323$ & 2,593 & 0,00014154 & $5,62 \mathrm{E}-03$ & Down in $\mathrm{KO}$ \\
\hline Tfpi & $-3,037$ & $-0,187$ & 2,10E-05 & $1,88 \mathrm{E}-03$ & Down in KO \\
\hline Gm41143 & 3,238 & 1,866 & 0,00026603 & 7,73E-03 & Up in KO \\
\hline Rgs1 & $-2,629$ & 3,914 & 0,00024198 & $7,30 \mathrm{E}-03$ & Down in KO \\
\hline Slit2 & 1,348 & 2,092 & 0,00016011 & $6,04 \mathrm{E}-03$ & Up in KO \\
\hline S100a11 & 1,392 & 7,024 & 0,00021938 & $6,96 \mathrm{E}-03$ & Up in KO \\
\hline Crlf2 & 1,336 & 2,436 & 8,24E-05 & 4,13E-03 & Up in KO \\
\hline Ldhb & 1,120 & 3,598 & 0,00012091 & 5,09E-03 & Up in KO \\
\hline Top2a & 1,653 & 6,880 & 0,00014695 & $5,68 \mathrm{E}-03$ & Up in KO \\
\hline Ldlrad4 & $-1,923$ & 1,729 & 0,00031166 & $8,42 \mathrm{E}-03$ & Down in $\mathrm{KO}$ \\
\hline Fancd2 & 1,855 & 2,999 & 0,00016887 & $6,15 E-03$ & Up in KO \\
\hline LOC102638993 & 1,039 & 2,997 & 0,00010004 & $4,65 E-03$ & Up in KO \\
\hline Ephx1 & 1,595 & 4,553 & 0,00014415 & $5,64 \mathrm{E}-03$ & Up in KO \\
\hline Apol7e & $-2,697$ & 2,075 & 0,00023785 & $7,26 \mathrm{E}-03$ & Down in KO \\
\hline Epdr1 & 2,906 & 1,817 & 0,00022256 & $6,99 \mathrm{E}-03$ & Up in KO \\
\hline Pls3 & 1,028 & 4,263 & 8,99E-05 & 4,34E-03 & Up in KO \\
\hline Ercc6l & 2,018 & 3,258 & 0,00019667 & $6,55 E-03$ & Up in KO \\
\hline Gzma & $-3,321$ & 3,071 & 0,00044965 & $1,04 \mathrm{E}-02$ & Down in KO \\
\hline Adgrg5 & $-3,405$ & 1,450 & 0,00028397 & 7,96E-03 & Down in $\mathrm{KO}$ \\
\hline Tbx21 & $-3,136$ & 0,759 & 0,00018317 & $6,41 \mathrm{E}-03$ & Down in $\mathrm{KO}$ \\
\hline Ndc1 & 1,263 & 4,189 & 0,00027088 & 7,84E-03 & Up in KO \\
\hline Hmcn2 & 4,107 & $-0,836$ & 2,08E-05 & $1,88 \mathrm{E}-03$ & Up in KO \\
\hline H2-DMa & $-2,005$ & 3,245 & 0,00132893 & $1,97 \mathrm{E}-02$ & Down in $\mathrm{KO}$ \\
\hline Rbp7 & 1,916 & 1,078 & 0,00024836 & $7,35 E-03$ & Up in KO \\
\hline Tulp3 & 1,585 & 1,490 & 0,00020566 & $6,63 \mathrm{E}-03$ & Up in KO \\
\hline Mogat2 & 1,440 & 3,726 & 0,00010571 & $4,80 \mathrm{E}-03$ & Up in KO \\
\hline Peg3 & $-2,243$ & $-0,053$ & 4,02E-05 & $2,71 E-03$ & Down in KO \\
\hline Hck & $-1,999$ & 0,854 & 0,00013494 & $5,48 \mathrm{E}-03$ & Down in $\mathrm{KO}$ \\
\hline ВC055324 & 1,474 & 2,613 & 0,00019426 & $6,55 \mathrm{E}-03$ & Up in KO \\
\hline LOC108168882 & 2,717 & 1,652 & 0,00024768 & 7,34E-03 & Up in KO \\
\hline Tcf23 & 1,228 & 2,819 & 1,55E-05 & 1,71E-03 & Up in KO \\
\hline
\end{tabular}




\begin{tabular}{|c|c|c|c|c|c|}
\hline Gm40902 & $-3,917$ & 0,146 & 0,00023808 & $7,26 \mathrm{E}-03$ & Down in KO \\
\hline Thbs1 & $-1,819$ & 9,472 & 0,00020567 & $6,63 \mathrm{E}-03$ & Down in KO \\
\hline Maats1 & 1,748 & 0,369 & 4,39E-05 & 2,79E-03 & Up in KO \\
\hline Rhobtb3 & $-1,480$ & 1,976 & 0,00020774 & $6,67 \mathrm{E}-03$ & Down in KO \\
\hline Gsta3 & 2,008 & 4,334 & 0,00023994 & 7,27E-03 & Up in KO \\
\hline 4931428L18Rik & 2,749 & $-0,268$ & 4,85E-05 & $3,00 \mathrm{E}-03$ & Up in KO \\
\hline Rad18 & 1,406 & 2,535 & 0,00021542 & $6,86 \mathrm{E}-03$ & Up in KO \\
\hline Pltp & 1,497 & 1,440 & 0,00017613 & $6,28 \mathrm{E}-03$ & Up in KO \\
\hline Resp18 & $-2,134$ & 0,748 & 0,00012934 & $5,35 E-03$ & Down in KO \\
\hline Tgtp2 & $-3,208$ & 1,836 & 0,00041424 & $9,81 \mathrm{E}-03$ & Down in $\mathrm{KO}$ \\
\hline Pclo & $-2,378$ & 0,273 & 0,00014989 & $5,77 E-03$ & Down in KO \\
\hline Krt79 & 3,984 & $-0,937$ & $1,72 \mathrm{E}-05$ & $1,80 \mathrm{E}-03$ & Up in KO \\
\hline Ttc21a & 2,186 & $-0,281$ & $1,89 \mathrm{E}-05$ & $1,85 \mathrm{E}-03$ & Up in KO \\
\hline Lipo3 & $-1,285$ & 3,322 & 0,00010436 & $4,76 E-03$ & Down in KO \\
\hline Grin3a & 2,292 & 4,457 & 0,00029925 & $8,18 \mathrm{E}-03$ & Up in KO \\
\hline Tagap & $-1,660$ & 0,905 & 0,00010277 & 4,72E-03 & Down in KO \\
\hline LY6E & 2,064 & 7,369 & 0,00029836 & 8,17E-03 & Up in KO \\
\hline Gm38946 & 2,782 & 3,268 & 0,00060339 & $1,24 \mathrm{E}-02$ & Up in KO \\
\hline Aspg & $-1,201$ & 5,882 & 0,00014036 & $5,60 \mathrm{E}-03$ & Down in KO \\
\hline Gm35630 & 2,735 & $-0,529$ & $2,28 \mathrm{E}-05$ & $1,95 \mathrm{E}-03$ & Up in KO \\
\hline Gm37416 & 1,592 & 2,943 & 0,00020159 & $6,60 \mathrm{E}-03$ & Up in $\mathrm{KO}$ \\
\hline Kif24 & 1,198 & 2,366 & 0,0002229 & 6,99E-03 & Up in KO \\
\hline Slc25a4 & 1,477 & 4,740 & 0,00019386 & $6,55 \mathrm{E}-03$ & Up in $\mathrm{KO}$ \\
\hline H2-DMb1 & $-5,015$ & 2,964 & 0,000194 & $6,55 \mathrm{E}-03$ & Down in KO \\
\hline Inpp5d & $-2,207$ & 1,519 & 0,00018372 & 6,41E-03 & Down in KO \\
\hline Adgrg2 & 1,504 & 0,944 & 0,00014264 & 5,63E-03 & Up in KO \\
\hline Arnt2 & 1,398 & 2,329 & 0,00018393 & $6,41 \mathrm{E}-03$ & Up in KO \\
\hline Adck3 & $-1,575$ & 4,274 & 0,00017734 & $6,28 \mathrm{E}-03$ & Down in KO \\
\hline Ugt8a & 1,893 & 3,466 & 0,00018512 & 6,43E-03 & Up in KO \\
\hline Sgol2a & 1,088 & 3,790 & $9,35 \mathrm{E}-05$ & $4,42 E-03$ & Up in KO \\
\hline Klrk1 & $-2,446$ & 0,750 & 0,00032127 & 8,58E-03 & Down in KO \\
\hline Sned1 & $-1,662$ & 4,529 & $6,32 \mathrm{E}-05$ & $3,52 \mathrm{E}-03$ & Down in KO \\
\hline Map2 & 1,860 & 2,199 & 0,00030738 & 8,33E-03 & Up in KO \\
\hline Slc7a15 & 2,596 & 1,938 & 0,00038362 & $9,43 \mathrm{E}-03$ & Up in $\mathrm{KO}$ \\
\hline Adcy4 & 3,051 & 0,524 & 0,00052691 & 1,13E-02 & Up in KO \\
\hline Dusp5 & $-1,313$ & 5,696 & 0,00011462 & $5,00 \mathrm{E}-03$ & Down in $\mathrm{KO}$ \\
\hline Fbxo48 & 2,148 & 0,024 & 4,11E-05 & $2,74 \mathrm{E}-03$ & Up in KO \\
\hline Gm41101 & 2,759 & 2,533 & 0,00046092 & $1,05 E-02$ & Up in KO \\
\hline Trip13 & 1,596 & 3,116 & 0,00024556 & 7,32E-03 & Up in $\mathrm{KO}$ \\
\hline Pbk & 2,182 & 4,688 & 0,0004331 & $1,02 \mathrm{E}-02$ & Up in KO \\
\hline KIrd1 & $-2,763$ & 1,300 & 0,0002314 & $7,15 E-03$ & Down in KO \\
\hline $\operatorname{Sh} 2 d 2 a$ & $-2,136$ & 1,914 & 0,00063308 & $1,28 \mathrm{E}-02$ & Down in KO \\
\hline Fam111a & 1,913 & 4,024 & 0,00028949 & 8,01E-03 & Up in KO \\
\hline Fignl1 & 1,882 & 3,125 & 0,00024609 & $7,32 \mathrm{E}-03$ & Up in $\mathrm{KO}$ \\
\hline Cav2 & 1,939 & 3,023 & 0,00027635 & $7,89 \mathrm{E}-03$ & Up in $\mathrm{KO}$ \\
\hline Foxm1 & 1,695 & 4,508 & 0,00024328 & 7,30E-03 & Up in KO \\
\hline Ccdc3 & 2,329 & 0,536 & 0,00020863 & $6,68 \mathrm{E}-03$ & Up in KO \\
\hline Rnf39 & $-1,170$ & 5,264 & 9,93E-05 & 4,62E-03 & Down in KO \\
\hline Сур3а44 & $-3,958$ & 0,185 & 0,00017986 & 6,31E-03 & Down in KO \\
\hline Cdsn & 2,464 & 0,830 & 0,00031814 & $8,51 \mathrm{E}-03$ & Up in KO \\
\hline H2-T10 & $-1,536$ & 2,482 & 0,00019496 & $6,55 \mathrm{E}-03$ & Down in KO \\
\hline Arhgap9 & 1,710 & 3,681 & 0,00064795 & $1,30 \mathrm{E}-02$ & Up in KO \\
\hline
\end{tabular}




\begin{tabular}{|c|c|c|c|c|c|}
\hline Slfn2 & $-2,086$ & 0,547 & 0,00010998 & $4,88 \mathrm{E}-03$ & Down in KO \\
\hline Pcdh17 & $-2,140$ & 2,945 & 0,00034049 & $8,92 \mathrm{E}-03$ & Down in KO \\
\hline Tacc1 & $-1,520$ & 1,616 & 0,0002421 & $7,30 \mathrm{E}-03$ & Down in KO \\
\hline Asf1b & 2,117 & 3,802 & 0,00039494 & 9,58E-03 & Up in KO \\
\hline Gzmb & $-3,041$ & 3,353 & 0,00067642 & 1,34E-02 & Down in KO \\
\hline Esco2 & 2,042 & 3,622 & 0,00036304 & $9,14 \mathrm{E}-03$ & Up in KO \\
\hline Dpyd & $-1,439$ & 5,176 & 0,00016689 & $6,14 \mathrm{E}-03$ & Down in KO \\
\hline Sprr2h & 3,776 & $-0,766$ & 0,00010206 & $4,72 \mathrm{E}-03$ & Up in KO \\
\hline C87977 & 6,108 & $-0,342$ & 5,11E-05 & $3,08 \mathrm{E}-03$ & Up in $\mathrm{KO}$ \\
\hline Ptprc & $-2,626$ & 3,892 & 0,00053854 & $1,14 \mathrm{E}-02$ & Down in KO \\
\hline Pdgfc & 1,329 & 3,633 & 0,00032511 & $8,65 \mathrm{E}-03$ & Up in KO \\
\hline Cd69 & $-2,418$ & 0,113 & 8,89E-05 & 4,32E-03 & Down in KO \\
\hline Eci3 & $-1,065$ & 3,129 & 0,00019018 & $6,55 \mathrm{E}-03$ & Down in KO \\
\hline Ces $2 b$ & $-1,377$ & 3,007 & 0,00018802 & $6,50 \mathrm{E}-03$ & Down in $\mathrm{KO}$ \\
\hline Fasl & $-3,375$ & 0,300 & 0,00029067 & 8,03E-03 & Down in KO \\
\hline Prrt1 & $-3,184$ & 0,341 & 0,00020425 & $6,62 \mathrm{E}-03$ & Down in KO \\
\hline Gpr171 & $-2,922$ & 0,727 & 0,0003137 & $8,46 \mathrm{E}-03$ & Down in KO \\
\hline Plekhh2 & 1,411 & 2,877 & 6,07E-05 & $3,50 \mathrm{E}-03$ & Up in KO \\
\hline $\mathrm{Cd} 7$ & $-2,629$ & 2,713 & 0,00050499 & $1,10 \mathrm{E}-02$ & Down in KO \\
\hline Mns1 & 1,490 & 1,896 & 0,00031673 & 8,48E-03 & Up in KO \\
\hline Bnip3 & 1,109 & 3,642 & 0,00020752 & 6,67E-03 & Up in KO \\
\hline E2f8 & 1,255 & 4,355 & 0,00014664 & $5,68 \mathrm{E}-03$ & Up in KO \\
\hline Gm40034 & 1,244 & 1,491 & 0,00028076 & $7,95 \mathrm{E}-03$ & Up in KO \\
\hline Limd2 & $-1,037$ & 1,155 & 0,00078046 & $1,46 \mathrm{E}-02$ & Down in KO \\
\hline Pde8b & $-1,058$ & 3,653 & 0,00017477 & $6,28 \mathrm{E}-03$ & Down in KO \\
\hline ANXA9 & 1,541 & 0,787 & 0,0001737 & $6,27 \mathrm{E}-03$ & Up in KO \\
\hline Nfam1 & 2,424 & 0,101 & 4,24E-05 & $2,74 \mathrm{E}-03$ & Up in KO \\
\hline Papln & 1,685 & 1,607 & 0,0003554 & 9,09E-03 & Up in KO \\
\hline Farp2 & $-1,056$ & 5,223 & 0,00013586 & 5,51E-03 & Down in KO \\
\hline Rad51 & 2,117 & 3,842 & 0,00046007 & $1,05 E-02$ & Up in KO \\
\hline Pgap1 & 1,068 & 5,520 & 0,0001594 & $6,03 \mathrm{E}-03$ & Up in KO \\
\hline Csrp2 & $-1,114$ & 6,726 & 0,00022475 & $7,03 \mathrm{E}-03$ & Down in KO \\
\hline Slain1 & $-1,175$ & 1,663 & 0,00030013 & 8,19E-03 & Down in $\mathrm{KO}$ \\
\hline Fzd3 & $-1,438$ & 2,213 & 0,00026632 & 7,73E-03 & Down in KO \\
\hline Dusp22 & 1,921 & 2,742 & 0,00023086 & $7,15 E-03$ & Up in KO \\
\hline P2ry10 & $-2,851$ & 2,505 & 0,00066367 & 1,32E-02 & Down in KO \\
\hline Snhg7os & 1,935 & 0,401 & 2,90E-05 & $2,25 \mathrm{E}-03$ & Up in KO \\
\hline Gm36595 & 3,501 & $-0,869$ & 0,00010266 & $4,72 E-03$ & Up in KO \\
\hline Snx32 & 1,943 & 0,443 & 0,00011226 & 4,94E-03 & Up in KO \\
\hline $\mathrm{E} 2 \mathrm{f} 2$ & 1,176 & 5,698 & 0,00017202 & $6,24 \mathrm{E}-03$ & Up in KO \\
\hline Ppp2r2c & $-2,878$ & $-0,234$ & 0,00012931 & $5,35 \mathrm{E}-03$ & Down in $\mathrm{KO}$ \\
\hline Grasp & $-1,404$ & 3,131 & 0,00027182 & 7,84E-03 & Down in KO \\
\hline Plat & 2,045 & 0,919 & 0,00025118 & $7,40 \mathrm{E}-03$ & Up in KO \\
\hline Arhgef17 & 1,791 & 0,334 & 0,00018817 & $6,50 \mathrm{E}-03$ & Up in KO \\
\hline Dmrta1 & 3,492 & $-0,772$ & 0,00011925 & $5,09 E-03$ & Up in KO \\
\hline Nrn1 & $-5,007$ & $-0,882$ & 2,62E-05 & $2,08 \mathrm{E}-03$ & Down in KO \\
\hline Fyb & $-1,868$ & 1,662 & 0,00022519 & $7,03 \mathrm{E}-03$ & Down in $\mathrm{KO}$ \\
\hline Clspn & 1,970 & 3,947 & 0,00047768 & $1,07 \mathrm{E}-02$ & Up in KO \\
\hline Gm29917 & $-2,197$ & $-0,286$ & $6,70 \mathrm{E}-05$ & 3,61E-03 & Down in KO \\
\hline Zap70 & $-2,516$ & 1,339 & 0,0004552 & $1,04 \mathrm{E}-02$ & Down in KO \\
\hline Bmp4 & 2,883 & $-0,363$ & 5,73E-05 & $3,38 \mathrm{E}-03$ & Up in KO \\
\hline KIf8 & 1,233 & 1,088 & 0,00013824 & $5,54 \mathrm{E}-03$ & Up in KO \\
\hline
\end{tabular}




\begin{tabular}{|c|c|c|c|c|c|}
\hline Lrmp & $-1,912$ & 1,983 & 0,0001612 & $6,04 \mathrm{E}-03$ & Down in KO \\
\hline Nespas & 5,341 & $-0,998$ & $2,41 \mathrm{E}-06$ & $5,64 \mathrm{E}-04$ & Up in KO \\
\hline Abcc4 & 1,377 & 3,468 & 0,0002865 & $8,00 \mathrm{E}-03$ & Up in KO \\
\hline Traf3ip3 & $-2,769$ & $-0,314$ & 0,00017139 & $6,23 E-03$ & Down in KO \\
\hline Gal3st2 & $-2,489$ & 1,149 & 0,00043189 & $1,02 E-02$ & Down in KO \\
\hline D630023F18Rik & 2,872 & $-0,382$ & 7,97E-05 & 4,08E-03 & Up in KO \\
\hline Proser2 & $-1,028$ & 3,768 & 0,00023064 & $7,15 E-03$ & Down in KO \\
\hline $\operatorname{lgsf23}$ & 1,804 & 4,634 & 0,00027807 & $7,90 \mathrm{E}-03$ & Up in KO \\
\hline Cenf & 1,989 & 3,831 & 0,00052194 & $1,13 E-02$ & Up in KO \\
\hline Ptpn22 & $-2,818$ & 2,307 & 0,00112434 & $1,78 \mathrm{E}-02$ & Down in KO \\
\hline Gent1 & 1,524 & 5,372 & 0,00031613 & $8,48 \mathrm{E}-03$ & Up in KO \\
\hline Chst12 & $-2,095$ & 0,436 & 0,00014991 & 5,77E-03 & Down in KO \\
\hline Blm & 1,408 & 2,664 & 0,00047863 & 1,07E-02 & Up in KO \\
\hline Bfsp1 & 1,767 & 3,648 & 0,00048192 & $1,07 E-02$ & Up in KO \\
\hline Treh & 2,110 & 1,682 & 0,00050212 & $1,10 \mathrm{E}-02$ & Up in KO \\
\hline Zfp385a & 1,692 & 0,477 & 0,00023478 & $7,20 \mathrm{E}-03$ & Up in KO \\
\hline Maml2 & $-2,458$ & $-0,528$ & 0,00013698 & $5,54 \mathrm{E}-03$ & Down in KO \\
\hline Xcl1 & $-1,745$ & 0,536 & 0,00013202 & $5,40 \mathrm{E}-03$ & Down in KO \\
\hline Map10 & $-1,710$ & 0,369 & 0,00016718 & $6,14 \mathrm{E}-03$ & Down in KO \\
\hline Rac2 & $-2,044$ & 2,487 & 0,00046107 & $1,05 E-02$ & Down in KO \\
\hline Sulf2 & 1,017 & 5,105 & 0,00017786 & $6,28 \mathrm{E}-03$ & Up in KO \\
\hline Nkg7 & $-2,637$ & 1,551 & 0,00058856 & $1,22 \mathrm{E}-02$ & Down in KO \\
\hline Hmgcll1 & 1,774 & 0,698 & 0,00040493 & $9,65 E-03$ & Up in KO \\
\hline 9130019022Rik & $-1,135$ & 2,454 & 0,00033361 & $8,79 E-03$ & Down in KO \\
\hline Ambp & 1,304 & 1,720 & 0,00034212 & 8,94E-03 & Up in KO \\
\hline $\mathrm{Cd} 247$ & $-2,114$ & 0,380 & 0,00035895 & $9,12 \mathrm{E}-03$ & Down in KO \\
\hline Ncapg2 & 1,715 & 4,266 & 0,00040333 & $9,65 \mathrm{E}-03$ & Up in KO \\
\hline Wdhd1 & 1,125 & 4,229 & 0,00035466 & $9,09 E-03$ & Up in KO \\
\hline Thop1 & 1,073 & 5,676 & 0,00028402 & $7,96 \mathrm{E}-03$ & Up in KO \\
\hline 2310069B03Rik & 2,466 & 0,931 & 0,0004787 & 1,07E-02 & Up in KO \\
\hline Gm28225 & 4,018 & $-0,644$ & 0,00028323 & $7,96 \mathrm{E}-03$ & Up in KO \\
\hline Pik3r5 & $-1,659$ & 1,069 & 0,00035203 & $9,05 E-03$ & Down in KO \\
\hline Gm8979 & $-1,286$ & 8,042 & 0,00036376 & $9,14 \mathrm{E}-03$ & Down in KO \\
\hline Itk & $-3,138$ & 2,047 & 0,00082063 & $1,50 \mathrm{E}-02$ & Down in KO \\
\hline Cd200r1 & $-2,995$ & 0,318 & 0,00045246 & $1,04 \mathrm{E}-02$ & Down in KO \\
\hline Slc6a19 & 1,928 & 2,035 & 0,00057332 & $1,20 \mathrm{E}-02$ & Up in KO \\
\hline Neurod1 & $-1,859$ & 0,237 & 0,00022083 & $6,99 \mathrm{E}-03$ & Down in KO \\
\hline Gm42151 & $-1,346$ & 1,224 & 0,00057838 & $1,21 E-02$ & Down in KO \\
\hline Gpr18 & $-3,511$ & $-0,610$ & 0,00017747 & $6,28 \mathrm{E}-03$ & Down in KO \\
\hline Sox 21 & $-1,331$ & 2,604 & 0,0004434 & $1,03 \mathrm{E}-02$ & Down in KO \\
\hline Tgtp1 & $-3,029$ & 1,778 & 0,00112874 & $1,78 \mathrm{E}-02$ & Down in $\mathrm{KO}$ \\
\hline Prss22 & 3,505 & 0,622 & 0,0007713 & $1,45 E-02$ & Up in KO \\
\hline Arntl2 & 1,492 & 1,046 & 0,00017837 & $6,28 \mathrm{E}-03$ & Up in KO \\
\hline Acap1 & $-2,403$ & 2,056 & 0,00076068 & $1,45 E-02$ & Down in KO \\
\hline Gm39847 & 2,100 & $-0,608$ & $2,38 \mathrm{E}-05$ & $1,98 \mathrm{E}-03$ & Up in KO \\
\hline Slamf7 & $-2,060$ & 0,175 & 0,00093021 & $1,60 \mathrm{E}-02$ & Down in $\mathrm{KO}$ \\
\hline Tbc1d10c & $-2,509$ & 1,386 & 0,00071363 & 1,39E-02 & Down in KO \\
\hline Hmgn3 & $-2,269$ & $-0,457$ & 0,00020112 & $6,60 \mathrm{E}-03$ & Down in KO \\
\hline Aadac & $-1,649$ & 2,704 & 0,00053154 & $1,13 \mathrm{E}-02$ & Down in KO \\
\hline Gimap6 & $-2,511$ & 1,859 & 0,00078408 & $1,46 \mathrm{E}-02$ & Down in KO \\
\hline Сур3а25 & $-2,621$ & $-0,050$ & 0,00025475 & $7,47 \mathrm{E}-03$ & Down in KO \\
\hline Cenpi & 1,682 & 2,555 & 0,00076224 & $1,45 E-02$ & Up in KO \\
\hline
\end{tabular}




\begin{tabular}{|c|c|c|c|c|c|}
\hline Grhl1 & 1,250 & 1,660 & 0,0006067 & $1,25 \mathrm{E}-02$ & Up in KO \\
\hline Mms22I & 1,115 & 3,339 & 0,00041004 & $9,74 \mathrm{E}-03$ & Up in KO \\
\hline Per2 & $-1,276$ & 5,172 & 0,00038849 & $9,48 \mathrm{E}-03$ & Down in KO \\
\hline Gm15286 & 2,523 & $-0,486$ & 0,00011703 & $5,05 E-03$ & Up in KO \\
\hline Gm20472 & 5,605 & $-1,410$ & 1,73E-05 & $1,80 \mathrm{E}-03$ & Up in KO \\
\hline ВC048559 & 1,940 & 0,541 & 0,00025976 & $7,58 \mathrm{E}-03$ & Up in KO \\
\hline Espl1 & 1,452 & 3,850 & 0,00048919 & $1,08 \mathrm{E}-02$ & Up in KO \\
\hline Dtx1 & $-3,095$ & 0,363 & 0,00060777 & $1,25 \mathrm{E}-02$ & Down in KO \\
\hline Rnd2 & 1,248 & 1,475 & 0,00037306 & $9,32 \mathrm{E}-03$ & Up in KO \\
\hline $\mathrm{Ccl} 4$ & $-3,316$ & 0,106 & 0,00044905 & $1,04 \mathrm{E}-02$ & Down in KO \\
\hline Sult1a1 & $-1,031$ & 7,910 & 0,00037979 & $9,40 \mathrm{E}-03$ & Down in $\mathrm{KO}$ \\
\hline Gngt2 & $-1,105$ & 1,092 & 0,00055175 & $1,16 \mathrm{E}-02$ & Down in KO \\
\hline Itgae & $-2,328$ & 2,830 & 0,00093394 & $1,60 \mathrm{E}-02$ & Down in KO \\
\hline Gm29758 & 1,183 & 1,973 & 0,0005185 & $1,12 \mathrm{E}-02$ & Up in KO \\
\hline Sectm1a & 1,061 & 4,133 & 0,00027454 & $7,86 \mathrm{E}-03$ & Up in KO \\
\hline Selplg & $-2,302$ & 2,105 & 0,00138746 & $2,02 \mathrm{E}-02$ & Down in KO \\
\hline Smoc2 & $-2,640$ & 2,430 & 0,00111427 & $1,77 \mathrm{E}-02$ & Down in KO \\
\hline It $\ln 1$ & 2,485 & 0,673 & 0,0005452 & $1,15 \mathrm{E}-02$ & Up in KO \\
\hline Des & 2,015 & $-0,057$ & 0,00027983 & $7,94 \mathrm{E}-03$ & Up in KO \\
\hline Fbp1 & $-2,067$ & $-0,070$ & 0,00014287 & $5,63 \mathrm{E}-03$ & Down in KO \\
\hline Arap3 & $-2,820$ & 0,820 & 0,0007171 & $1,40 E-02$ & Down in $\mathrm{KO}$ \\
\hline Trim35 & 1,312 & 3,954 & 0,00053061 & $1,13 E-02$ & Up in KO \\
\hline 1500009L16Rik & 1,060 & 3,257 & 0,00034305 & $8,94 \mathrm{E}-03$ & Up in KO \\
\hline Nav3 & 5,365 & $-1,602$ & $1,29 \mathrm{E}-05$ & $1,58 \mathrm{E}-03$ & Up in KO \\
\hline Gm36840 & 3,442 & $-1,205$ & 2,53E-05 & $2,04 \mathrm{E}-03$ & Up in KO \\
\hline Hvcn1 & $-2,143$ & 0,720 & 0,00050702 & $1,11 \mathrm{E}-02$ & Down in KO \\
\hline Arhgdig & 1,791 & 0,527 & 0,00064826 & $1,30 \mathrm{E}-02$ & Up in KO \\
\hline Peg13 & $-1,119$ & 3,521 & 0,00035581 & $9,09 E-03$ & Down in KO \\
\hline Hoxd8 & $-3,021$ & $-0,143$ & 0,00082302 & $1,50 \mathrm{E}-02$ & Down in KO \\
\hline $\mathrm{Cd} 160$ & $-1,748$ & 0,699 & 0,0002616 & $7,62 \mathrm{E}-03$ & Down in KO \\
\hline Gm41090 & 2,834 & 0,877 & 0,00089282 & $1,57 \mathrm{E}-02$ & Up in KO \\
\hline Rasal3 & $-2,235$ & 1,497 & 0,00098349 & $1,65 \mathrm{E}-02$ & Down in KO \\
\hline Ctsw & $-2,515$ & 2,357 & 0,00092757 & $1,60 \mathrm{E}-02$ & Down in KO \\
\hline LOC108168395 & $-1,094$ & 4,166 & 0,00034444 & $8,95 \mathrm{E}-03$ & Down in KO \\
\hline Mdm1 & 1,052 & 2,478 & 0,00058116 & $1,21 \mathrm{E}-02$ & Up in KO \\
\hline Akna & $-1,175$ & 3,116 & 0,00043418 & $1,02 \mathrm{E}-02$ & Down in KO \\
\hline $\mathrm{H} 2-\mathrm{Ab} 1$ & $-3,759$ & 5,223 & 0,00052409 & $1,13 \mathrm{E}-02$ & Down in KO \\
\hline Lgsn & 3,242 & $-0,598$ & 0,00047325 & $1,06 \mathrm{E}-02$ & Up in KO \\
\hline Rasal1 & 2,114 & 0,058 & 0,0001967 & $6,55 \mathrm{E}-03$ & Up in KO \\
\hline LOC108168067 & 1,462 & 6,302 & 0,00064785 & $1,30 \mathrm{E}-02$ & Up in KO \\
\hline Zfp37 & 1,122 & 4,152 & 0,00037627 & $9,35 \mathrm{E}-03$ & Up in KO \\
\hline Cd96 & $-2,739$ & 0,740 & 0,00082467 & $1,50 \mathrm{E}-02$ & Down in $\mathrm{KO}$ \\
\hline Gbp9 & $-2,333$ & 1,306 & 0,00101083 & $1,68 \mathrm{E}-02$ & Down in KO \\
\hline Egr3 & $-1,500$ & 1,133 & 0,00047748 & $1,07 E-02$ & Down in KO \\
\hline Slc37a2 & $-3,493$ & 4,708 & 0,00046958 & $1,06 \mathrm{E}-02$ & Down in $\mathrm{KO}$ \\
\hline 2410018L13Rik & 3,815 & $-1,284$ & $4,21 \mathrm{E}-05$ & $2,74 \mathrm{E}-03$ & Up in KO \\
\hline Abcg1 & $-1,162$ & 1,469 & 0,00052335 & $1,13 E-02$ & Down in KO \\
\hline Zgrf1 & 1,572 & 2,354 & 0,0001935 & $6,55 \mathrm{E}-03$ & Up in KO \\
\hline Ptprn & $-1,547$ & 1,066 & 0,00049473 & $1,09 E-02$ & Down in KO \\
\hline Rad54I & 1,726 & 3,228 & 0,0016963 & $2,29 E-02$ & Up in KO \\
\hline Bard1 & 1,657 & 2,419 & 0,00086894 & $1,54 \mathrm{E}-02$ & Up in KO \\
\hline Al504432 & $-2,648$ & $-0,173$ & 0,00033191 & $8,78 \mathrm{E}-03$ & Down in KO \\
\hline
\end{tabular}




\begin{tabular}{|c|c|c|c|c|c|}
\hline Gm32298 & 1,100 & 3,134 & 0,00039133 & $9,52 \mathrm{E}-03$ & Up in KO \\
\hline $\mathrm{H} 2-\mathrm{BI}$ & $-1,455$ & 4,772 & 0,00053458 & $1,14 \mathrm{E}-02$ & Down in KO \\
\hline Mvb12b & $-1,249$ & 2,033 & 0,00121508 & $1,87 \mathrm{E}-02$ & Down in KO \\
\hline Rbms3 & $-1,394$ & 1,834 & 0,00079133 & $1,47 \mathrm{E}-02$ & Down in $\mathrm{KO}$ \\
\hline Fabp5 & 1,894 & 3,386 & 0,0010978 & $1,75 E-02$ & Up in KO \\
\hline Spn & $-2,558$ & 1,499 & 0,00099167 & $1,66 \mathrm{E}-02$ & Down in KO \\
\hline Phf1 & $-1,101$ & 5,380 & 0,00037431 & $9,32 \mathrm{E}-03$ & Down in KO \\
\hline Slc5a4b & 1,493 & 0,262 & 0,0002045 & $6,62 \mathrm{E}-03$ & Up in KO \\
\hline Gen1 & 1,214 & 2,549 & 0,000177 & $6,28 \mathrm{E}-03$ & Up in KO \\
\hline Sema3d & 2,604 & $-0,627$ & 0,00013998 & $5,60 \mathrm{E}-03$ & Up in $\mathrm{KO}$ \\
\hline Gm13056 & 1,438 & 1,321 & 0,00048886 & $1,08 \mathrm{E}-02$ & Up in KO \\
\hline Adgrb1 & 2,340 & 1,579 & 0,00123554 & $1,89 \mathrm{E}-02$ & Up in KO \\
\hline Gbp4 & $-3,316$ & 1,583 & 0,00037173 & 9,31E-03 & Down in KO \\
\hline Ereg & 1,821 & 6,352 & 0,00091078 & $1,58 \mathrm{E}-02$ & Up in KO \\
\hline Ackr3 & $-2,496$ & 0,004 & 0,00038059 & $9,40 \mathrm{E}-03$ & Down in KO \\
\hline Sez612 & $-1,538$ & 0,264 & 0,0002006 & $6,60 \mathrm{E}-03$ & Down in KO \\
\hline Ptgr1 & 1,652 & 4,884 & 0,00082604 & $1,50 \mathrm{E}-02$ & Up in KO \\
\hline Sh3rf2 & $-1,357$ & 3,791 & 0,00027287 & $7,84 \mathrm{E}-03$ & Down in KO \\
\hline Slc4a11 & 1,966 & 0,161 & 0,00140527 & $2,04 \mathrm{E}-02$ & Up in KO \\
\hline Dact1 & 2,181 & 0,050 & 0,00035332 & $9,07 E-03$ & Up in KO \\
\hline Gpr34 & $-3,065$ & 0,549 & 0,00103438 & $1,70 \mathrm{E}-02$ & Down in KO \\
\hline C630043F03Rik & 1,053 & 1,441 & 0,00066492 & $1,32 \mathrm{E}-02$ & Up in KO \\
\hline Gpr132 & $-2,437$ & 1,582 & 0,00110239 & $1,76 \mathrm{E}-02$ & Down in KO \\
\hline Hist1h3d & 2,111 & 0,622 & 0,00059078 & $1,22 \mathrm{E}-02$ & Up in KO \\
\hline Lax1 & $-2,635$ & $-0,444$ & 0,00018747 & $6,50 \mathrm{E}-03$ & Down in KO \\
\hline Cdk14 & $-2,654$ & $-1,063$ & $2,31 \mathrm{E}-05$ & $1,96 \mathrm{E}-03$ & Down in KO \\
\hline Magi2 & 2,349 & $-0,583$ & 0,00016477 & $6,12 \mathrm{E}-03$ & Up in KO \\
\hline Gimap3 & $-2,318$ & 2,776 & 0,0012921 & $1,94 \mathrm{E}-02$ & Down in KO \\
\hline Ltbp3 & 1,433 & 0,174 & 0,00028873 & $8,01 E-03$ & Up in KO \\
\hline Eva1c & $-1,933$ & 0,372 & 0,0001224 & $5,09 E-03$ & Down in KO \\
\hline Edn1 & $-1,341$ & 7,181 & 0,00071481 & $1,39 \mathrm{E}-02$ & Down in KO \\
\hline Alox5 & $-2,095$ & $-0,470$ & 0,00015866 & $6,01 E-03$ & Down in KO \\
\hline$\| 21 r$ & $-2,745$ & 2,231 & 0,00248991 & $2,91 \mathrm{E}-02$ & Down in KO \\
\hline H2-Eb1 & $-3,879$ & 4,479 & 0,00075311 & $1,44 \mathrm{E}-02$ & Down in KO \\
\hline Anln & 1,200 & 4,368 & 0,00014664 & $5,68 \mathrm{E}-03$ & Up in KO \\
\hline Prrx1 & 2,981 & $-1,300$ & 1,87E-05 & $1,85 \mathrm{E}-03$ & Up in KO \\
\hline Per1 & $-1,320$ & 6,234 & 0,00063234 & $1,28 \mathrm{E}-02$ & Down in KO \\
\hline Trib3 & 1,652 & $-0,348$ & 4,12E-05 & $2,74 \mathrm{E}-03$ & Up in KO \\
\hline Gusb & 1,121 & 5,225 & 0,00034909 & $9,00 E-03$ & Up in KO \\
\hline Dsn1 & 1,579 & 2,965 & 0,00098108 & $1,65 \mathrm{E}-02$ & Up in KO \\
\hline Tle6 & 1,496 & 2,492 & 0,00082007 & $1,50 \mathrm{E}-02$ & Up in $K O$ \\
\hline Hacd4 & 1,449 & 1,198 & 0,00403165 & $3,88 \mathrm{E}-02$ & Up in $\mathrm{KO}$ \\
\hline Mcm10 & 1,012 & 4,344 & 0,00041552 & $9,82 \mathrm{E}-03$ & Up in KO \\
\hline 1133 & 2,056 & 1,332 & 0,00087297 & $1,54 \mathrm{E}-02$ & Up in KO \\
\hline Cdkl1 & $-2,963$ & $-0,183$ & 0,00036063 & $9,12 \mathrm{E}-03$ & Down in KO \\
\hline Cxxc4 & 1,235 & 0,706 & 0,00093031 & $1,60 \mathrm{E}-02$ & Up in KO \\
\hline Kifc5b & 1,154 & 2,615 & 0,0009351 & $1,60 \mathrm{E}-02$ & Up in KO \\
\hline Krtap13 & 3,408 & $-0,928$ & 0,00033313 & 8,79E-03 & Up in KO \\
\hline Gm34572 & 2,323 & 0,273 & 0,00084386 & $1,51 \mathrm{E}-02$ & Up in KO \\
\hline Sla2 & $-1,960$ & 0,684 & 0,00073164 & $1,41 E-02$ & Down in KO \\
\hline$\| 2 \mathrm{rg}$ & $-2,248$ & 1,315 & 0,00111736 & $1,77 \mathrm{E}-02$ & Down in KO \\
\hline A930004D18Rik & 3,053 & $-1,025$ & 0,00024058 & $7,28 \mathrm{E}-03$ & Up in KO \\
\hline
\end{tabular}




\begin{tabular}{|c|c|c|c|c|c|}
\hline LOC108167858 & 1,990 & 1,974 & 0,00165975 & $2,26 \mathrm{E}-02$ & Up in KO \\
\hline Kif15 & 1,333 & 4,258 & 0,0004485 & $1,04 \mathrm{E}-02$ & Up in KO \\
\hline Ms4a4b & $-3,025$ & $-0,368$ & 0,00063765 & $1,29 E-02$ & Down in $\mathrm{KO}$ \\
\hline Rtp3 & 4,166 & $-1,498$ & $2,36 \mathrm{E}-05$ & 1,97E-03 & Up in KO \\
\hline Nuf2 & 1,784 & 3,525 & 0,00120281 & $1,85 \mathrm{E}-02$ & Up in KO \\
\hline Sp140 & $-1,533$ & 1,058 & 0,00077628 & $1,46 \mathrm{E}-02$ & Down in KO \\
\hline Gm30311 & 1,885 & 3,748 & 0,00016428 & $6,12 \mathrm{E}-03$ & Up in KO \\
\hline Dock2 & $-2,454$ & 1,305 & 0,00105386 & $1,72 \mathrm{E}-02$ & Down in $\mathrm{KO}$ \\
\hline Nr4a3 & $-1,783$ & 2,244 & 7,62E-05 & $3,94 \mathrm{E}-03$ & Down in KO \\
\hline Pde4b & $-1,743$ & 1,930 & 0,00104633 & $1,72 \mathrm{E}-02$ & Down in $\mathrm{KO}$ \\
\hline Gm38978 & $-1,811$ & $-0,257$ & 0,00012251 & $5,09 \mathrm{E}-03$ & Down in $\mathrm{KO}$ \\
\hline Aqp3 & 4,015 & $-1,391$ & 4,09E-05 & $2,74 \mathrm{E}-03$ & Up in KO \\
\hline Gtse1 & 1,713 & 3,639 & 0,0012719 & $1,92 \mathrm{E}-02$ & Up in $\mathrm{KO}$ \\
\hline Gm30438 & 1,239 & 0,860 & 0,00040543 & $9,65 \mathrm{E}-03$ & Up in KO \\
\hline Corola & $-1,960$ & 2,502 & 0,00115885 & 1,81E-02 & Down in KO \\
\hline Rrm1 & 1,599 & 5,706 & 0,00113276 & $1,78 \mathrm{E}-02$ & Up in KO \\
\hline $\mathrm{H} 2-\mathrm{Aa}$ & $-4,311$ & 4,937 & 0,00102971 & $1,70 \mathrm{E}-02$ & Down in $\mathrm{KO}$ \\
\hline Gm8995 & $-1,397$ & 4,066 & 0,00077434 & $1,46 \mathrm{E}-02$ & Down in $\mathrm{KO}$ \\
\hline Rab37 & $-1,160$ & 2,253 & 0,00075906 & $1,44 \mathrm{E}-02$ & Down in $\mathrm{KO}$ \\
\hline Gsdma & $-1,669$ & $-0,033$ & 0,00023988 & 7,27E-03 & Down in $\mathrm{KO}$ \\
\hline Dcbld2 & 1,581 & 2,845 & 0,00119513 & $1,84 \mathrm{E}-02$ & Up in KO \\
\hline Thy1 & $-2,317$ & 1,130 & 0,00113314 & $1,78 \mathrm{E}-02$ & Down in $\mathrm{KO}$ \\
\hline Serpinb9 & $-1,393$ & 2,058 & 0,00057888 & $1,21 \mathrm{E}-02$ & Down in KO \\
\hline Cers3 & 1,936 & $-0,005$ & 0,00036055 & $9,12 \mathrm{E}-03$ & Up in KO \\
\hline Glipr2 & $-1,111$ & 2,099 & 0,00068699 & $1,35 E-02$ & Down in $\mathrm{KO}$ \\
\hline sept-01 & $-1,964$ & 1,576 & 0,00058776 & $1,22 \mathrm{E}-02$ & Down in $\mathrm{KO}$ \\
\hline Rcsd1 & $-2,269$ & 0,889 & 0,00140079 & $2,04 \mathrm{E}-02$ & Down in KO \\
\hline Enpep & 2,226 & 5,967 & 0,00171897 & 2,31E-02 & Up in KO \\
\hline Fut9 & $-4,068$ & $-0,250$ & 0,00161494 & $2,22 \mathrm{E}-02$ & Down in KO \\
\hline Notch3 & 2,253 & $-0,241$ & 0,00067424 & $1,34 \mathrm{E}-02$ & Up in KO \\
\hline Kif11 & 1,242 & 5,034 & 0,00084398 & 1,51E-02 & Up in KO \\
\hline Fli1 & $-2,238$ & $-0,038$ & 0,00061764 & $1,26 \mathrm{E}-02$ & Down in KO \\
\hline $\mathrm{Cd} 84$ & 1,221 & 4,837 & 0,00072809 & $1,41 E-02$ & Up in KO \\
\hline Ptprt & $-1,458$ & 1,125 & 0,00077201 & $1,45 \mathrm{E}-02$ & Down in $\mathrm{KO}$ \\
\hline Nup133 & 1,021 & 4,292 & 0,00071904 & $1,40 E-02$ & Up in KO \\
\hline Gm9292 & 2,713 & $-1,023$ & $9,40 \mathrm{E}-05$ & 4,43E-03 & Up in KO \\
\hline Laptm5 & $-2,201$ & 3,188 & 0,0016517 & $2,25 \mathrm{E}-02$ & Down in $\mathrm{KO}$ \\
\hline E130012A19Rik & 1,338 & 4,843 & 0,00080254 & $1,48 \mathrm{E}-02$ & Up in KO \\
\hline Mndal & $-2,065$ & 1,039 & 0,00230631 & $2,77 E-02$ & Down in KO \\
\hline Dna2 & 1,458 & 2,924 & 0,00113832 & $1,79 E-02$ & Up in KO \\
\hline A330049N07Rik & 1,040 & 0,893 & 0,00060597 & $1,25 \mathrm{E}-02$ & Up in KO \\
\hline BC021614 & 1,762 & 2,194 & 0,00108652 & $1,75 E-02$ & Up in KO \\
\hline Gm40405 & 2,563 & 1,279 & 0,0024652 & $2,88 \mathrm{E}-02$ & Up in KO \\
\hline Klhl13 & $-2,293$ & 0,083 & 0,00080823 & $1,48 \mathrm{E}-02$ & Down in $\mathrm{KO}$ \\
\hline Rdh1 & 1,113 & 3,620 & 0,00030731 & 8,33E-03 & Up in KO \\
\hline Chaf1a & 1,471 & 4,197 & 0,00113062 & $1,78 \mathrm{E}-02$ & Up in KO \\
\hline Ccne2 & 1,289 & 2,730 & 0,00096213 & $1,63 \mathrm{E}-02$ & Up in KO \\
\hline Stat4 & $-2,912$ & 0,300 & 0,00127892 & 1,93E-02 & Down in KO \\
\hline Pde7b & 1,503 & 0,325 & 0,00071279 & 1,39E-02 & Up in KO \\
\hline Nptx2 & 1,846 & 0,710 & 0,00097239 & $1,64 \mathrm{E}-02$ & Up in KO \\
\hline ВC025446 & 1,026 & 4,401 & 0,00071202 & 1,39E-02 & Up in KO \\
\hline Mst1 & 2,143 & $-0,437$ & 0,00028165 & $7,95 \mathrm{E}-03$ & Up in KO \\
\hline
\end{tabular}




\begin{tabular}{|c|c|c|c|c|c|}
\hline Srgn & $-1,852$ & 1,679 & 0,00138214 & $2,02 \mathrm{E}-02$ & Down in $\mathrm{KO}$ \\
\hline$\| 2 \mathrm{rb}$ & $-2,344$ & 3,237 & 0,0027074 & $3,06 \mathrm{E}-02$ & Down in KO \\
\hline Ncapg & 1,315 & 4,390 & 0,00127388 & $1,92 \mathrm{E}-02$ & Up in KO \\
\hline Acot12 & 1,828 & $-0,234$ & 0,0001218 & 5,09E-03 & Up in KO \\
\hline Ass1 & 1,618 & 4,271 & 0,00141611 & $2,05 E-02$ & Up in $\mathrm{KO}$ \\
\hline Sema3f & 1,105 & 3,070 & 0,00074942 & $1,43 E-02$ & Up in $\mathrm{KO}$ \\
\hline Arhgap25 & $-2,605$ & 0,313 & 0,00091417 & $1,58 \mathrm{E}-02$ & Down in KO \\
\hline Slc26a7 & 4,538 & $-1,657$ & 1,34E-05 & $1,60 \mathrm{E}-03$ & Up in KO \\
\hline SIc16a2 & $-1,777$ & 0,470 & 0,00091949 & $1,59 \mathrm{E}-02$ & Down in $\mathrm{KO}$ \\
\hline Rnf122 & $-1,138$ & 1,199 & 0,00076332 & $1,45 \mathrm{E}-02$ & Down in $\mathrm{KO}$ \\
\hline Gm12216 & $-1,542$ & 0,492 & 0,00049248 & $1,08 \mathrm{E}-02$ & Down in $\mathrm{KO}$ \\
\hline Gm15441 & 1,005 & 1,267 & 0,00083742 & 1,51E-02 & Up in KO \\
\hline Ppp3r2 & 2,372 & $-0,139$ & 0,00077883 & $1,46 E-02$ & Up in KO \\
\hline RASSF5-8 & 1,483 & 0,169 & 0,00267778 & $3,04 \mathrm{E}-02$ & Up in KO \\
\hline Evi2b & $-2,560$ & 0,161 & 0,00093816 & 1,61E-02 & Down in KO \\
\hline Sla & $-2,499$ & 0,988 & 0,00286465 & $3,16 \mathrm{E}-02$ & Down in KO \\
\hline Irx3 & 2,331 & $-0,836$ & 0,00035097 & $9,04 \mathrm{E}-03$ & Up in KO \\
\hline Skap1 & $-2,199$ & $-0,125$ & 0,00073749 & $1,41 E-02$ & Down in KO \\
\hline Vsir & $-1,783$ & 0,754 & 0,00083635 & 1,51E-02 & Down in KO \\
\hline Ciita & $-3,727$ & 2,846 & 0,00094266 & 1,61E-02 & Down in KO \\
\hline Prkg2 & $-1,390$ & 5,844 & 0,00079704 & $1,48 \mathrm{E}-02$ & Down in KO \\
\hline Incenp & 1,043 & 5,288 & 0,00086284 & $1,54 \mathrm{E}-02$ & Up in KO \\
\hline 9030619P08Rik & 1,764 & 0,897 & 0,00123834 & $1,89 \mathrm{E}-02$ & Up in KO \\
\hline 4930427A07Rik & 1,041 & 4,072 & 0,00095102 & $1,62 \mathrm{E}-02$ & Up in KO \\
\hline Sox12 & 1,415 & 0,644 & 0,00090043 & 1,57E-02 & Up in KO \\
\hline Rhoh & $-1,941$ & 0,826 & 0,00116022 & 1,81E-02 & Down in KO \\
\hline Cd53 & $-2,444$ & 1,068 & 0,00154813 & $2,16 \mathrm{E}-02$ & Down in KO \\
\hline Phgdh & 2,057 & 4,085 & 0,00212819 & $2,63 \mathrm{E}-02$ & Up in KO \\
\hline C330027C09Rik & 1,116 & 4,452 & 0,00059408 & $1,23 E-02$ & Up in KO \\
\hline Gm10354 & 3,802 & $-1,816$ & 0,00011972 & 5,09E-03 & Up in KO \\
\hline Dlgap5 & 1,360 & 3,877 & 0,00128164 & 1,93E-02 & Up in KO \\
\hline Sash3 & $-2,333$ & 0,811 & 0,00135057 & 1,99E-02 & Down in KO \\
\hline Gprc5b & 2,135 & $-0,533$ & 0,00016307 & $6,09 E-03$ & Up in KO \\
\hline Gpr55 & $-2,909$ & 0,874 & 0,00200586 & $2,54 \mathrm{E}-02$ & Down in KO \\
\hline Cdc6 & 1,065 & 3,037 & 0,00143632 & $2,06 \mathrm{E}-02$ & Up in KO \\
\hline Lck & $-1,234$ & 3,014 & 0,00076412 & $1,45 \mathrm{E}-02$ & Down in $\mathrm{KO}$ \\
\hline Lrp8 & 1,781 & 2,381 & 0,00150065 & $2,12 \mathrm{E}-02$ & Up in KO \\
\hline Lgals1 & 1,355 & 1,000 & 0,00142939 & $2,06 \mathrm{E}-02$ & Up in KO \\
\hline Zfp184 & 1,155 & 0,956 & 0,00164003 & $2,25 \mathrm{E}-02$ & Up in KO \\
\hline Cxcr6 & $-2,670$ & 0,523 & 0,00153243 & $2,15 E-02$ & Down in KO \\
\hline Bub1 & 1,231 & 3,646 & 0,00117634 & $1,82 \mathrm{E}-02$ & Up in KO \\
\hline Suv39h2 & 1,056 & 1,850 & 0,00132817 & 1,97E-02 & Up in KO \\
\hline Neil3 & 1,668 & 3,378 & 0,00184415 & $2,41 \mathrm{E}-02$ & Up in $K O$ \\
\hline Hsf2bp & 1,559 & 1,159 & 0,00059494 & $1,23 E-02$ & Up in KO \\
\hline Mdfi & 1,950 & $-0,489$ & 0,00012169 & $5,09 E-03$ & Up in KO \\
\hline Fosb & $-1,088$ & 9,850 & 0,00125668 & $1,90 \mathrm{E}-02$ & Down in $\mathrm{KO}$ \\
\hline Dmkn & 2,754 & 0,178 & 0,0001118 & 4,93E-03 & Up in KO \\
\hline Ska1 & 1,660 & 1,681 & 0,00162236 & $2,23 E-02$ & Up in KO \\
\hline AW551984 & 2,227 & 0,156 & 0,00115103 & $1,80 \mathrm{E}-02$ & Up in $K O$ \\
\hline Mastl & 1,139 & 3,013 & 0,00090399 & $1,58 \mathrm{E}-02$ & Up in KO \\
\hline Pou6f1 & $-1,313$ & 1,675 & 0,00077777 & $1,46 \mathrm{E}-02$ & Down in KO \\
\hline Gm42368 & 1,321 & 2,831 & 0,00107493 & $1,74 \mathrm{E}-02$ & Up in KO \\
\hline
\end{tabular}




\begin{tabular}{|c|c|c|c|c|c|}
\hline Pik3cd & $-1,891$ & 2,450 & 0,00212176 & $2,62 \mathrm{E}-02$ & Down in KO \\
\hline Lrrc8c & $-2,451$ & 0,622 & 0,00101877 & 1,69E-02 & Down in KO \\
\hline Tlr2 & $-1,114$ & 4,337 & 0,00087864 & $1,55 \mathrm{E}-02$ & Down in KO \\
\hline Pxdc1 & 1,435 & 2,753 & 0,00135778 & 1,99E-02 & Up in KO \\
\hline Zfp658 & $-1,091$ & 1,250 & 0,00103313 & $1,70 \mathrm{E}-02$ & Down in KO \\
\hline Bco1 & 1,018 & 1,625 & 0,00164215 & $2,25 \mathrm{E}-02$ & Up in KO \\
\hline H2-T-ps & $-1,313$ & 2,513 & 0,00086557 & 1,54E-02 & Down in KO \\
\hline $\mathrm{Cd} 48$ & $-2,437$ & 0,376 & 0,00130213 & $1,95 \mathrm{E}-02$ & Down in $\mathrm{KO}$ \\
\hline Apob & 1,074 & 8,121 & 0,00109122 & $1,75 \mathrm{E}-02$ & Up in KO \\
\hline Nab2 & 1,053 & 1,344 & 0,00188234 & $2,44 \mathrm{E}-02$ & Up in $\mathrm{KO}$ \\
\hline Pigz & 2,637 & 0,228 & 0,00118072 & 1,83E-02 & Up in KO \\
\hline Dusp14 & 1,179 & 0,420 & 0,00048971 & $1,08 \mathrm{E}-02$ & Up in $\mathrm{KO}$ \\
\hline D7Ertd128e & 2,982 & $-1,528$ & $2,09 \mathrm{E}-05$ & $1,88 \mathrm{E}-03$ & Up in KO \\
\hline Trp53cor1 & 3,022 & $-1,307$ & 0,0003812 & $9,40 \mathrm{E}-03$ & Up in $\mathrm{KO}$ \\
\hline Gm32677 & 1,159 & 1,579 & 0,00107163 & $1,74 \mathrm{E}-02$ & Up in KO \\
\hline Cyp2r1 & $-2,136$ & $-0,568$ & $8,92 \mathrm{E}-05$ & 4,32E-03 & Down in KO \\
\hline Rnf212 & $-1,170$ & 2,062 & 0,00103089 & $1,70 \mathrm{E}-02$ & Down in KO \\
\hline Melk & 1,777 & 4,466 & 0,00200669 & $2,54 \mathrm{E}-02$ & Up in KO \\
\hline Pitpnm2 & 1,062 & 2,472 & 0,00147413 & $2,10 \mathrm{E}-02$ & Up in $\mathrm{KO}$ \\
\hline ВС030867 & 1,685 & 1,857 & 0,00080399 & $1,48 \mathrm{E}-02$ & Up in KO \\
\hline Fbn1 & $-1,698$ & 1,090 & 0,00123063 & $1,88 \mathrm{E}-02$ & Down in $\mathrm{KO}$ \\
\hline Gm9994 & $-1,806$ & 0,689 & 0,00103234 & $1,70 \mathrm{E}-02$ & Down in KO \\
\hline Dock10 & $-2,457$ & 2,108 & 0,00288812 & $3,17 \mathrm{E}-02$ & Down in KO \\
\hline Arhgap30 & $-2,238$ & 1,542 & 0,00209056 & $2,61 \mathrm{E}-02$ & Down in $\mathrm{KO}$ \\
\hline ВС018473 & 1,674 & $-0,398$ & 0,00038503 & $9,44 \mathrm{E}-03$ & Up in KO \\
\hline $117 r$ & $-2,368$ & $-0,645$ & 0,00043693 & $1,02 \mathrm{E}-02$ & Down in $\mathrm{KO}$ \\
\hline Cd200r4 & $-2,827$ & 0,921 & 0,00217729 & $2,66 \mathrm{E}-02$ & Down in KO \\
\hline Ptgs1 & $-1,633$ & $-0,108$ & 0,00058956 & $1,22 \mathrm{E}-02$ & Down in KO \\
\hline Txk & $-2,099$ & 0,345 & 0,0012203 & $1,87 \mathrm{E}-02$ & Down in KO \\
\hline Zfp454 & $-2,330$ & $-1,337$ & 0,00020082 & $6,60 \mathrm{E}-03$ & Down in KO \\
\hline Pcdh19 & 3,816 & $-1,532$ & 0,00016827 & $6,14 \mathrm{E}-03$ & Up in KO \\
\hline Slc10a2 & 1,334 & 7,970 & 0,00155329 & $2,16 \mathrm{E}-02$ & Up in $\mathrm{KO}$ \\
\hline Tchh & 1,241 & 0,786 & 0,00105163 & $1,72 \mathrm{E}-02$ & Up in KO \\
\hline LOC108168870 & 2,721 & 1,087 & 0,00340341 & $3,52 \mathrm{E}-02$ & Up in KO \\
\hline Ces2a & $-1,077$ & 8,142 & 0,00118673 & $1,84 \mathrm{E}-02$ & Down in KO \\
\hline Emb & $-2,364$ & 1,252 & 0,0022251 & $2,70 \mathrm{E}-02$ & Down in KO \\
\hline Dhrs9 & 1,375 & 4,954 & 0,0014565 & $2,08 \mathrm{E}-02$ & Up in KO \\
\hline Ccl25 & 1,014 & 2,032 & 0,00120081 & $1,85 \mathrm{E}-02$ & Up in KO \\
\hline $\mathrm{Cd} 2$ & $-2,929$ & $-1,454$ & 6,16E-05 & $3,50 \mathrm{E}-03$ & Down in KO \\
\hline Scg5 & $-2,325$ & $-1,070$ & 0,00013268 & $5,42 \mathrm{E}-03$ & Down in KO \\
\hline XIr4a & $-3,170$ & 1,030 & 0,00354146 & $3,60 \mathrm{E}-02$ & Down in KO \\
\hline Rnase1 & 1,992 & $-0,899$ & 8,81E-05 & 4,29E-03 & Up in KO \\
\hline Fam84a & 1,185 & 2,277 & 0,00161773 & $2,23 \mathrm{E}-02$ & Up in KO \\
\hline Fyn & $-2,026$ & 1,802 & 0,00202851 & $2,56 \mathrm{E}-02$ & Down in KO \\
\hline Apol7b & $-2,087$ & 0,308 & 0,00109274 & $1,75 E-02$ & Down in KO \\
\hline Mtfr2 & 1,334 & 1,488 & 0,00167937 & $2,27 \mathrm{E}-02$ & Up in KO \\
\hline Rnf24 & 1,079 & 4,004 & 0,00117138 & $1,82 \mathrm{E}-02$ & Up in KO \\
\hline Nim1k & 2,254 & $-0,976$ & 0,00029108 & 8,03E-03 & Up in KO \\
\hline LOC108169043 & 1,092 & 4,202 & 0,00144987 & $2,08 \mathrm{E}-02$ & Up in KO \\
\hline Ikzf3 & $-2,315$ & 1,923 & 0,00401494 & $3,87 \mathrm{E}-02$ & Down in $\mathrm{KO}$ \\
\hline $\mathrm{Dm} \times 12$ & 1,583 & 0,035 & 0,00047171 & $1,06 \mathrm{E}-02$ & Up in KO \\
\hline $\mathrm{Nr} 4 \mathrm{a} 2$ & $-1,315$ & 3,567 & 0,00065744 & $1,32 \mathrm{E}-02$ & Down in $\mathrm{KO}$ \\
\hline
\end{tabular}




\begin{tabular}{|c|c|c|c|c|c|}
\hline Cyfip2 & $-2,672$ & 1,425 & 0,00294777 & $3,20 \mathrm{E}-02$ & Down in KO \\
\hline P3h2 & 3,127 & $-1,444$ & 0,00029403 & 8,09E-03 & Up in KO \\
\hline Gata4 & 2,172 & 1,930 & 0,0027564 & $3,10 \mathrm{E}-02$ & Up in KO \\
\hline Spc25 & 1,288 & 3,904 & 0,00170547 & $2,30 \mathrm{E}-02$ & Up in KO \\
\hline Mcm8 & 1,067 & 2,382 & 0,00282458 & $3,14 \mathrm{E}-02$ & Up in $\mathrm{KO}$ \\
\hline Ak4 & 1,788 & 5,407 & 0,00238826 & $2,82 \mathrm{E}-02$ & Up in KO \\
\hline Khdc1a & 6,083 & 1,618 & $2,26 \mathrm{E}-05$ & $1,95 \mathrm{E}-03$ & Up in KO \\
\hline LOC108168394 & $-1,909$ & 1,023 & 0,00154407 & $2,16 \mathrm{E}-02$ & Down in KO \\
\hline Arhgdib & $-1,793$ & 1,119 & 0,00113428 & $1,78 \mathrm{E}-02$ & Down in $\mathrm{KO}$ \\
\hline Gm33595 & $-1,455$ & 2,683 & 0,00159461 & $2,20 \mathrm{E}-02$ & Down in KO \\
\hline Gsta1 & 1,071 & 6,081 & 0,00133604 & $1,98 \mathrm{E}-02$ & Up in KO \\
\hline Ppp1r14a & $-1,939$ & $-0,704$ & 0,00023325 & $7,17 \mathrm{E}-03$ & Down in $\mathrm{KO}$ \\
\hline Itgb7 & $-2,170$ & 1,829 & 0,00255071 & $2,94 \mathrm{E}-02$ & Down in KO \\
\hline Cdca2 & 1,034 & 3,871 & 0,00045208 & $1,04 \mathrm{E}-02$ & Up in KO \\
\hline Unc119 & 1,261 & 4,731 & 0,00126293 & $1,91 \mathrm{E}-02$ & Up in KO \\
\hline Col25a1 & $-2,167$ & $-0,919$ & 4,17E-05 & $2,74 \mathrm{E}-03$ & Down in KO \\
\hline St6gal1 & $-1,444$ & 4,397 & 0,0019478 & $2,50 \mathrm{E}-02$ & Down in KO \\
\hline Hcls1 & $-1,618$ & 0,787 & 0,0012538 & $1,90 \mathrm{E}-02$ & Down in KO \\
\hline Cdca5 & 1,342 & 3,363 & 0,00202008 & $2,55 \mathrm{E}-02$ & Up in KO \\
\hline Rnf183 & 1,443 & $-0,171$ & 0,00036027 & $9,12 \mathrm{E}-03$ & Up in KO \\
\hline Rnf157 & 1,700 & 0,219 & 0,000977 & $1,65 E-02$ & Up in KO \\
\hline Lcp2 & $-2,573$ & 1,352 & 0,00294786 & $3,20 \mathrm{E}-02$ & Down in KO \\
\hline Clca4a & 1,068 & 10,143 & 0,00157117 & $2,18 \mathrm{E}-02$ & Up in KO \\
\hline Fxyd5 & $-2,039$ & 0,960 & 0,00201226 & $2,55 \mathrm{E}-02$ & Down in $\mathrm{KO}$ \\
\hline Cyth4 & $-2,396$ & 1,542 & 0,00283807 & $3,15 E-02$ & Down in KO \\
\hline Itgb2 & $-2,086$ & 1,139 & 0,00252821 & $2,92 \mathrm{E}-02$ & Down in KO \\
\hline Tmed6 & 1,844 & 1,580 & 0,00270599 & $3,06 \mathrm{E}-02$ & Up in KO \\
\hline $\mathrm{C} 2$ & 1,269 & 2,631 & 0,00179916 & 2,37E-02 & Up in KO \\
\hline AA414768 & 1,292 & 0,382 & 0,0006395 & $1,29 E-02$ & Up in KO \\
\hline $\mathrm{Nt5dc2}$ & 2,199 & 1,903 & 0,00231041 & $2,77 \mathrm{E}-02$ & Up in KO \\
\hline Dennd4a & $-1,061$ & 3,615 & 0,00110784 & $1,77 \mathrm{E}-02$ & Down in KO \\
\hline Cnnm1 & $-1,180$ & 1,730 & 0,00130997 & $1,96 \mathrm{E}-02$ & Down in $\mathrm{KO}$ \\
\hline Cacna1h & $-1,212$ & 4,111 & 0,0015638 & $2,17 \mathrm{E}-02$ & Down in KO \\
\hline Skida1 & 1,564 & $-0,258$ & 0,00121459 & $1,87 \mathrm{E}-02$ & Up in KO \\
\hline ligp1 & $-3,884$ & 3,659 & 0,00219801 & $2,68 \mathrm{E}-02$ & Down in $\mathrm{KO}$ \\
\hline Lpxn & $-1,302$ & 1,448 & 0,00148938 & $2,11 \mathrm{E}-02$ & Down in KO \\
\hline Cxcl5 & 2,096 & 1,069 & 0,00250601 & $2,92 \mathrm{E}-02$ & Up in KO \\
\hline Reg4 & 1,422 & 5,261 & 0,00221985 & $2,70 \mathrm{E}-02$ & Up in KO \\
\hline Trim6 & 1,137 & 3,954 & 0,0008866 & $1,56 \mathrm{E}-02$ & Up in KO \\
\hline Ifit3b & 1,647 & 2,974 & 0,00225586 & $2,73 E-02$ & Up in KO \\
\hline Traip & 1,681 & 2,817 & 0,00342784 & $3,53 \mathrm{E}-02$ & Up in KO \\
\hline Cst6 & 1,135 & 1,472 & 0,00182229 & 2,39E-02 & Up in KO \\
\hline Nfkbie & $-1,044$ & 1,367 & 0,00124494 & $1,89 \mathrm{E}-02$ & Down in $\mathrm{KO}$ \\
\hline Gm30235 & $-1,913$ & 0,891 & 0,00210744 & $2,62 \mathrm{E}-02$ & Down in $\mathrm{KO}$ \\
\hline Agap2 & $-1,816$ & 0,983 & 0,00097516 & $1,65 \mathrm{E}-02$ & Down in $\mathrm{KO}$ \\
\hline Grm4 & $-1,381$ & 1,860 & 0,00016473 & $6,12 \mathrm{E}-03$ & Down in $\mathrm{KO}$ \\
\hline Cadm4 & 1,457 & $-0,069$ & 0,0004695 & $1,06 \mathrm{E}-02$ & Up in KO \\
\hline Zfp365 & 2,780 & $-1,538$ & 4,27E-05 & $2,74 \mathrm{E}-03$ & Up in KO \\
\hline BC021767 & $-1,053$ & 2,069 & 0,00180996 & $2,38 \mathrm{E}-02$ & Down in KO \\
\hline Ano3 & 4,854 & $-1,403$ & $8,14 \mathrm{E}-05$ & $4,12 \mathrm{E}-03$ & Up in KO \\
\hline Prss41 & 1,947 & 0,045 & 0,00053881 & $1,14 \mathrm{E}-02$ & Up in KO \\
\hline Malrd1 & $-1,244$ & 4,700 & 0,0016996 & $2,29 \mathrm{E}-02$ & Down in $\mathrm{KO}$ \\
\hline
\end{tabular}




\begin{tabular}{|c|c|c|c|c|c|}
\hline Pla2g2a & 3,849 & 3,309 & 0,00116304 & $1,81 \mathrm{E}-02$ & Up in $\mathrm{KO}$ \\
\hline Pak6 & 1,029 & 1,856 & 0,00195536 & $2,50 \mathrm{E}-02$ & Up in KO \\
\hline Pygl & $-1,165$ & 0,807 & 0,00101953 & $1,69 \mathrm{E}-02$ & Down in KO \\
\hline Fmnl1 & $-2,130$ & 1,642 & 0,00285589 & $3,16 \mathrm{E}-02$ & Down in KO \\
\hline Ankle1 & 1,552 & 3,303 & 0,00288601 & $3,17 E-02$ & Up in KO \\
\hline Dsel & $-1,590$ & 0,628 & 0,00172537 & $2,31 \mathrm{E}-02$ & Down in KO \\
\hline Ang4 & 1,867 & 4,176 & 0,00410212 & $3,91 E-02$ & Up in KO \\
\hline A930001C03Rik & 1,438 & 0,547 & 0,00146848 & $2,09 E-02$ & Up in KO \\
\hline Glp1r & $-1,928$ & $-0,683$ & 0,00051071 & $1,11 \mathrm{E}-02$ & Down in KO \\
\hline Myo1f & $-2,212$ & 0,775 & 0,00239981 & 2,83E-02 & Down in KO \\
\hline LOC102639958 & 1,661 & $-0,357$ & 0,00056628 & 1,19E-02 & Up in KO \\
\hline Kntc1 & 1,586 & 3,418 & 0,00037443 & $9,32 \mathrm{E}-03$ & Up in KO \\
\hline Gm36704 & 2,121 & 1,938 & 0,00358203 & $3,62 \mathrm{E}-02$ & Up in KO \\
\hline Gm39275 & 1,314 & 1,518 & 0,00198811 & $2,53 \mathrm{E}-02$ & Up in $\mathrm{KO}$ \\
\hline Evx1os & 1,888 & 0,260 & 0,0021603 & $2,66 \mathrm{E}-02$ & Up in KO \\
\hline Lpcat4 & 1,156 & 6,628 & 0,00173655 & 2,32E-02 & Up in KO \\
\hline Gm2115 & $-1,071$ & 1,827 & 0,00155288 & $2,16 \mathrm{E}-02$ & Down in KO \\
\hline Nanos1 & 1,288 & 0,793 & 0,00134964 & $1,99 \mathrm{E}-02$ & Up in KO \\
\hline Efr3b & 1,728 & $-0,072$ & 0,00123082 & $1,88 \mathrm{E}-02$ & Up in KO \\
\hline Ncapd2 & 1,192 & 5,857 & 0,00264074 & $3,01 E-02$ & Up in KO \\
\hline Mttp & 1,433 & 1,594 & 0,00136093 & $2,00 \mathrm{E}-02$ & Up in KO \\
\hline Ifi203 & $-2,195$ & 0,921 & 0,00186195 & $2,42 \mathrm{E}-02$ & Down in KO \\
\hline $\operatorname{xrcc2}$ & 1,122 & 1,664 & 0,00256017 & $2,95 \mathrm{E}-02$ & Up in KO \\
\hline Lat & $-2,074$ & 0,130 & 0,00128773 & $1,94 \mathrm{E}-02$ & Down in KO \\
\hline Cst7 & $-2,140$ & $-0,698$ & 0,00077552 & $1,46 \mathrm{E}-02$ & Down in KO \\
\hline Trat1 & $-3,137$ & $-0,461$ & 0,00051969 & $1,12 \mathrm{E}-02$ & Down in KO \\
\hline Arhgef6 & $-2,141$ & 0,006 & 0,00193523 & $2,49 \mathrm{E}-02$ & Down in KO \\
\hline Vsig2 & 1,028 & 4,574 & 0,00216662 & $2,66 \mathrm{E}-02$ & Up in KO \\
\hline Dnah10 & 1,712 & 0,508 & 0,00238498 & $2,82 \mathrm{E}-02$ & Up in KO \\
\hline Slfng & 1,226 & 4,176 & 0,00209848 & $2,61 \mathrm{E}-02$ & Up in KO \\
\hline Gm34154 & 2,407 & $-1,359$ & $9,08 \mathrm{E}-05$ & 4,34E-03 & Up in KO \\
\hline LOC101056001 & 1,638 & 2,274 & 0,00231015 & $2,77 \mathrm{E}-02$ & Up in $\mathrm{KO}$ \\
\hline C1qtnf6 & 1,278 & 5,415 & 0,00265814 & $3,03 E-02$ & Up in KO \\
\hline Fzd2 & $-1,833$ & $-0,043$ & 0,00129745 & $1,95 \mathrm{E}-02$ & Down in KO \\
\hline Gpc1 & 1,085 & 0,705 & 0,00094527 & 1,61E-02 & Up in KO \\
\hline Ecm1 & 1,206 & 1,757 & 0,00296649 & $3,22 \mathrm{E}-02$ & Up in KO \\
\hline Kctd15 & $-1,183$ & 0,215 & 0,00062398 & 1,27E-02 & Down in KO \\
\hline Akr1c18 & 1,288 & 2,589 & 0,00234465 & $2,79 E-02$ & Up in KO \\
\hline Aaas & 1,043 & 3,911 & 0,00217532 & $2,66 \mathrm{E}-02$ & Up in KO \\
\hline Acox 2 & 1,020 & 3,219 & 0,00172459 & $2,31 \mathrm{E}-02$ & Up in $\mathrm{KO}$ \\
\hline Sema7a & 1,523 & 3,553 & 0,00181911 & 2,39E-02 & Up in KO \\
\hline Chtf18 & 1,428 & 3,099 & 0,00281942 & $3,14 \mathrm{E}-02$ & Up in KO \\
\hline Arhgap22 & 1,446 & $-0,498$ & 0,00039924 & $9,64 \mathrm{E}-03$ & Up in KO \\
\hline 9030612E09Rik & $-3,220$ & $-1,740$ & 0,00019758 & $6,55 \mathrm{E}-03$ & Down in KO \\
\hline $\mathrm{Hnmt}$ & $-1,927$ & 0,151 & 0,00086534 & $1,54 \mathrm{E}-02$ & Down in KO \\
\hline Csta1 & 1,950 & 0,684 & 0,00281394 & $3,14 \mathrm{E}-02$ & Up in KO \\
\hline Gdpd2 & $-1,199$ & 3,238 & 0,00211535 & 2,62E-02 & Down in KO \\
\hline Mad2I1 & 1,374 & 4,600 & 0,00290845 & $3,19 E-02$ & Up in KO \\
\hline Megf9 & 1,007 & 2,803 & 0,0021889 & $2,67 \mathrm{E}-02$ & Up in KO \\
\hline Bag2 & 1,125 & 1,795 & 0,00287442 & $3,17 E-02$ & Up in KO \\
\hline Ciart & $-1,559$ & 2,709 & 0,00277656 & $3,11 E-02$ & Down in KO \\
\hline Pydc3 & $-2,108$ & $-0,729$ & 0,0007661 & $1,45 E-02$ & Down in KO \\
\hline
\end{tabular}




\begin{tabular}{|c|c|c|c|c|c|}
\hline Gm40892 & $-3,124$ & 0,030 & 0,00251563 & $2,92 \mathrm{E}-02$ & Down in KO \\
\hline Pole & 1,477 & 3,651 & 0,00307228 & $3,29 \mathrm{E}-02$ & Up in KO \\
\hline Nlrc3 & $-2,017$ & 1,278 & 0,00331264 & $3,45 \mathrm{E}-02$ & Down in KO \\
\hline Kif4 & 1,358 & 4,498 & 0,00077532 & $1,46 E-02$ & Up in KO \\
\hline Evx1 & 1,709 & 2,332 & 0,0016611 & $2,26 \mathrm{E}-02$ & Up in KO \\
\hline Hmha1 & $-1,802$ & 3,060 & 0,00238475 & $2,82 \mathrm{E}-02$ & Down in KO \\
\hline Mal & 1,238 & 6,364 & 0,00233132 & $2,78 \mathrm{E}-02$ & Up in KO \\
\hline Gm33333 & 1,282 & 0,967 & 0,00188467 & $2,44 \mathrm{E}-02$ & Up in KO \\
\hline LOC102632156 & 1,153 & 0,136 & 0,00107994 & $1,75 \mathrm{E}-02$ & Up in KO \\
\hline Slc34a2 & 1,326 & 4,835 & 0,00270176 & $3,06 \mathrm{E}-02$ & Up in KO \\
\hline Myom3 & $-1,250$ & 2,630 & 0,00145181 & $2,08 \mathrm{E}-02$ & Down in KO \\
\hline Spc24 & 1,323 & 3,463 & 0,00304692 & $3,27 E-02$ & Up in KO \\
\hline Pappa & 2,283 & $-0,648$ & 0,0029866 & $3,23 \mathrm{E}-02$ & Up in KO \\
\hline Prox1 & $-2,270$ & $-1,118$ & 0,00016049 & $6,04 \mathrm{E}-03$ & Down in KO \\
\hline Mthfd2 & 1,229 & 3,596 & 0,00298253 & $3,23 E-02$ & Up in KO \\
\hline Gm41029 & 2,285 & $-0,969$ & 0,00211018 & $2,62 \mathrm{E}-02$ & Up in $\mathrm{KO}$ \\
\hline Dnajb4 & $-1,033$ & 4,872 & 0,00186179 & $2,42 \mathrm{E}-02$ & Down in KO \\
\hline Hic1 & $-2,235$ & $-0,388$ & 0,00118905 & $1,84 \mathrm{E}-02$ & Down in KO \\
\hline Adcy7 & $-2,050$ & 1,697 & 0,00368368 & $3,68 \mathrm{E}-02$ & Down in KO \\
\hline Fbxo5 & 1,293 & 3,192 & 0,00297396 & $3,22 \mathrm{E}-02$ & Up in KO \\
\hline Galnt18 & 1,939 & 0,340 & 0,00282735 & $3,14 \mathrm{E}-02$ & Up in KO \\
\hline Gm40491 & $-1,585$ & 0,446 & 0,00172118 & 2,31E-02 & Down in KO \\
\hline Lat2 & $-1,392$ & 1,041 & 0,00365462 & $3,66 \mathrm{E}-02$ & Down in KO \\
\hline Hirip3 & 1,167 & 4,120 & 0,00412621 & $3,92 \mathrm{E}-02$ & Up in KO \\
\hline Gimap5 & $-1,772$ & $-0,034$ & 0,00188281 & $2,44 \mathrm{E}-02$ & Down in KO \\
\hline Gm40833 & 2,915 & $-1,437$ & 0,00101829 & $1,69 \mathrm{E}-02$ & Up in KO \\
\hline Gm3776 & 1,074 & 5,340 & 0,00230314 & $2,77 \mathrm{E}-02$ & Up in KO \\
\hline Sp110 & $-1,227$ & 2,871 & 0,00235354 & $2,80 \mathrm{E}-02$ & Down in KO \\
\hline Oip5 & 1,281 & 1,705 & 0,00321797 & $3,39 \mathrm{E}-02$ & Up in KO \\
\hline Wdr90 & 1,024 & 3,704 & 0,00252429 & 2,92E-02 & Up in KO \\
\hline Grap2 & $-1,677$ & 1,741 & 0,00315604 & $3,35 \mathrm{E}-02$ & Down in KO \\
\hline 9430085M18Rik & 1,742 & $-0,741$ & 0,00106183 & $1,73 E-02$ & Up in KO \\
\hline Tnip3 & 1,509 & 3,314 & 0,00355821 & $3,61 \mathrm{E}-02$ & Up in KO \\
\hline Ndrg4 & 2,566 & $-1,564$ & 0,00012006 & 5,09E-03 & Up in KO \\
\hline Iqgap3 & 1,378 & 4,605 & 0,00251105 & $2,92 \mathrm{E}-02$ & Up in KO \\
\hline LOC108167332 & $-2,453$ & 0,211 & 0,00289759 & $3,18 \mathrm{E}-02$ & Down in KO \\
\hline Gemin6 & 1,400 & 2,178 & 0,00357961 & $3,62 \mathrm{E}-02$ & Up in KO \\
\hline Ncaph & 1,470 & 4,325 & 0,00365846 & $3,66 \mathrm{E}-02$ & Up in KO \\
\hline LOC108167862 & 1,584 & $-0,503$ & 0,00078735 & $1,47 E-02$ & Up in KO \\
\hline Gpr146 & $-1,695$ & $-0,415$ & 0,00066681 & $1,32 \mathrm{E}-02$ & Down in KO \\
\hline Fanci & 1,516 & 2,761 & 0,00367239 & $3,67 E-02$ & Up in KO \\
\hline Sipa1 & $-1,091$ & 2,487 & 0,0020446 & $2,57 \mathrm{E}-02$ & Down in KO \\
\hline Cd300If & $-1,836$ & $-0,075$ & 0,00041987 & 9,91E-03 & Down in KO \\
\hline Gm6093 & $-1,676$ & 1,020 & 0,00288868 & $3,17 \mathrm{E}-02$ & Down in KO \\
\hline Gm39942 & 1,034 & 5,138 & 0,00237745 & $2,81 \mathrm{E}-02$ & Up in KO \\
\hline Sstr2 & $-1,387$ & 0,890 & 0,00144519 & 2,07E-02 & Down in KO \\
\hline LOC108167999 & 2,534 & $-0,684$ & 0,00369191 & $3,68 \mathrm{E}-02$ & Up in KO \\
\hline LOC108169123 & 2,534 & $-0,684$ & 0,00369191 & $3,68 \mathrm{E}-02$ & Up in KO \\
\hline Cor1 & 1,390 & 0,580 & 0,00163129 & $2,24 \mathrm{E}-02$ & Up in KO \\
\hline Nek5 & $-1,496$ & $-0,448$ & 0,00053688 & $1,14 \mathrm{E}-02$ & Down in KO \\
\hline Id 4 & 1,281 & 1,923 & 0,00334691 & $3,48 \mathrm{E}-02$ & Up in KO \\
\hline Was & $-2,069$ & $-0,215$ & 0,00173257 & $2,32 \mathrm{E}-02$ & Down in KO \\
\hline
\end{tabular}




\begin{tabular}{|c|c|c|c|c|c|}
\hline Angpt2 & $-2,404$ & $-0,970$ & 0,00100263 & 1,67E-02 & Down in KO \\
\hline Pax4 & $-2,430$ & $-1,450$ & $8,66 \mathrm{E}-05$ & $4,26 \mathrm{E}-03$ & Down in KO \\
\hline Cd8a & $-1,874$ & 2,607 & 0,0042327 & $3,98 \mathrm{E}-02$ & Down in KO \\
\hline Nckap1l & $-2,115$ & 1,122 & 0,0032501 & $3,41 \mathrm{E}-02$ & Down in KO \\
\hline Gbp6 & $-1,858$ & 3,220 & 0,00482735 & 4,33E-02 & Down in KO \\
\hline Gm32796 & 1,590 & $-0,559$ & 0,00065055 & $1,30 \mathrm{E}-02$ & Up in KO \\
\hline Rgs17 & $-1,111$ & 3,556 & 0,00269469 & $3,05 E-02$ & Down in KO \\
\hline Riiad1 & $-1,033$ & 0,555 & 0,00105587 & $1,72 \mathrm{E}-02$ & Down in KO \\
\hline Eme1 & 1,465 & 1,955 & 0,00211991 & $2,62 \mathrm{E}-02$ & Up in KO \\
\hline KIre1 & $-1,738$ & $-0,268$ & 0,00167751 & 2,27E-02 & Down in KO \\
\hline Gm1966 & $-1,264$ & 2,846 & 0,00278761 & $3,12 \mathrm{E}-02$ & Down in KO \\
\hline Ptgis & 1,851 & $-0,004$ & 0,00210069 & 2,61E-02 & Up in KO \\
\hline Gpx7 & 1,102 & 0,482 & 0,00211976 & $2,62 \mathrm{E}-02$ & Up in KO \\
\hline Exo1 & 1,799 & 2,565 & 0,00415539 & $3,93 \mathrm{E}-02$ & Up in $\mathrm{KO}$ \\
\hline Per3 & $-1,091$ & 4,350 & 0,00357556 & $3,62 \mathrm{E}-02$ & Down in $\mathrm{KO}$ \\
\hline Itgax & $-2,161$ & 0,540 & 0,00383771 & $3,77 E-02$ & Down in KO \\
\hline Mfge8 & 1,457 & 3,741 & 0,0044542 & 4,09E-02 & Up in KO \\
\hline LOC105242408 & 1,743 & 0,278 & 0,00209475 & $2,61 E-02$ & Up in KO \\
\hline Ltb4r1 & 1,093 & 0,217 & 0,00214952 & $2,65 \mathrm{E}-02$ & Up in KO \\
\hline Slc2a12 & 2,463 & $-1,412$ & 0,00021187 & 6,77E-03 & Up in KO \\
\hline Gm2808 & $-2,788$ & 0,693 & 0,00537045 & $4,62 \mathrm{E}-02$ & Down in $\mathrm{KO}$ \\
\hline Lysmd2 & 1,217 & 1,205 & 0,00381264 & $3,75 E-02$ & Up in KO \\
\hline Lrr1 & 1,716 & 0,780 & 0,00455688 & $4,15 E-02$ & Up in KO \\
\hline$c d 3 d$ & $-1,583$ & 1,185 & 0,00503479 & $4,43 E-02$ & Down in $\mathrm{KO}$ \\
\hline Wwtr1 & 1,003 & 0,526 & 0,00114733 & $1,80 \mathrm{E}-02$ & Up in KO \\
\hline Rad51ap1 & 1,849 & 2,775 & 0,00582729 & 4,87E-02 & Up in KO \\
\hline Plin4 & 1,856 & 0,877 & 0,00300738 & $3,24 \mathrm{E}-02$ & Up in KO \\
\hline Gm42245 & 1,409 & $-0,466$ & 0,00050762 & $1,11 \mathrm{E}-02$ & Up in KO \\
\hline St8sia4 & $-2,672$ & 0,338 & 0,00276806 & $3,11 E-02$ & Down in $\mathrm{KO}$ \\
\hline Oprd1 & $-1,378$ & $-0,455$ & 0,00056625 & $1,19 \mathrm{E}-02$ & Down in $\mathrm{KO}$ \\
\hline Ubd & $-4,335$ & 0,870 & 0,00403909 & $3,88 \mathrm{E}-02$ & Down in $\mathrm{KO}$ \\
\hline Dock3 & $-1,357$ & 0,106 & 0,00145582 & $2,08 \mathrm{E}-02$ & Down in KO \\
\hline Nek2 & 1,149 & 4,690 & 0,00349497 & 3,57E-02 & Up in KO \\
\hline 4930503L19Rik & $-2,082$ & 0,443 & 0,00293957 & $3,20 \mathrm{E}-02$ & Down in $\mathrm{KO}$ \\
\hline Mfap3I & $-1,078$ & 5,471 & 0,00338426 & $3,50 E-02$ & Down in KO \\
\hline Lmcd1 & 1,695 & $-0,415$ & 0,00117815 & $1,83 \mathrm{E}-02$ & Up in KO \\
\hline Saxo1 & 2,712 & $-1,448$ & 0,00116462 & 1,81E-02 & Up in KO \\
\hline Soga1 & $-1,160$ & 3,060 & 0,00269528 & $3,05 E-02$ & Down in KO \\
\hline Rps6ka6 & 1,034 & 1,234 & 0,00355829 & $3,61 E-02$ & Up in KO \\
\hline Dpysl3 & 1,111 & 3,225 & 0,00336972 & $3,49 E-02$ & Up in KO \\
\hline Gm30762 & 1,169 & 0,722 & 0,00359169 & $3,62 \mathrm{E}-02$ & Up in KO \\
\hline Psmb8 & $-1,300$ & 5,397 & 0,00371619 & 3,69E-02 & Down in KO \\
\hline E330020D12Rik & 1,204 & 0,074 & 0,00105118 & $1,72 \mathrm{E}-02$ & Up in KO \\
\hline Gimap7 & $-3,027$ & 0,262 & 0,00500873 & $4,42 \mathrm{E}-02$ & Down in KO \\
\hline Plekho2 & $-1,013$ & 1,108 & 0,00231228 & $2,77 E-02$ & Down in KO \\
\hline Tnfsf10 & $-1,328$ & 3,679 & 0,00363779 & $3,65 E-02$ & Down in $\mathrm{KO}$ \\
\hline Ikzf1 & $-2,243$ & 1,185 & 0,00488953 & $4,36 \mathrm{E}-02$ & Down in KO \\
\hline Ric3 & $-2,181$ & $-1,409$ & 0,00040333 & $9,65 \mathrm{E}-03$ & Down in KO \\
\hline Cdc45 & 1,408 & 3,267 & 0,0045869 & 4,17E-02 & Up in KO \\
\hline Atp8b2 & $-1,309$ & 1,575 & 0,00288106 & $3,17 E-02$ & Down in KO \\
\hline Agt & $-1,456$ & 1,196 & 0,00351218 & $3,59 \mathrm{E}-02$ & Down in $\mathrm{KO}$ \\
\hline Vwa7 & 1,066 & 0,698 & 0,00255446 & $2,94 \mathrm{E}-02$ & Up in KO \\
\hline
\end{tabular}




\begin{tabular}{|c|c|c|c|c|c|}
\hline Nup62cl & 4,365 & $-1,779$ & $2,83 \mathrm{E}-05$ & 2,21E-03 & Up in KO \\
\hline Usp2 & $-1,116$ & 5,106 & 0,00287021 & $3,17 \mathrm{E}-02$ & Down in KO \\
\hline B9d1 & 1,183 & 1,575 & 0,00526947 & $4,56 \mathrm{E}-02$ & Up in KO \\
\hline Kcnab2 & $-2,111$ & $-0,147$ & 0,00324235 & $3,40 E-02$ & Down in KO \\
\hline Bmf & $-1,142$ & 2,794 & 0,00334108 & $3,47 \mathrm{E}-02$ & Down in KO \\
\hline Ipcef1 & $-2,164$ & 0,807 & 0,00309071 & $3,30 \mathrm{E}-02$ & Down in KO \\
\hline Bub1b & 1,066 & 4,631 & 0,00369597 & $3,68 \mathrm{E}-02$ & Up in KO \\
\hline Aldh3b3 & 2,189 & $-0,872$ & 0,00142285 & $2,06 \mathrm{E}-02$ & Up in KO \\
\hline Adgrf1 & 1,175 & 3,234 & 0,00483835 & $4,33 \mathrm{E}-02$ & Up in KO \\
\hline Gm11735 & 1,382 & 1,961 & 0,00458529 & 4,17E-02 & Up in KO \\
\hline Myo1g & $-2,132$ & 1,378 & 0,00602351 & 4,97E-02 & Down in KO \\
\hline Gm36767 & $-2,117$ & $-1,152$ & 0,00068655 & $1,35 \mathrm{E}-02$ & Down in KO \\
\hline Ror1 & $-1,551$ & 0,733 & 0,00357727 & $3,62 \mathrm{E}-02$ & Down in KO \\
\hline Gm42286 & 1,940 & $-0,178$ & 0,00230177 & $2,77 \mathrm{E}-02$ & Up in KO \\
\hline $\operatorname{Sh} 2 d 7$ & $-2,057$ & $-0,017$ & 0,00503451 & 4,43E-02 & Down in KO \\
\hline KIra7 & $-2,334$ & $-0,358$ & 0,00324102 & $3,40 E-02$ & Down in KO \\
\hline Defb37 & $-1,309$ & 1,594 & 0,00251184 & $2,92 \mathrm{E}-02$ & Down in KO \\
\hline Spaca7 & $-2,494$ & $-1,411$ & 0,00068735 & $1,35 \mathrm{E}-02$ & Down in $\mathrm{KO}$ \\
\hline Tnfrsf11b & 1,377 & $-0,288$ & 0,00109751 & $1,75 \mathrm{E}-02$ & Up in KO \\
\hline Iffo1 & $-1,802$ & $-0,704$ & 0,00183729 & $2,40 \mathrm{E}-02$ & Down in KO \\
\hline Penk & 2,588 & $-1,228$ & 0,00201792 & $2,55 \mathrm{E}-02$ & Up in KO \\
\hline Myh10 & 1,114 & 0,295 & 0,0016474 & $2,25 \mathrm{E}-02$ & Up in KO \\
\hline Gm40498 & 1,485 & 0,354 & 0,00294685 & $3,20 \mathrm{E}-02$ & Up in $\mathrm{KO}$ \\
\hline Pola1 & 1,232 & 3,515 & 0,00464662 & $4,21 \mathrm{E}-02$ & Up in KO \\
\hline Ndc80 & 1,433 & 3,177 & 0,00547814 & 4,67E-02 & Up in KO \\
\hline Myt1 & $-1,321$ & $-0,603$ & 0,00024689 & 7,33E-03 & Down in KO \\
\hline Snn & 1,509 & $-0,433$ & 0,00112736 & $1,78 \mathrm{E}-02$ & Up in KO \\
\hline Peli3 & $-1,230$ & 0,524 & 0,00137298 & 2,01E-02 & Down in KO \\
\hline Tmem86a & $-1,109$ & 0,642 & 0,0034141 & $3,52 E-02$ & Down in KO \\
\hline 4930526L06Rik & 1,211 & 0,123 & 0,00199884 & 2,54E-02 & Up in KO \\
\hline Ms4a6b & $-2,380$ & $-0,512$ & 0,00308598 & $3,30 \mathrm{E}-02$ & Down in KO \\
\hline Ptrf & 1,025 & 2,353 & 0,00442206 & 4,08E-02 & Up in KO \\
\hline $\mathrm{Cd} 244$ & $-2,227$ & 1,056 & 0,00559078 & 4,74E-02 & Down in KO \\
\hline Kcnk7 & 1,358 & $-0,007$ & 0,0028547 & $3,16 \mathrm{E}-02$ & Up in KO \\
\hline Gm15283 & 1,729 & 0,336 & 0,00421957 & $3,97 \mathrm{E}-02$ & Up in KO \\
\hline Asb2 & $-2,103$ & $-0,082$ & 0,00356001 & $3,61 \mathrm{E}-02$ & Down in KO \\
\hline Pex5I & $-1,181$ & 1,221 & 0,00481907 & $4,32 \mathrm{E}-02$ & Down in KO \\
\hline Map1b & $-1,570$ & $-0,651$ & 0,00083233 & $1,50 \mathrm{E}-02$ & Down in KO \\
\hline Mfng & $-2,280$ & $-0,556$ & 0,00110859 & 1,77E-02 & Down in KO \\
\hline Fcer1g & $-1,781$ & 0,807 & 0,00441485 & $4,08 \mathrm{E}-02$ & Down in KO \\
\hline Krt12 & 1,357 & 2,596 & 0,00407128 & $3,89 \mathrm{E}-02$ & Up in KO \\
\hline Adarb2 & 1,333 & 0,676 & 0,00352081 & 3,59E-02 & Up in $\mathrm{KO}$ \\
\hline Tmc3 & 1,421 & $-0,013$ & 0,00426629 & $4,00 E-02$ & Up in KO \\
\hline Rgs13 & $-2,421$ & $-0,411$ & 0,00305771 & $3,28 E-02$ & Down in KO \\
\hline Smpdl3b & 1,375 & 2,623 & 0,00586181 & $4,89 E-02$ & Up in KO \\
\hline Col18a1 & 1,292 & 1,220 & 0,00401089 & $3,87 \mathrm{E}-02$ & Up in KO \\
\hline Syn2 & $-2,024$ & 0,415 & 0,00513755 & 4,48E-02 & Down in KO \\
\hline Rbm11 & 1,624 & 0,705 & 0,00132814 & $1,97 \mathrm{E}-02$ & Up in KO \\
\hline Cd68 & 1,131 & 1,631 & 0,00279074 & $3,12 \mathrm{E}-02$ & Up in KO \\
\hline Hcst & $-1,317$ & 0,082 & 0,00166313 & $2,26 \mathrm{E}-02$ & Down in KO \\
\hline Gm38875 & $-1,159$ & 0,277 & 0,00246641 & $2,88 \mathrm{E}-02$ & Down in KO \\
\hline LOC108169069 & 1,222 & 0,434 & 0,00292857 & 3,19E-02 & Up in KO \\
\hline
\end{tabular}




\begin{tabular}{|c|c|c|c|c|c|}
\hline Smoc1 & $-2,180$ & $-0,908$ & 0,00194557 & $2,50 \mathrm{E}-02$ & Down in KO \\
\hline Gm35437 & $-1,235$ & 0,259 & 0,00316927 & $3,36 \mathrm{E}-02$ & Down in KO \\
\hline Slc22a17 & $-1,479$ & 0,325 & 0,00353694 & $3,60 \mathrm{E}-02$ & Down in KO \\
\hline Gm15401 & 1,106 & 4,813 & 0,00540418 & $4,64 \mathrm{E}-02$ & Up in KO \\
\hline Snora70 & $-1,289$ & 0,412 & 0,00254351 & 2,93E-02 & Down in KO \\
\hline Pnliprp2 & 1,305 & 0,829 & 0,00478028 & $4,29 E-02$ & Up in KO \\
\hline Zfp189 & $-1,109$ & 0,828 & 0,00384782 & $3,78 \mathrm{E}-02$ & Down in KO \\
\hline D16Ertd472e & $-1,519$ & 1,742 & 0,00490032 & $4,36 \mathrm{E}-02$ & Down in KO \\
\hline Drc1 & 1,094 & 0,572 & 0,00229024 & $2,76 \mathrm{E}-02$ & Up in KO \\
\hline Gm42226 & 1,744 & 0,129 & 0,00536451 & 4,62E-02 & Up in KO \\
\hline Gimap1 & $-1,072$ & 1,707 & 0,00578403 & $4,84 \mathrm{E}-02$ & Down in KO \\
\hline Tbc1d16 & $-1,079$ & 3,085 & 0,00494531 & 4,38E-02 & Down in KO \\
\hline Sgol1 & 1,149 & 3,108 & 0,00556653 & 4,73E-02 & Up in KO \\
\hline Myrip & $-1,221$ & 1,583 & 0,0044539 & $4,09 E-02$ & Down in KO \\
\hline Grhl3 & 1,620 & 0,592 & 0,00440938 & $4,08 \mathrm{E}-02$ & Up in KO \\
\hline Retnlb & 2,515 & 6,172 & 0,00355561 & 3,61E-02 & Up in KO \\
\hline Cps1 & 1,536 & 1,201 & 0,00548605 & 4,67E-02 & Up in KO \\
\hline Ltb & $-1,515$ & $-0,456$ & 0,001354 & $1,99 \mathrm{E}-02$ & Down in KO \\
\hline Gm14149 & 1,028 & 3,532 & 0,00456121 & 4,15E-02 & Up in KO \\
\hline Fam110b & $-1,292$ & $-0,685$ & 0,00266992 & $3,04 \mathrm{E}-02$ & Down in KO \\
\hline Pbp2 & 1,302 & 1,071 & 0,00501203 & $4,42 E-02$ & Up in KO \\
\hline Capn3 & $-1,474$ & $-0,024$ & 0,00237893 & $2,81 \mathrm{E}-02$ & Down in KO \\
\hline Paqr3 & 1,081 & 0,143 & 0,00314244 & $3,34 \mathrm{E}-02$ & Up in KO \\
\hline Gm15731 & 1,738 & $-1,090$ & 0,00062081 & $1,27 \mathrm{E}-02$ & Up in KO \\
\hline Gpc3 & 1,689 & 0,440 & 0,00492501 & 4,38E-02 & Up in KO \\
\hline Kif18b & 1,029 & 3,150 & 0,00559595 & 4,74E-02 & Up in KO \\
\hline Adamts16 & $-2,561$ & $-1,370$ & 0,00196829 & 2,51E-02 & Down in KO \\
\hline Ccdc96 & 2,005 & $-1,362$ & 0,00061828 & $1,26 \mathrm{E}-02$ & Up in KO \\
\hline Olfm1 & $-1,375$ & $-0,432$ & 0,00258343 & $2,96 \mathrm{E}-02$ & Down in KO \\
\hline Slc15a1 & $-1,054$ & 4,518 & 0,00525143 & $4,56 \mathrm{E}-02$ & Down in KO \\
\hline Fev & $-2,338$ & $-1,524$ & 0,00203973 & 2,57E-02 & Down in KO \\
\hline Gm12865 & 1,384 & $-0,019$ & 0,00388616 & $3,80 \mathrm{E}-02$ & Up in KO \\
\hline Slc24a3 & $-1,676$ & 0,333 & 0,00531138 & 4,59E-02 & Down in KO \\
\hline 2210011K15Rik & 1,256 & $-0,413$ & 0,00111109 & $1,77 \mathrm{E}-02$ & Up in KO \\
\hline Flrt2 & $-1,853$ & $-0,400$ & 0,00310965 & $3,32 \mathrm{E}-02$ & Down in KO \\
\hline Plin5 & 1,110 & $-0,072$ & 0,0023164 & $2,77 \mathrm{E}-02$ & Up in KO \\
\hline Kif1a & $-1,729$ & $-0,557$ & 0,00253279 & $2,93 \mathrm{E}-02$ & Down in KO \\
\hline Pdgfd & $-2,177$ & $-0,910$ & 0,00017575 & $6,28 \mathrm{E}-03$ & Down in KO \\
\hline Slc38a3 & 1,440 & 0,297 & 0,00483105 & $4,33 \mathrm{E}-02$ & Up in KO \\
\hline Spag5 & 1,187 & 4,244 & 0,00426185 & $4,00 E-02$ & Up in KO \\
\hline Hрca & $-1,304$ & 0,765 & 0,00439722 & $4,08 \mathrm{E}-02$ & Down in KO \\
\hline Klra5 & $-2,241$ & $-0,140$ & 0,00503401 & $4,43 E-02$ & Down in KO \\
\hline Syp & $-1,339$ & $-0,205$ & 0,00297213 & $3,22 \mathrm{E}-02$ & Down in KO \\
\hline Shank3 & 1,394 & $-0,432$ & 0,00244118 & $2,86 \mathrm{E}-02$ & Up in KO \\
\hline Scn3a & $-1,541$ & $-0,557$ & 0,00267406 & $3,04 \mathrm{E}-02$ & Down in KO \\
\hline Ly9 & $-2,155$ & $-1,122$ & 0,0013158 & $1,96 \mathrm{E}-02$ & Down in KO \\
\hline Gm20752 & 1,389 & $-0,248$ & 0,00385688 & $3,78 \mathrm{E}-02$ & Up in KO \\
\hline Slc2a6 & $-1,007$ & 2,152 & 0,00513141 & 4,48E-02 & Down in KO \\
\hline Gm29891 & $-2,175$ & $-0,670$ & 0,00541829 & $4,64 \mathrm{E}-02$ & Down in KO \\
\hline $\mathrm{Npb}$ & 1,084 & $-0,946$ & 0,00314403 & $3,34 \mathrm{E}-02$ & Up in KO \\
\hline LOC108168988 & 1,029 & 0,718 & 0,00520613 & 4,53E-02 & Up in KO \\
\hline Slc11a2 & 1,310 & 6,113 & 0,0032312 & $3,40 E-02$ & Up in KO \\
\hline
\end{tabular}




\begin{tabular}{|c|c|c|c|c|c|}
\hline Cdh26 & $-1,934$ & $-1,518$ & 0,00036328 & $9,14 \mathrm{E}-03$ & Down in $\mathrm{KO}$ \\
\hline Pcdhgc5 & 1,288 & 0,057 & 0,00436191 & $4,05 E-02$ & Up in KO \\
\hline Homer3 & 1,124 & 0,483 & 0,00595657 & 4,94E-02 & Up in KO \\
\hline Gm830 & $-1,784$ & $-0,311$ & 0,00453656 & $4,14 \mathrm{E}-02$ & Down in KO \\
\hline C130083M11Rik & 1,241 & $-0,284$ & 0,00173645 & $2,32 \mathrm{E}-02$ & Up in KO \\
\hline 4933439K11Rik & $-1,131$ & $-0,079$ & 0,00200667 & $2,54 \mathrm{E}-02$ & Down in $\mathrm{KO}$ \\
\hline Tmem173 & $-1,340$ & 1,124 & 0,00599396 & $4,96 \mathrm{E}-02$ & Down in KO \\
\hline Gm41866 & $-1,379$ & $-0,484$ & 0,00187441 & $2,43 E-02$ & Down in $\mathrm{KO}$ \\
\hline Mrc1 & 1,104 & 0,569 & 0,00530918 & 4,59E-02 & Up in KO \\
\hline Fancb & 1,361 & 1,576 & 0,00534088 & $4,61 \mathrm{E}-02$ & Up in KO \\
\hline Ttll11 & $-1,021$ & 0,304 & 0,00337062 & $3,49 E-02$ & Down in $\mathrm{KO}$ \\
\hline Zbtb20 & $-1,289$ & 3,592 & 0,00251164 & $2,92 \mathrm{E}-02$ & Down in $\mathrm{KO}$ \\
\hline Gm35039 & 3,206 & $-0,706$ & 0,00585559 & $4,89 \mathrm{E}-02$ & Up in KO \\
\hline Gm30806 & 1,040 & 0,407 & 0,00507868 & $4,45 E-02$ & Up in KO \\
\hline Clec2i & $-2,342$ & $-0,066$ & 0,00580039 & $4,85 \mathrm{E}-02$ & Down in $\mathrm{KO}$ \\
\hline Nudt11 & $-1,308$ & $-0,643$ & 0,00143302 & $2,06 \mathrm{E}-02$ & Down in KO \\
\hline Gm9199 & $-2,035$ & $-1,359$ & 0,00181244 & 2,39E-02 & Down in $\mathrm{KO}$ \\
\hline Mlf1 & 1,926 & $-0,757$ & 0,00460405 & 4,17E-02 & Up in KO \\
\hline Pstpip1 & $-1,133$ & 0,829 & 0,00449647 & $4,12 \mathrm{E}-02$ & Down in $\mathrm{KO}$ \\
\hline Adgrf5 & 1,075 & $-0,030$ & 0,0024231 & $2,85 \mathrm{E}-02$ & Up in KO \\
\hline Gpsm3 & $-1,734$ & $-0,477$ & 0,00495862 & 4,39E-02 & Down in $\mathrm{KO}$ \\
\hline Btbd11 & 1,122 & 0,509 & 0,00262985 & $3,00 E-02$ & Up in KO \\
\hline H2afy2 & $-1,732$ & $-0,621$ & 0,00374077 & $3,70 E-02$ & Down in $\mathrm{KO}$ \\
\hline $\mathrm{Cd} 27$ & $-2,062$ & $-0,576$ & 0,00414105 & $3,92 \mathrm{E}-02$ & Down in $\mathrm{KO}$ \\
\hline Zfp773 & $-1,333$ & $-0,646$ & 0,00140651 & $2,04 \mathrm{E}-02$ & Down in $\mathrm{KO}$ \\
\hline Azin2 & 1,441 & 0,224 & 0,00190949 & $2,46 \mathrm{E}-02$ & Up in KO \\
\hline Pdxp & 1,243 & $-0,182$ & 0,00446192 & $4,10 \mathrm{E}-02$ & Up in KO \\
\hline Hesx1 & 1,944 & $-1,268$ & 0,00230163 & $2,77 E-02$ & Up in KO \\
\hline Chrm4 & 1,298 & $-0,614$ & 0,00329729 & $3,44 \mathrm{E}-02$ & Up in KO \\
\hline ВС049715 & 1,427 & 0,605 & 0,00415333 & $3,93 E-02$ & Up in KO \\
\hline Calcb & 4,076 & $-0,036$ & 0,0017946 & 2,37E-02 & Up in KO \\
\hline $\mathrm{Cd} 72$ & $-1,674$ & $-0,146$ & 0,00575876 & $4,82 \mathrm{E}-02$ & Down in $\mathrm{KO}$ \\
\hline St18 & $-1,676$ & $-1,130$ & 0,00125045 & $1,90 \mathrm{E}-02$ & Down in $\mathrm{KO}$ \\
\hline Vmn2r98 & 1,161 & $-0,562$ & 0,00218312 & $2,67 \mathrm{E}-02$ & Up in KO \\
\hline Siglecf & $-1,707$ & $-0,619$ & 0,00508847 & $4,46 \mathrm{E}-02$ & Down in KO \\
\hline Tspyl3 & $-1,205$ & $-0,140$ & 0,0049253 & $4,38 \mathrm{E}-02$ & Down in $\mathrm{KO}$ \\
\hline Acsbg1 & $-1,913$ & $-0,427$ & 0,00544187 & $4,66 \mathrm{E}-02$ & Down in KO \\
\hline Pfn2 & 1,014 & $-0,157$ & 0,00284561 & $3,15 E-02$ & Up in KO \\
\hline LOC108167368 & 1,076 & $-0,238$ & 0,00182094 & $2,39 E-02$ & Up in KO \\
\hline Gm31619 & 1,527 & $-0,610$ & 0,0036502 & $3,66 \mathrm{E}-02$ & Up in KO \\
\hline Gm35543 & $-1,534$ & $-1,236$ & 0,00094396 & $1,61 \mathrm{E}-02$ & Down in $\mathrm{KO}$ \\
\hline Gm41662 & 1,087 & $-0,073$ & 0,00491378 & 4,37E-02 & Up in KO \\
\hline Pcdhga6 & $-1,681$ & $-0,882$ & 0,00602192 & 4,97E-02 & Down in $\mathrm{KO}$ \\
\hline Aqp12 & $-1,528$ & $-1,347$ & 0,00048354 & 1,07E-02 & Down in $\mathrm{KO}$ \\
\hline Gm34389 & $-1,025$ & $-0,078$ & 0,00374758 & $3,70 E-02$ & Down in $\mathrm{KO}$ \\
\hline Tet1 & $-1,771$ & $-0,698$ & 0,00179335 & 2,37E-02 & Down in $\mathrm{KO}$ \\
\hline Faxc & 1,423 & $-0,798$ & 0,00420068 & $3,96 \mathrm{E}-02$ & Up in KO \\
\hline Rbpms2 & 1,180 & $-0,294$ & 0,0044922 & $4,12 \mathrm{E}-02$ & Up in KO \\
\hline Gm32652 & $-1,423$ & $-0,869$ & 0,00402076 & $3,87 \mathrm{E}-02$ & Down in $\mathrm{KO}$ \\
\hline Gm16984 & $-1,256$ & $-0,625$ & 0,00237043 & $2,81 \mathrm{E}-02$ & Down in $\mathrm{KO}$ \\
\hline KIrb1 & 1,147 & $-0,125$ & 0,00563657 & $4,76 \mathrm{E}-02$ & Up in KO \\
\hline Gm8493 & 1,593 & $-1,055$ & 0,00311186 & $3,32 \mathrm{E}-02$ & Up in KO \\
\hline
\end{tabular}




$\begin{array}{lccccc}\text { Fbxl16 } & -1,199 & -0,649 & 0,00250215 & 2,92 \mathrm{E}-02 & \text { Down in KO } \\ \text { C9 } & -1,505 & -0,784 & 0,00498674 & 4,41 \mathrm{E}-02 & \text { Down in KO } \\ \text { Aldh1a3 } & 1,312 & -0,548 & 0,00541827 & 4,64 \mathrm{E}-02 & \text { Up in KO } \\ \text { Gm30120 } & 1,204 & -0,237 & 0,00588685 & 4,90 \mathrm{E}-02 & \text { Up in KO } \\ \text { Mum1l1 } & 1,549 & -1,332 & 0,00118804 & 1,84 \mathrm{E}-02 & \text { Up in KO } \\ \text { Jam3 } & 1,469 & -0,966 & 0,00403924 & 3,88 \mathrm{E}-02 & \text { Up in KO } \\ \text { AY512931 } & 1,376 & -0,497 & 0,00497673 & 4,40 \mathrm{E}-02 & \text { Up in KO } \\ \text { Gm42235 } & 1,050 & -0,320 & 0,00521896 & 4,54 \mathrm{E}-02 & \text { Up in KO } \\ \text { Gm40417 } & 1,591 & -1,405 & 0,00176233 & 2,34 \mathrm{E}-02 & \text { Up in KO } \\ \text { Zdhhc19 } & 1,023 & -1,005 & 0,00318355 & 3,36 \mathrm{E}-02 & \text { Up in KO } \\ \text { Duoxa1 } & 1,277 & -0,731 & 0,00320935 & 3,38 \mathrm{E}-02 & \text { Up in KO } \\ \text { Rarres1 } & 1,467 & -1,144 & 0,00201318 & 2,55 \mathrm{E}-02 & \text { Up in KO } \\ \text { Kbtbd6 } & 1,055 & -0,390 & 0,00405499 & 3,88 \mathrm{E}-02 & \text { Up in KO } \\ \text { Fam105a } & -1,583 & -0,438 & 0,00308418 & 3,30 \mathrm{E}-02 & \text { Down in KO } \\ \text { Sall2 } & -1,257 & -1,072 & 0,00084131 & 1,51 \mathrm{E}-02 & \text { Down in KO } \\ \text { Rbp1 } & 1,364 & -1,022 & 0,00386579 & 3,78 \mathrm{E}-02 & \text { Up in KO } \\ \text { Dennd1c } & -1,620 & 0,336 & 0,00586437 & 4,89 \mathrm{E}-02 & \text { Down in KO } \\ \text { Ackr2 } & 1,053 & -0,641 & 0,00476788 & 4,29 \mathrm{E}-02 & \text { Up in KO } \\ \text { LOC108168298 } & -1,758 & -1,714 & 0,00211104 & 2,62 \mathrm{E}-02 & \text { Down in KO } \\ \text { Gm30877 } & 1,070 & -0,574 & 0,00358161 & 3,62 \mathrm{E}-02 & \text { Up in KO } \\ \text { Gm40559 } & 1,563 & -1,155 & 0,00538343 & 4,63 \mathrm{E}-02 & \text { Up in KO } \\ \text { Gm30247 } & 1,380 & -0,963 & 0,00544597 & 4,66 \mathrm{E}-02 & \text { Up in KO } \\ \text { Adamts9 } & 1,990 & -1,214 & 0,00458122 & 4,17 \mathrm{E}-02 & \text { Up in KO } \\ \text { Rab3c } & -1,390 & -0,607 & 0,00234698 & 2,79 \mathrm{E}-02 & \text { Down in KO } \\ \text { Nckap5I } & -1,171 & -0,858 & 0,00489819 & 4,36 \mathrm{E}-02 & \text { Down in KO }\end{array}$


bioRxiv preprint doi: https://doi.org/10.1101/690404; this version posted July 3, 2019. The copyright holder for this preprint (which was not certified by peer review) is the author/funder. All rights reserved. No reuse allowed without permission.

Table 2 : Clinicopathological characteristics and correlations with the CCNA2-based classification. MMR: Mismatch repair, MSI: Microsatellite instable, MSS: Microsatellite stable, CMS: Consensus Molecular Subtypes, RFS : Relapse Free Survival

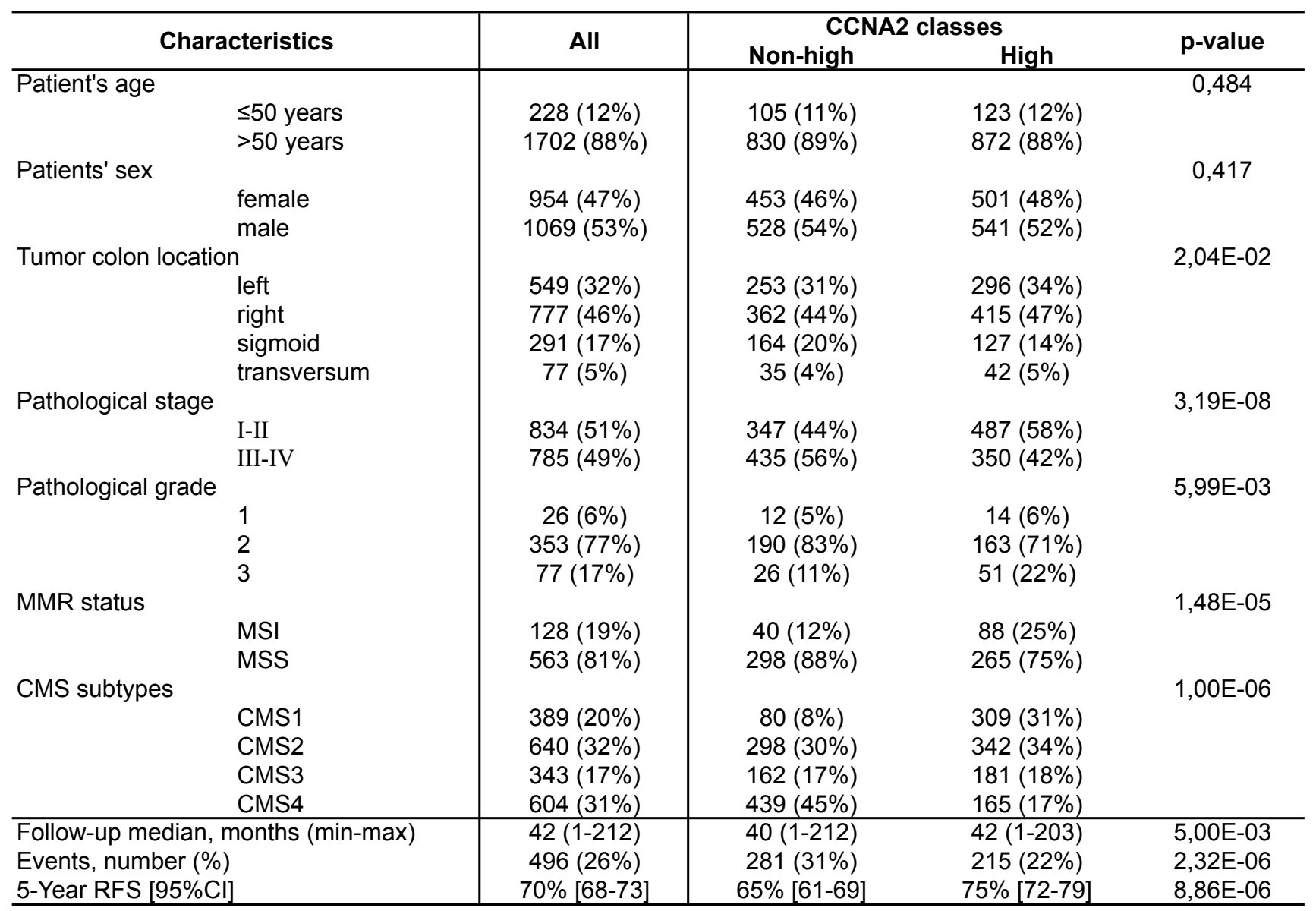


bioRxiv preprint doi: https://doi.org/10.1101/690404; this version posted July 3, 2019. The copyright holder for this preprint (which was not certified by peer review) is the author/funder. All rights reserved. No reuse allowed without permission.

Table 3: Univariate and multivariate prognostic analyses for RFS.

MMR: Mismatch repair, MSI: Microsatellite instable, MSS: Microsatellite stable,

CMS: Consensus Molecular Subtypes, RFS: Relapse Free Survival, HR: Hazard Ratio

\begin{tabular}{|c|c|c|c|c|c|c|c|c|c|c|}
\hline \multirow{2}{*}{\multicolumn{2}{|c|}{ Variables }} & \multicolumn{3}{|c|}{ Univariate } & \multicolumn{3}{|c|}{ Multivariate } & \multicolumn{3}{|c|}{ Multivariate } \\
\hline & & $\mathbf{N}$ & $\mathrm{HR}[95 \mathrm{Cl}]$ & $p$-value & $\mathbf{N}$ & $\mathrm{HR}[95 \mathrm{Cl}]$ & p-value & $\mathbf{N}$ & $\mathrm{HR}[95 \mathrm{Cl}]$ & p-value \\
\hline Patient's age & $>50$ vs. $\leq 50$ years & 1630 & $1.02[0.76-1.39]$ & 0,882 & & & & & & \\
\hline Patients' sex & male vs. female & 1722 & $1.11[0.92-1.34]$ & 0,254 & & & & & & \\
\hline \multirow[t]{3}{*}{ Tumor colon location } & right vs. left & 1440 & $0.82[0.67-1.01]$ & $5,09 \mathrm{E}-08$ & 489 & $0.97[0.69-1.37]$ & 0,880 & & & \\
\hline & sigmoid vs. left & & $0.33[0.22-0.50]$ & & 489 & $0.37[0.17-0.81]$ & $1,28 \mathrm{E}-02$ & & & \\
\hline & transversum vs. left & & $0.20[0.07-0.53]$ & & 489 & $0.21[0.03-1.53]$ & 0,124 & & & \\
\hline Pathological stage & III-IV vs. I-II & 1374 & 2.65 [2.08-3.38] & $2,78 \mathrm{E}-15$ & 489 & $2.43[1.72-3.43]$ & $5,03 \mathrm{E}-07$ & & & \\
\hline \multirow[t]{2}{*}{ Pathological grade } & 2 vs. 1 & 408 & $1.40[0.51-3.84]$ & 0,463 & & & & & & \\
\hline & 3 vs. 1 & & $1.87[0.61-5.71]$ & & & & & & & \\
\hline MMR status & MSS vs. MSI & 606 & $2.59[1.55-4.32]$ & 2,97E-04 & 489 & $2.65[1.47-4.76]$ & $1,18 \mathrm{E}-03$ & & & \\
\hline \multirow[t]{3}{*}{ CMS subtypes } & CMS2 vs. CMS1 & 1657 & $0.81[0.61-1.07]$ & $1,44 \mathrm{E}-04$ & & & & 1700 & $0.73[0.56-0.97]$ & $2,90 \mathrm{E}-02$ \\
\hline & CMS3 vs. CMS1 & & 0.99 [0.73-1.36] & & & & & 1700 & $0.95[0.70-1.29]$ & 0,743 \\
\hline & CMS4 vs. CMS1 & & $1.38[1.06-1.81]$ & & & & & 1700 & $1.23[0.93-1.62]$ & 0,151 \\
\hline CCNA2 classes & high vs. non-high & 1882 & $0.67[0.56-0.8]$ & $1,01 \mathrm{E}-05$ & 489 & $0.61[0.44-0.85]$ & $2,99 \mathrm{E}-03$ & 1700 & $0.70[0.58-0.85]$ & $4,13 \mathrm{E}-04$ \\
\hline
\end{tabular}




\begin{tabular}{|c|c|c|c|c|c|c|c|c|c|}
\hline Gene Symbol & Entrez Gene ID & $\begin{array}{c}\text { CCNA2 } \\
\text { (logon-high average) }\end{array}$ & $\begin{array}{c}\text { CCNA2 } 2^{\text {High }} \\
\text { (log2, average) }\end{array}$ & $\begin{array}{l}\text { CCNA2, } \\
\text { high vs. non-high } \\
\text { (log2-ratio) }\end{array}$ & $\mathrm{p}$-value & q-value & Associated to & $\begin{array}{c}\text { Associated } \\
\text { pathways }\end{array}$ & Notes \\
\hline CCNA2 & 890 & 9,46 & 10,57 & 1,11 & $4,94 \mathrm{E}-91$ & $1,90 \mathrm{E}-87$ & up CCNA2 ${ }^{\text {High }}$ and CCNA2 $2^{\text {Non-high }}$ & $\begin{array}{l}\text { TP53, BRCA1, } \\
\text { CDKN1A, KRAS }\end{array}$ & 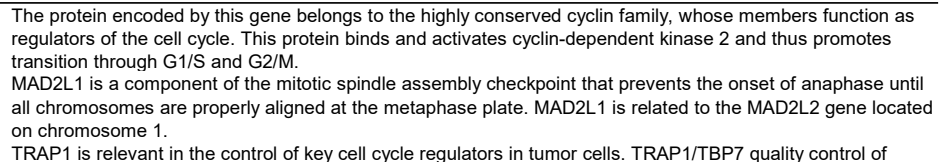 \\
\hline MAD2L1 & 4085 & 9,16 & 10,23 & 1,06 & $3,82 E-56$ & $4,90 E-53$ & up CCNA2 $2^{\text {High }}$ and $\mathrm{CCNA}^{\text {Non-high }}$ & $\begin{array}{l}\text { BRCA1, TERT, } \\
\text { MLH1, APC }\end{array}$ & $\begin{array}{l}\text { TRAP1 is relevant in the control of key cell cycle regulators in tumor cells. TRAP1/TBP7 quality control of } \\
\text { CDK1 and MAD2 contributes mechanistically to the regulation of mittotic entry and transit. } \\
\text { in addition to its role in checkpoint signaling, MAD2 ensures chromosome stability through the regulation of } \\
\text { AURORA B. } \\
\text { catalytic activation of the spindle assembly checkpoint depends on regulated protein-protein interactions that } \\
\text { accelerate the spontaneous but rate-limiting conversion of MAD2 required for mitotic checkpoint complex } \\
\text { assembly }\end{array}$ \\
\hline NEIL3 & 55247 & 5,82 & 6,82 & 1,01 & $7,76 \mathrm{E}-40$ & $4,26 E-37$ & up $\mathrm{CCNA} 2^{\text {2ligh }}$ and $\mathrm{CCNA} 2^{\mathrm{Non-high}}$ & $\begin{array}{l}\text { TP53, EGFR, VEGF, } \\
\text { BRAC1 }\end{array}$ & $\begin{array}{l}\text { NEIL3 belongs to a class of DNA glycosylases homologous to the bacterial Fpg/Nei family. These } \\
\text { glycosylases initiate the first step in base excision repair by cleaving bases damaged by reactive oxygen } \\
\text { species and introducing a DAA strand break via the associated lyase reaction } \\
\text { NEILI Repairs Telomere Damage during } S \text { Phase to Secured Chromosome Segregation at Mitosis. } \\
\text { NEIL3 protects genome stability through targeted repair of oxidative damage in telomeres during S/G2 phase. }\end{array}$ \\
\hline DEPDC1 & 55635 & 7,63 & 8,72 & 1,09 & $7,07 E-34$ & $9,38 E-32$ & up CCNA2 ${ }^{\text {ligh }}$ and CCNA2 $2^{\text {Non-high }}$ & & $\begin{array}{l}\text { DEPDC1 is a novel cell cycle related gene that regulates mittotic progression. } \\
\text { DEPDC } \mathrm{mRNA} \text { and protein expression levels were dramatically increased in prostate cancer tissues and cell } \\
\text { lines. Overexpression of DEPDC1 promoted, but depletion of DEPDC } 1 \text { inhibited cell proliferation by regulating } \\
\text { the G1-S phase cell cycle transition. } \\
\text { DEP domain containing } 1 \text { is a novel diagnostic marker and prognostic predictor for hepatocelllular carcinoma. }\end{array}$ \\
\hline PBK & 55872 & 8,10 & 9,26 & 1,16 & $6,70 E-31$ & $4,60 \mathrm{E}-29$ & up $\mathrm{CCNA} 2^{\text {2ligh }}$ and $\mathrm{CCNA} 2^{\mathrm{Non-high}}$ & $\begin{array}{l}\text { TGFB, TP53, } \\
\text { CDKN1A, TERT }\end{array}$ & 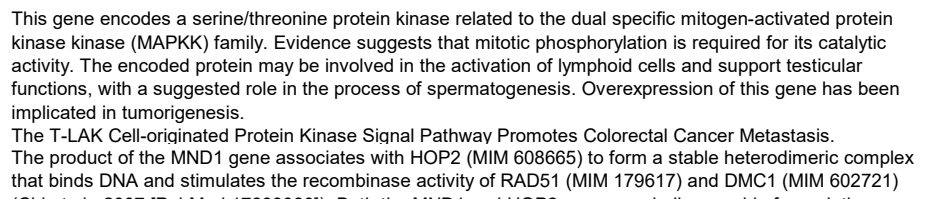 \\
\hline MND1 & 84057 & 6,25 & 7,28 & 1,03 & $9,33 \mathrm{E}-31$ & $6,19 \mathrm{E}-29$ & up CCNA $2^{\text {High }}$ and $C C N A 2^{\text {Non-high }}$ & & $\begin{array}{l}\text { (Chi et al, 2007 [PubMed 17639080]). Both the MND1 and HOP2 genes are indispensable for meiotic } \\
\text { recombination } \\
\text { Datat suggest that the human TBPIP/Hop2-Mnd1 complex may ensure proper pairing between homologous } \\
\text { chromosomes through its stimulation of strand exchange during meiosis. }\end{array}$ \\
\hline MLF1IP & 79682 & 8,29 & 9,29 & 1,00 & $5,86 E-30$ & $3,52 E-28$ & up CCNA2 $2^{\text {High }}$ and CCNA2 $2^{\text {Non-high }}$ & & 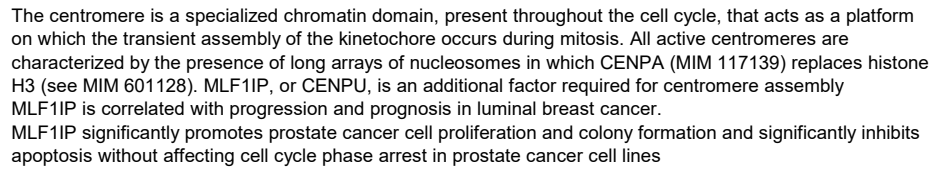 \\
\hline ESCO2 & 157570 & 7,19 & 8,30 & 1,12 & $1,89 \mathrm{E}-27$ & $8,17 \mathrm{E}-26$ & up CCNA $2^{\text {High }}$ and $C C N A 2^{\text {Non-high }}$ & mitosis & 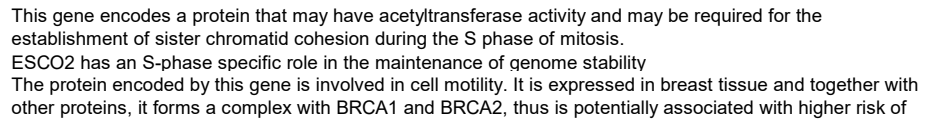 \\
\hline HMMR & 3161 & 8,43 & 9,53 & 1,10 & $5,60 \mathrm{E}-27$ & $2,27 \mathrm{E}-25$ & up CCNA2 $2^{\text {High }}$ and $C C N A 2^{\text {Non-high }}$ & BRCA1 & $\begin{array}{l}\text { breast cancer. } \\
\text { RHAMM expression identifies an aggressive subpopulation of tumor budding cells and is an independent } \\
\text { adverse prognostic factor for colorectal cancer patients. }\end{array}$ \\
\hline CHAC2 & 494143 & 5,73 & 6,75 & 1,02 & $3,05 E-26$ & $1,17 \mathrm{E}-24$ & up $\mathrm{CCNA} 2^{\text {High }}$ and $\mathrm{CCNA} 2^{\text {Non-high }}$ & & 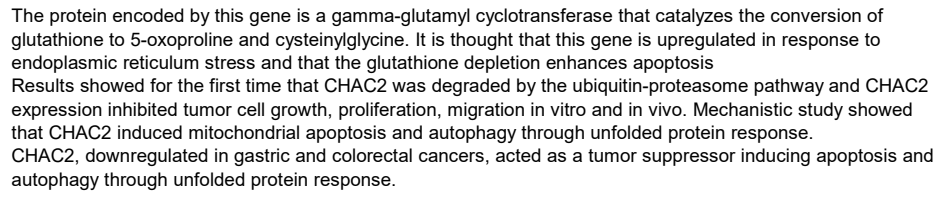 \\
\hline HSPA4L & 22824 & 5,95 & 7,18 & 1,23 & $9,47 E-14$ & $6,52 E-13$ & up CCNA2 ${ }^{\text {Righ }}$ and CCNA2 $2^{\text {Non-high }}$ & $\begin{array}{l}\text { TP53, EGFR, VEGF, } \\
\text { BRAC1 }\end{array}$ & \\
\hline
\end{tabular}


This gene encodes a protein that belongs to the secreted phospholipase A2 family, whose members include the bee venom enzyme. The encoded enzyme functions in lipid metabolism and catalyzes the calcium-

作 development by stimulating tumor cell growth and angiogenesis.
Phospholipase A2 Group III and Group X Have Opposing Associations with Prognosis in Colorectal Cancer. The protein encoded by this gene is primarily found in the nucleolus, where it can bind to the $5^{\prime}$ UTR of the insulin-like growth factor III leader $3 \mathrm{mRNA}$ and may repress translation of insulin-like growth factor II during late development. The encoded protein contains several $\mathrm{KH}$ domains, which are impottant in RNA binding and
are known to be involved in RNA synthesis and metabolism

TP53, BRCA1, Myc $\begin{aligned} & \text { breast cancers } \\ & \text { Post-transcriptional regulation of cyclins D1, D3 and G1 and proliferation of human cancer cells depend on }\end{aligned}$
a

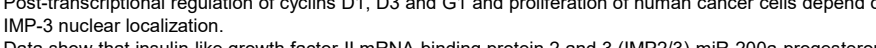
Data show that insulin-like growth factor-ll mRNA-binding protein 2 and 3 (IMP2/3)-miR-200a-progesterone
receptor axis represents a dowble-negative feedthack loop and serves as a new potential therapeutic target for receptor axis represents a double-negative feedback loop and serves as a new potential therapeutic targe
the treatment of Triple-enegative breast cancer (TNBC).
The membrane-associated protein encoded by this gene is a member of the superfamily of ATP-binding
cassette (ABC) transporters. ABC proteins transport various molecules across extra- and intracellular membranes. ABC genes are divided into seven distinct subfamilies (ABC1, MDR/TAP, MRP, ALD, OABP,
GCN20, and White). This encoded protein is a member of the ABC1 subfamily, which is the only major ABC

This gene encodes a member of the ZIC family of $\mathrm{C} 2 \mathrm{H} 2$-type zinc finger proteins. The encoded protein may act as a transcriptional repressor. Studies in mouse and Xenopus support a role for this gene in neural development. Elevalud expression oh this gene has been observed in various human cancers and may

as a survival factor of prostate and colorectal cancer cells.
ZIC5 is highly upregulated in non-small cell lung cancer tumor tissues and may act as an oncogene by influencing CCNB1 and CDK1 complex expression

COLORECTAL Polymeric Immunoglobulin Receptor Expression is Correlated with Hepatic Metastasis and Poor Prognosis in Colon Carcinoma Patients with Hepatic Metastasis

This gene encodes a member of the vasopressin/oxytocin subfamily of $G$ protein-coupled receptors. The encoded membrane protein acts as a receptor for neuropeptide $S$ and affects a variety of cellular processes
through its signaling. Increased expression of this gene in ciliated cells of the respiratory epithelium and in bronchial smooth muscle cells is associated with asthma.

The protein encoded by this gene is a member of the calcium-binding protein superfamily that includes calmodulin and troponin C. Originally described as a $27 \mathrm{kDa}$ protein, it is now known to be a $28 \mathrm{kDa}$ protein. contains four active calcium-binding domains, and has two modified domains that are thought to have lost
their calcium binding capability. This protein is thought to buffer entry of calcium upon stimulation of glutamate
receptors. up CCNA2 $2^{\text {High }}$ and CCNA2 $2^{\text {Non-high }}$

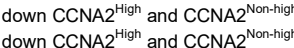

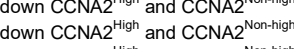
down CCNA2 $2^{\text {High }}$ and CCNA2 $2^{\text {Non-high }}$ down CCNA2 $2^{\text {High }}$ and CCNA2 $2^{\text {Norn-high }}$ down CCNA2 $2^{\text {High }}$ and CCNA2 $2^{\text {Non-hilig }}$ down CCNA2 $2^{\text {High }}$ and CCNA2 $2^{\text {Non-hig }}$ down CCNA $2^{\text {Hinh }}$ and CCNA $2^{\text {Nononthos }}$ down CCNA2 $2^{\text {High }}$ and CCNA2 $2^{\text {Non-high }}$ down CCNA2 ${ }^{\text {tigh }}$ and CCNA2 $2^{\text {Non-high }}$ down CCNA $2^{\text {High }}$ and CCNA2 $2^{\text {Non-high }}$ down CCNA2 $2^{\text {High }}$ and CCNA2 $2^{\text {Non-hilion }}$ down CCNA2 $2^{\text {High }}$ and CCNA2 $2^{\text {Non-hilig }}$ down CCNA2 $2^{\text {til }}$ and CCNA2 $2^{\text {Nonn-hion }}$ down CCNA2 $2^{\text {High }}$ and CCNA $2^{\mathrm{Nonn} \text {-ilig }}$ down CCNA2 $2^{\text {High }}$ and CCNA2 $2^{\text {Non-high }}$ down CCNA $2^{\text {High }}$ and CCNA2 $2^{\text {Non-high }}$ down CCNA2 $2^{\text {High }}$ and $C C N 2_{2}^{\text {Non-hilio }}$ down CCNA2 $2^{\text {High }}$ and CCNA2 $2^{\text {Non-hilig }}$ down CCNA2 $2^{\text {High }}$ and CCNA2 $2^{\text {Non-high }}$ 


\begin{tabular}{|c|c|c|c|c|c|c|c|}
\hline C6orf15 & 29113 & 3,90 & 2,48 & $-1,42$ & 8,61E-09 & 1,91E-08 & down CCNA $2^{\text {High }}$ and $\operatorname{CCNA} 2^{\text {Non-high }}$ \\
\hline LMO3 & 55885 & 4,51 & 3,43 & $-1,08$ & $6,44 \mathrm{E}-09$ & $1,47 E-08$ & down $\mathrm{CCNA} 2^{\text {High }}$ and CCNA2 $2^{\text {Non-high }}$ \\
\hline PKP1 & 5317 & 7,30 & 6,22 & $-1,08$ & $6,18 \mathrm{E}-09$ & $1,42 E-08$ & down CCNA $2^{\text {High }}$ and CCNA2 $2^{\text {Non-high }}$ \\
\hline DRD2 & 1813 & 4,96 & 3,55 & $-1,41$ & $4,78 \mathrm{E}-09$ & $1,13 \mathrm{E}-08$ & down CCNA2 $2^{\text {High }}$ and CCNA2 ${ }^{\text {Non-high }}$ \\
\hline SLC7A4 & 6545 & 6,37 & 5,29 & $-1,08$ & $4,35 \mathrm{E}-09$ & $1,03 \mathrm{E}-08$ & down CCNA $2^{\text {High }}$ and CCNA2 ${ }^{\text {Non-high }}$ \\
\hline L1CAM & 3897 & 6,66 & 5,39 & $-1,27$ & $4,26 \mathrm{E}-09$ & $1,02 E-08$ & down CCNA2 $2^{\text {High }}$ and CCNA2 $2^{\text {Non-high }}$ \\
\hline CHRDL1 & 91851 & 6,12 & 4,80 & $-1,32$ & $4,18 \mathrm{E}-09$ & $1,00 E-08$ & down CCNA2 $2^{\text {High }}$ and CCNA2 $2^{\text {Non-high }}$ \\
\hline LONRF2 & 164832 & 2,74 & 1,71 & $-1,03$ & $3,14 \mathrm{E}-09$ & $7,79 E-09$ & down CCNA $2^{\text {High }}$ and CCNA $2^{\text {Non-high }}$ \\
\hline ADCY5 & 111 & 4,99 & 3,97 & $-1,02$ & $2,91 \mathrm{E}-09$ & $7,29 E-09$ & down CCNA2 $2^{\text {High }}$ and CCNA2 $2^{\text {Non-high }}$ \\
\hline HAND2 & 9464 & 4,68 & 3,55 & $-1,13$ & $1,99 \mathrm{E}-09$ & $5,15 \mathrm{E}-09$ & down CCNA $2^{\text {High }}$ and CCNA2 $2^{\text {Non-nigh }}$ \\
\hline SYNM & 23336 & 8,15 & 7,12 & $-1,03$ & $1,24 \mathrm{E}-09$ & $3,36 \mathrm{E}-09$ & down CCNA $2^{\text {High }}$ and CCNA2 $2^{\text {Non-high }}$ \\
\hline PLXNB3 & 5365 & 5,59 & 4,45 & $-1,14$ & $7,56 \mathrm{E}-10$ & $2,16 \mathrm{E}-09$ & down CCNA $2^{\text {High }}$ \\
\hline THBS4 & 7060 & 5,60 & 3,95 & $-1,65$ & $6,96 \mathrm{E}-10$ & $2,01 E-09$ & down CCNA2 $2^{\text {High }}$ and CCNA2 $2^{\text {Non-high }}$ \\
\hline CRTAC1 & 55118 & 2,67 & 1,67 & $-1,00$ & $6,72 \mathrm{E}-10$ & 1,94E-09 & down $\mathrm{CCNA} 2^{\text {High }}$ and $\mathrm{CCNA} 2^{\text {Non-high }}$ \\
\hline CILP & 8483 & 5,46 & 4,13 & $-1,33$ & $4,88 \mathrm{E}-10$ & $1,46 \mathrm{E}-09$ & down $\mathrm{CCNA} 2^{\text {High }}$ and CCNA2 $2^{\text {Non-high }}$ \\
\hline LOC100127888 & 100127888 & 6,76 & 5,61 & $-1,15$ & $2,51 \mathrm{E}-10$ & $7,94 E-10$ & down CCNA $2^{\text {High }}$ and CCNA2 $2^{\text {Non-high }}$ \\
\hline APOD & 347 & 7,58 & 6,42 & $-1,16$ & $2,46 \mathrm{E}-10$ & $7,82 E-10$ & down CCNA2 $2^{\text {High }}$ and CCNA2 ${ }^{\text {Non-high }}$ \\
\hline SLIT2 & 9353 & 5,29 & 4,08 & $-1,21$ & $1,49 \mathrm{E}-10$ & $4,97 E-10$ & down CCNA $2^{\text {High }}$ and CCNA2 $2^{\text {Non-high }}$ \\
\hline ADAM33 & 80332 & 5,36 & 4,35 & $-1,01$ & $1,20 \mathrm{E}-10$ & $4,08 E-10$ & down CCNA $2^{\text {High }}$ and CCNA2 $2^{\text {Non-high }}$ \\
\hline SFRP4 & 6424 & 9,04 & 7,57 & $-1,47$ & $9,83 E-11$ & $3,41 E-10$ & down CCNA $2^{\text {High }}$ and CCNA $2^{\text {Non-high }}$ \\
\hline C5orf23 & 79614 & 4,29 & 3,12 & $-1,17$ & $8,32 \mathrm{E}-11$ & $2,93 E-10$ & down CCNA2 $2^{\text {High }}$ and CCNA2 $2^{\text {Non-high }}$ \\
\hline MYH11 & 4629 & 11,21 & 9,96 & $-1,24$ & $5,47 E-11$ & $2,02 E-10$ & down CCNA $2^{\text {High }}$ and CCNA2 $2^{\text {Non-high }}$ \\
\hline GAP43 & 2596 & 3,16 & 2,10 & $-1,06$ & $3,27 E-11$ & $1,26 \mathrm{E}-10$ & down CCNA $2^{\text {High }}$ and CCNA2 $2^{\text {Non-nigh }}$ \\
\hline NGFR & 4804 & 5,26 & 4,16 & $-1,10$ & $2,80 \mathrm{E}-11$ & $1,10 \mathrm{E}-10$ & down CCNA $2^{\text {High }}$ and CCNA2 $2^{\text {Non-high }}$ \\
\hline PSD & 5662 & 5,64 & 4,59 & $-1,05$ & $2,71 \mathrm{E}-11$ & $1,07 E-10$ & down CCNA $2^{\text {High }}$ and CCNA2 $2^{\text {Non-high }}$ \\
\hline GPR133 & 283383 & 5,49 & 4,48 & $-1,01$ & $2,66 \mathrm{E}-11$ & $1,06 \mathrm{E}-10$ & down CCNA2 $2^{\text {High }}$ and CCNA2 $2^{\text {Non-high }}$ \\
\hline PTGIS & 5740 & 6,98 & 5,76 & $-1,21$ & $1,63 E-11$ & $6,73 E-11$ & down $\mathrm{CCNA} 2^{\text {High }}$ and $\mathrm{CCNA2} 2^{\text {Non-high }}$ \\
\hline CSDC2 & 27254 & 4,64 & 3,56 & $-1,08$ & $1,39 \mathrm{E}-11$ & $5,82 E-11$ & down $\mathrm{CCNA} 2^{\text {High }}$ and CCNA2 $2^{\text {Non-high }}$ \\
\hline ATP1A2 & 477 & 3,87 & 2,58 & $-1,29$ & $1,21 \mathrm{E}-11$ & $5,19 E-11$ & down CCNA $2^{\text {High }}$ and CCNA2 $2^{\text {Non-high }}$ \\
\hline NALCN & 259232 & 3,09 & 2,00 & $-1,08$ & $9,93 \mathrm{E}-12$ & $4,33 E-11$ & down CCNA2 $2^{\text {High }}$ and CCNA2 $2^{\text {Non-high }}$ \\
\hline RGMA & 56963 & 6,89 & 5,82 & $-1,07$ & $7,70 \mathrm{E}-12$ & $3,44 E-11$ & down CCNA2 $2^{\text {High }}$ and CCNA2 $2^{\text {Non-high }}$ \\
\hline PLIN4 & 729359 & 5,65 & 4,16 & $-1,49$ & $4,34 \mathrm{E}-12$ & $2,06 \mathrm{E}-11$ & down CCNA2 $2^{\text {High }}$ and CCNA2 $2^{\text {Non-high }}$ \\
\hline SGCA & 6442 & 4,02 & 2,84 & $-1,18$ & $2,66 \mathrm{E}-12$ & $1,31 \mathrm{E}-11$ & down CCNA $2^{\text {High }}$ and CCNA $2^{\text {Non-high }}$ \\
\hline TNXB & 7148 & 7,77 & 6,68 & $-1,09$ & $2,33 \mathrm{E}-12$ & $1,16 \mathrm{E}-11$ & down CCNA2 $2^{\text {High }}$ and CCNA $2^{\text {Non-high }}$ \\
\hline CAPS & 828 & 8,03 & 7,02 & $-1,01$ & $1,67 \mathrm{E}-12$ & $8,58 \mathrm{E}-12$ & down CCNA $2^{\text {High }}$ and CCNA2 ${ }^{\text {Non-high }}$ \\
\hline COMP (= THSB5) & 1311 & 7,59 & 5,73 & $-1,86$ & $1,17 \mathrm{E}-12$ & $6,27 \mathrm{E}-12$ & down CCNA $2^{\text {High }}$ and CCNA $2^{\text {Non-high }}$ \\
\hline HSPB7 & 27129 & 6,08 & 4,82 & $-1,26$ & $1,16 \mathrm{E}-12$ & $6,26 \mathrm{E}-12$ & down CCNA2 $2^{\text {High }}$ and CCNA2 ${ }^{\text {Non-high }}$ \\
\hline VIPR2 & 7434 & 4,14 & 3,08 & $-1,05$ & $1,06 \mathrm{E}-12$ & $5,79 E-12$ & down CCNA $2^{\text {High }}$ and CCNA2 $2^{\text {Non-high }}$ \\
\hline C1orf175 & 374977 & 5,79 & 4,74 & $-1,05$ & $9,91 \mathrm{E}-13$ & $5,45 E-12$ & down CCNA2 $2^{\text {High }}$ and CCNA2 $2^{\text {Non-high }}$ \\
\hline LRRN2 & 10446 & 5,69 & 4,62 & $-1,07$ & $4,33 E-13$ & $2,57 E-12$ & down $\mathrm{CCNA} 2^{\text {High }}$ and $\mathrm{CCNA} 2^{\text {Non-high }}$ \\
\hline SCUBE2 & 57758 & 6,06 & 5,06 & $-1,00$ & $3,52 E-13$ & $2,13 E-12$ & down CCNA2 $2^{\text {High }}$ and CCNA2 $2^{\text {Non-high }}$ \\
\hline ELN & 2006 & 9,83 & 8,81 & $-1,02$ & $1,51 \mathrm{E}-13$ & 9,91E-13 & down $\mathrm{CCNA} 2^{\text {High }}$ and $\mathrm{CCNA} 2^{\mathrm{Non} \text { lingh }}$ \\
\hline IGFN1 & 91156 & 3,13 & 1,86 & $-1,28$ & $8,81 \mathrm{E}-14$ & $6,12 E-13$ & down CCNA2 $2^{\text {High }}$ and CCNA2 $2^{\text {Non-high }}$ \\
\hline SPEG & 10290 & 6,13 & 4,79 & $-1,33$ & $6,97 \mathrm{E}-14$ & 4,94E-13 & down CCNA $2^{\text {High }}$ and CCNA2 $2^{\text {Non-high }}$ \\
\hline PDZD4 & 57595 & 4,21 & 3,20 & $-1,01$ & $2,21 \mathrm{E}-14$ & 1,69E-13 & down CCNA2 $2^{\text {High }}$ and CCNA2 $2^{\text {Non-high }}$ \\
\hline ISLR2 & 57611 & 4,83 & 3,74 & $-1,09$ & $4,48 \mathrm{E}-15$ & 3,89E-14 & down CCNA $2^{\text {High }}$ and CCNA $2^{\text {Non-high }}$ \\
\hline PALM & 5064 & 6,90 & 5,89 & $-1,01$ & $4,09 E-15$ & $3,58 \mathrm{E}-14$ & down CCNA2 $2^{\text {High }}$ and CCNA2 $2^{\text {Non-high }}$ \\
\hline GGT7 & 2686 & 9,14 & 8,06 & $-1,08$ & $1,20 \mathrm{E}-15$ & $1,14 \mathrm{E}-14$ & down CCNA $2^{\text {High }}$ and CCNA2 $2^{\text {Non-high }}$ \\
\hline PRELP & 5549 & 7,74 & 6,23 & $-1,51$ & $7,20 \mathrm{E}-16$ & $7,12 \mathrm{E}-15$ & down CCNA2 $2^{\text {High }}$ and CCNA2 ${ }^{\text {Non-high }}$ \\
\hline
\end{tabular}

